\title{
Alguns resultados envolvendo cardinais e uma determinada propriedade topológica
}

\author{
Samuel Gomes da Silva
}

TESE APRESENTADA

AO

INSTITUTO DE MATEMÁTICA E ESTATÍSTICA

DA

UNIVERSIDADE DE SÃO PAULO

PARA

OBTENÇÃO DO GRAU DE DOUTOR

EM

MATEMÁTICA

\section{Área de Concentração: Topologia Geral e Conjuntística Orientadora: Profa. Dra. Lúcia Renato Junqueira}

\footnotetext{
Durante a elaboração deste trabalho o autor recebeu apoio financeiro da FAPESP Processo 98/03633-2
}

-São Paulo, março de 2004- 


\title{
Alguns resultados envolvendo cardinais e uma determinada propriedade topológica
}

\author{
Este exemplar corresponde à redação \\ final da tese devidamente corrigida \\ e defendida por Samuel Gomes da Silva \\ e que foi aprovada pela comissão julgadora.
}

São Paulo, 11 de março de 2004.

Comissão Julgadora:

- Profa. Dra. Lúcia Renato Junqueira (Orientadora) - IME/USP

- Prof. Dr. Artur Hideyuki Tomita - IME/USP

- Prof. Dr. Janey Antonio Daccach - ICMC/USP-Mackenzie

- Profa. Dra. Itala Maria Loffredo D'Ottaviano - IFCH/Unicamp

- Prof. Dr. Hércules de Araújo Feitosa - FC/Unesp/Bauru 
Este trabalho é dedicado a todos os meus colegas e amigos do doutorado do IME - essa verdadeira raça de heróis. Eles e elas que são ou serão doutores em uma dentre as áreas de matemática, matemática aplicada, estatística ou ciência da computação.

Admiro muito a todos e a cada um desses incansáveis jovens. Espero manter vívidos em mim os seus exemplos de dedicação e coragem, o que será uma maneira de tê-los comigo pelo resto de minha vida.

... E em $\mathfrak{p}$ articular (e muito especialmente), o trabalho destas páginas vai para minhas grandes e sempre bem informadas amigas Irene e Bárbara - pelos motivos óbvios. 


\section{Agradecimentos}

À minha orientadora e "chefe", Lúcia Junqueira, por ter confiado em mim no começo do caminho, por sua extrema paciência no meio do processo (período em que estive mergulhado em uma longa, memorável e fatídica "crise dos 30 "...) e por sua postura firme e exigente academicamente no final da jornada. Cada uma dessas atitudes teve uma participação fundamental na realização deste doutorado. Espero ter aprendido a lição, chefe!

Aos professores Piotr Koszmider e Ofélia Teresa Alas, agradeço as sugestões feitas durante e depois do meu exame de qualificação; essas sugestões contribuíram muitíssimo para a "produção" desta tese. Também sou muito grato à Ofélia por sua ajuda durante a licença-maternidade da Lúcia.

Meus heróis e heroínas do IME! Zé, sempre calmo, sempre tranqüilo, sempre trabalhando, fazendo suas "contas". Irene e Bárbara, minhas "terapeutas de plantão", tudo o que eu dissesse a mais seria pouco, então não vou dizer mais nada. Cecília e Sônia, deveria ter aproveitado muito mais da companhia de vocês! "Companheiro" Mário, entusiasta da capoeira (e que está sempre enxergando longe). Fernando, que como eu adora um pub. O Raul reinventou os conceitos de "café" e "lanchinho", só isso já o tornaria inesquecível. Major, que tem que agüentar as bobagens que eu falo no caminho do bandeijão... Daniel e Liane, mesmo distantes, sempre presentes. Pablo, cujas visitas fazem com que nos sintamos mais em casa. Jocirei: tu és guerreiro, rapaz! Antonio Ronaldo, homem de muita sabedoria, observador e crítico contumaz do "movimento nas escadas do IME" (e quem quiser saber o que é isso que pergunte pra ele). Claus, companheiro de fundamentos. Gláucio, querido amigo enxadrista, que tanto nos divertiu nos seus tradicionais karaokês comemorativos. Um abraço para o Elmo e para o William (e obrigado a vocês dois pela cafeteira !), para o Rudimar e para a Olga, para a Cristina, para o Rodrigo que adora uma festa, para o Aldo, para o Washington, para o Fábio que me ajudou a deletar "17 mega de emails", para a Sandra gaúcha, minha "colega de infortúnios"... E a todos os outros que esqueci de citar, muito obrigado. (E, antes que eu me esqueça: Sidnei e Walquíria, vocês fizeram falta por aqui.)

Bird, Evandro e Zeca, obrigado por terem "segurado as pontas" nos dias difíceis de 2003. Helião e Wagnão (que estão vivendo "os seus momentos"), mesmo que os veja. 
menos eu sei que posso contar com vocês pro que der e vier. Marcelo (o "Horse") e Sérgio (o "Pônei"), grandes professores, grandes amigos. Elba, Fabiana, Glória e Ciça, obrigado por tomarem conta dos meninos. Paulo e Lobo, eu sei que vocês não gostam de "aparecer juntos na mesma frase", mas de todo modo podem ter certeza que, como bem disse o Lobo em sua dissertação, eu sempre estarei por perto! O Luciano não precisava ter feito várias das coisas que fez (na minha opiniâo, é claro, e se isso for apenas um problema meu então o que estou dizendo não tem nenhuma utilidade). Mônica, bendito seja o filme "O filho da noiva" ! Claudinéia, mãe do Artur e do Heitor, querida amiga dos velhos tempos. E o que poderia eu dizer de Maurício, de André e de Paula, de Silvana e de Sílvia ? E dos filhos da Dona Zélia, Ricardo e Rosana ? E de Eliezer ?...

Orlando, esse que estará sempre a nos lembrar dos momentos em que "é tudo muito amador" (e de outras máximas não-publicáveis). Leandro, meu caro, o que está dentro da gente, ninguém tira de nós; você sabe disso, só não pode esquecer... Solange e Pastel, Rose e Dionizio, Alejandra e Castilho (saudades !!), obrigado por não se esquecerem de mim, "o resto na divisão por 2". Povo das antigas do IME (Galê, Helô, Vivi, Paulo, Odilon, Natiê), saber que vocês "têm noção do que estou fazendo" e estão sempre torcendo é uma satisfação e tanto !! Ieda, Aline, André, Zanellato, Clayton, Lis, Diana, Sheila Peres: é bom manter o contato com vocês, acreditem nisso. Galera do "plost", desculpem a ausência do Samuca ultimamente, mas o Samuel tinha coisas pra fazer. Sou grato à Sabrina por termos feito bastante companhia um para o outro e sobretudo por ela ter me apresentado à sua família. Miriam, gosto muito que você seja assim como você é, calma, meiga e tranquiila (apesar de pegar no meu pé de vez em quando, não é mesmo ?) - e prometo solenemente que irei parar no farol vermelho numa possível próxima vez... 
"Um cardinal infinito é um passarinho highlander." (Emerson Gomes Galhardo, o Projeto)

"Don't say that later will be better, now you're stuck in a moment and you can't get out of it.

And if the night runs over, and if the day won't last and if your way should falter along the stony pass It's just a moment - this time will pass." (Paul Hewson, o Bono Vox)

"Posso sair daqui para me organizar Posso sair daqui para desorganizar ... comecei a pensar Que eu me organizando posso desorganizar Que eu desorganizando posso me organizar." (Francisco de Assis França, o Chico Science) 


\section{Resumo}

Este trabalho apresenta diversos resultados topológicos relacionados com a Propriedade $(a)$, que é uma propriedade definida a partir de estrelas com respeito a coberturas abertas. Esses resultados são obtidos usando diferentes "ferramentas" da teoria de cardinais infinitos, como cardinais regulares, pequenos cardinais e grandes cardinais. Propriedades de coberturas (como metacompacidade e metacompacidade enumerável) e espaços construídos a partir de famílias almost disjoint de subconjuntos infinitos de $\omega$ ("espaços $\Psi$-like") também são estudados, e apresentamos o primeiro exemplo consistente de um espaço $\Psi$-like que é anti-Dowker.

\footnotetext{
Abstract

This work presents several topological results related to the Property $(a)$ - which is a star covering property. These results were obtained using different "tools" from the theory of infinite cardinals, such as regular cardinals, small cardinals and large cardinals. Covering properties (like metacompactness and countable metacompactness) and spaces constructed from almost disjoint families of infinite subsets of $\omega$ (" $\Psi$-like spaces") are also studied, and we present the first consistent example of a anti-Dowker $\Psi$-like space.
} 


\section{Sumário}

Introdução $\quad$ iv

1 Preliminares Conjuntísticas

e Topológicas $\quad 1$

1.1 Teoria dos Conjuntos . . . . . . . . . . . . . . . . . . . 1

1.2 Topologia Geral . . . . . . . . . . . . . . . . . . 11

2 A Propriedade (a) 18

2.1 Uma propriedade definida por estrelas . . . . . . . . . . . . . 18

2.2 Resultados negativos usando cardinais . . . . . . . . . . . . . . 21

2.2 .1 Um lema com cardinais regulares . . . . . . . . . . . . 21

2.2 .2 Uma versão do Lema de Jones para $(a)$-espaços . . . . . . . . . . 24

3 Os espaços $\Psi(\mathcal{A}) \quad 27$

3.1 Uma caracterização dos espaços " $\Psi$-like" . . . . . . . . . . . . . . . 28

3.2 Caracterização combinatória da normalidade para espaços $\Psi(\mathcal{A}) \ldots \ldots \ldots \ldots \ldots . \ldots \ldots . \ldots \ldots$

3.2.1 "Existe um espaço $\Psi(\mathcal{A})$ normal $\operatorname{com} \mathcal{A}$ não-enumerável"

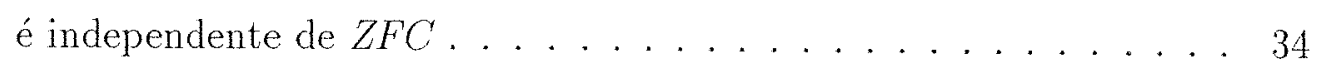

3.3 Caracterização combinatória da. Propriedade $(a)$ para espaços $\Psi(\mathcal{A}) \ldots \ldots \ldots \ldots \ldots \ldots \ldots$

3.3.1 "Existe um $(a)$-espaço $\Psi(\mathcal{A}) \operatorname{com} \mathcal{A}$ não-enumerável" é independente de $Z F C$. . . . . . . . . . . . . . . . . . . . . . 39

3.4 Questões e conjecturas ........................ 41 


\section{Espaços metacompactos e}

enumeravelmente metacompactos

4.1 Uma questão de Matveev . . . . . . . . . . . . . . . . . . . . 45

4.2 Exemplos usando o cardinal $t \ldots \ldots \ldots \ldots$. . . . . . . . . . 47

4.3 O Plano de Niemytzki . . . . . . . . . . . . . . . . . . . 53

4.4 Resultados envolvendo os espaços $\Psi(\mathcal{A}) \ldots \ldots \ldots \ldots \ldots$

4.4.1 Metacompacidade e paracompacidade enumeráveis "versus" normalidade . . . . . . . . . . . . . 55

4.4.2 "Existe um espaço $\Psi(\mathcal{A})$ que é anti-Dowker" é independente de $Z F C$. . . . . . . . . . . . . . . . . . . . . . . . . 59

4.4 .3 Questões e conjecturas ................... 63

5 Propriedade $(a)$ e famílias dominantes:

casos com alguma compacidade local

5.1 Duas questões a respeito da versão do Lema de Jones . . . . . . . . . . . . . . . . . . . . . . . 66

5.2 Resultados e questões envolvendo hipóteses sobre grandes cardinais . . . . . . . . . . . . . . . . 68

5.3 Famílias cofinais e os invariantes $d d c(X)$ e $d d c_{1}(X) \ldots \ldots \ldots . \ldots 71$

5.4 Resultados envolvendo o cardinal o e invariantes cardinais assemelhados . . . . . . . . . . . . . . 74

5.5 Mais questões envolvendo hipóteses sobre grandes cardinais . . . . . . . . . . . . . . . 87

\section{A Sobre o Lema de Jones}

e seu análogo para $(a)$-espaços

A.1 Comparando o Lema de Jones com o Teorema de Matveev . . . . . . . . 89

\section{B Caracterização combinatória}

dos espaços $\Psi(\mathcal{A})$

enumeravelmente paracompactos 
Índice 


\section{Introdução}

Este trabalho tem como objetivo investigar e apresentar diversos tipos de resultados que envolvam cardinais e que estejam relacionados a uma determinada propriedade topológica - a saber, a Propriedade (a), que é uma propriedade definida a partir de estrelas com respeito a coberturas abertas (i.e., trata-se de uma das chamadas star covering properties). Por explorar interações existentes entre a Teoria dos Conjuntos e a Topologia Geral, este trabalho insere-se claramente no ramo de pesquisa em topologia denominado "Topologia Conjuntística" (set theoretic topology).

Os resultados (topológicos) apresentados utilizam várias "ferramentas" distintas da teoria dos cardinais, como por exemplo: cardinais regulares, pequenos cardinais e grandes cardinais. Questões relativas às chamadas funçôes cardinais também aparecem em nosso estudo.

Inclúmos neste trabalho algumas demonstrações de certos resultados que são "folklore" em Topologia Conjuntística. No entanto, esses resultados costumam aparecer na literatura sem uma demonstração, ou sem uma referência de uma demonstração. Incluímos essas demonstrações principalmente nas ocasiões em que um determinado resultado foi bastante utilizado para demonstrar as nossas contribuições originais; nesse sentido, as demonstraçôes desses resultados de "folklore" visam tornar este texto auto-suficiente.

O Capítulo 1 é destinado a apresentar alguns fatos e resultados preliminares (em Teoria dos Conjuntos e Topologia Geral) que serão utilizados em todo o restante do texto. Também com o objetivo de tornar este trabalho auto-suficiente e facilitar sua leitura, foram incluídas algumas definições básicas.

No Capítulo 2 apresentamos a Propriedade $(a)$ e alguns fatos básicos relacionados a essa propriedade; por exemplo, apresentamos uma demonstração para o fato de que 
espaços paracompactos $T_{1}$ possuem a Propriedade (a) (Proposição 2.3). Em seguida, destacamos alguns resultados negativos que usam cardinais. Nossas contribuições neste capítulo foram: o Teorema 2.4 e o Lema 2.5, que generalizam um resultado de Just, Matveev e Szeptycki ([JMS00]) e a demonstração da generalização de um resultado de Matveev, que é uma versão do Lema de Jones para (a)-espaços ([Mat97]). Apresentamos também, como uma contribuição original, um Corolário para essa versão do Lema de Jones (Corolário 2.9) que "captura" o argumento essencial do resultado de Matveev.

No Capítulo 3 estudamos certos espaços construidos a partir de famílias almost disjoint de subconjuntos infinitos de $\omega$, aos quais nos referiremos como "espaços $\Psi(\mathcal{A})$ " ou "espaços $\Psi$-like". Apresentamos a demonstração de uma caracterização desses espaços a partir de certas propriedades topológicas, e também uma caracterização combinatória da situação em que um dado espaço $\Psi(\mathcal{A})$ é normal; esses são resultados de "folklore", e essas demonstrações foram incluídas aqui pelo propósito de auto-suficiência, conforme já observado. A Propriedade (a) também é estudada no contexto desses espaços, e vários resultados de consistência são demonstrados ou referenciados. Apresentamos também uma questão relacionando a Propriedade $(a)$ com a presença da paracompacidade enumerável en espaços $\Psi(\mathcal{A})$.

No Capítulo 4 estudamos a Propriedade $(a)$ no contexto de certas versões mais fracas da paracompacidade e da paracompacidade enumerável. Como contribuições deste capítulo, destacamos a demonstração de que existem espaços metacompactos $T_{1}$ que não possuem a Propriedade $(a)$ e, voltando aos espaços construídos a partir de famílias almost disjoint, apresentamos o primeiro exemplo consistente de um espaço $\Psi(\mathcal{A})$ que é antiDowker (enumeravelmente paracompacto, regular e não-normal). Apresentamos também várias questões relacionadas a espaços $\Psi(\mathcal{A})$ e o cardinal $\mathfrak{D}$.

No Capítulo 5, discutimos os (a)-espaços localmente compactos, e introduzimos a noção de famílias dominantes de funções nessa discussão (o que já é uma contribuição original deste trabalho). Com esse instrumental, e com o auxílio de alguns resultados de consistência que constam na literatura, provamos o seguinte resultado: sob as hipóteses " $2^{\omega}<2^{\omega_{1}}$ " e "2w é regular", a existência de um (a)-espaço $T_{1}$ localmente compacto e separável que contenha um fechado e discreto não-enumerável implica a existência de modelos internos com cardinais mensuráveis. Usamos também a noção de famílias dominantes e certos invariantes cardinais associados a elas para apresentar resultados negativos 
para a Propriedade (a) que, restritos à classe dos localmente compactos e localmente enumeravelmente compactos, constituem resultados negativos mais fortes do que aqueles que constam na. Subseção 2.2 do Capítulo 2. Apresentamos também algumas questões relacionadas a certas famílias dominantes e discutimos um exemplo devido a Watson ([Wat85]). A menos de alguns poucos resultados que são explicitamente creditados a outros autores, todos os resultados do Capítulo 5 são originais.

Este trabalho possui dois apêndices. O Apêndice A tem por objetivo estudar certas diferenças entre as técnicas utilizadas para a demonstração de resultados do tipo do Lema de Jones para espaços normais e para (a)-espaços; tendo em vista essas diferenças, duas questões que motivaram vários dos resultados demonstrados no Capítulo 5 são apresentadas e contextualizadas. No Apêndice B apresentamos uma caracterização combinatória das famílias a.d. $\mathcal{A} \subseteq[\omega]^{\omega}$ para as quais o respectivo espaço $\Psi(\mathcal{A})$ é enumeravelmente paracompacto. Nosso objetivo ao apresentar essa caracterização (que é uma contribuição deste trabalho) é fornecer elementos para a discussão de certas questôes que formulamos (a saber, Questões 3.15 e 4.17). 


\section{Capítulo 1}

\section{Preliminares Conjuntísticas e Topológicas}

Neste capítulo apresentaremos (de forma resumida) algumas definições e resultados (em Teoria dos Conjuntos e Topologia Geral) que serão utilizados em todo o restante do texto. Com o objetivo de tornar este trabalho auto-suficiente e facilitar sua leitura, incluímos definições e fatos básicos.

\subsection{Teoria dos Conjuntos}

Utilizaremos o sistema axiomático de Zermelo-Fraenkel com o Axioma da Escotha, tradicionalmente denominado " $Z F C$ ". Nossa referência principal é o livro de Kunen ([Kun80]). O livro de Jech ([Jec78]) é bastante adequado no que se refere à Aritmética Cardinal.

Operações básicas sobre conjuntos e noções relativas ao conceito de ordem (relações, ordens parciais e totais, boas-ordens e isomorfismos entre boas-ordens, segmentos iniciais, elementos maximais e minimais, máximos e mínimos, supremos e ínfimos) serão supostos conhecidos. A diferença entre dois conjuntos $A$ e $B$ será denotada por $A \backslash B$. O conjunto de todos os subconjuntos de um conjunto $A$ será denotado por $\mathcal{P}(A)$. Como em qualquer texto fortemente baseado em teoria dos conjuntos, relações e funções serão consideradas 
como conjuntos de pares ordenados.

Um conjunto $A$ é dito transitivo se todo elemento de $A$ é também subconjunto de A. Um conjunto é dito um ordinal se for transitivo e bem-ordenado por $\epsilon$. Com isso, todos os elementos de um ordinal são também ordinais. Ordinais serão sempre designados por letras gregas minúsculas: $\alpha, \beta, \gamma, \delta, \xi, \eta, \zeta$, etc. Freqüentemente escreveremos " $\alpha<\beta$ " ao invés de " $\alpha \in \beta$ ". Assim, para todo ordinal $\alpha$ tem-se $\alpha=\{\beta: \beta<\alpha\}$, isto é, um ordinal $\alpha$ é o conjunto formado por todos os ordinais menores do que $\alpha$.

Dado um ordinal $\alpha$, definimos o sucessor de $\alpha$, denotado por $\alpha+1$, pondo $\alpha+1=$ $\alpha \cup\{\alpha\} . \alpha+1$ é um ordinal. Um ordinal $\alpha$ é dito um ordinal sucessor se existir $\beta$ para o qual $\alpha=\beta+1$. Em particular, tem-se $0=\emptyset, 1=\{0\}, 2=\{0,1\}$, etc. Um ordinal $\alpha \neq 0$ que não é ordinal sucessor é dito um ordinal limite. O menor ordinal limite é $\omega=\{0,1,2, \ldots\}$, o conjunto de todos os números naturais. Números naturais serão designados por letras minúsculas: $\mathrm{i}, \mathrm{j}, \mathrm{k}, \mathrm{l}, \mathrm{m}, \mathrm{n}$, etc.

Todo conjunto não-vazio de ordinais admite um mínimo, que é dado pela interseç̧ão do conjunto. Todo conjunto de ordinais admite um supremo, que é dado pela união do conjunto. Assim, se $A$ é um conjunto de ordinais, $\sup (A)=\bigcup A$, que é o menor limitante superior de $A$, e, no caso de $A \neq \emptyset, \min (A)=\bigcap A$.

Se $A$ e $B$ são conjuntos, denotamos por ${ }^{A} B$ o conjunto das funções de $A$ em $B$, isto é, ${ }^{A} B=\{f: f$ é função, $\operatorname{dom}(f)=A$ e $i m(f) \subseteq B\}$ (em particular, ${ }^{\omega} \omega$ é conjunto de todas as funções de $\omega$ em $\omega)$. Dados $f: X \mapsto Y, A \subseteq X$ e $B \subseteq Y, f[A]$ e $f^{-1}[B]$ denotam respectivamente a imagem de $A$ por $f$ e a pré-imagem de $B$ por $f$. No caso particular em que $B=\{y\}$, é usual abusar-se da linguagem e escrever $f^{-1}(y)$ em vez de $f^{-1}(\{y\})$; deve-se apenas tomar cuidado no caso de existir a função inversa $f^{-1}$. Se $\operatorname{dom}(f)=\alpha$ para algum ordinal $\alpha$, freqüentemente escrevemos $f=\left\langle f_{\xi}: \xi<\alpha\right\rangle$ (onde, obviamente, $f_{\xi}=f(\xi)$ para todo $\left.\xi<\alpha\right)$ e $f$ é dita uma seqüencia de comprimento $\alpha$. No caso $\alpha=\omega$, $f$ é dita simplesmente uma seqüência.

Se $A$ e $B$ são conjuntos, dizemos que $A$ e $B$ são equipotentes (e denotamos isso por $A \approx B$ ) se existir $f: A \mapsto B$ bijetora. Sob $A C$ (Axioma da Escolha) todo conjunto $A$ pode ser bem-ordenado, donde $\{\alpha: \alpha \approx A\}$ é sempre um conjunto não-vazio de ordinais. Definimos então a cardinalidade de um conjunto $A$ pondo $|A|=\min \{\alpha: \alpha \approx A\}$ Um ordinal $\alpha$ é dito um cardinal se $|\alpha|=\alpha$. Assim, $\alpha$ é um cardinal se e só se $\alpha$ não é equipotente a nenhum ordinal menor que $\alpha$. Usaremos as letras $\kappa, \lambda, \mu, \theta$ para designar 
cardinais.

Se $X$ é um conjunto de cardinalidade $\kappa$ e $\delta$ é um ordinal de cardinalidade $\kappa$, então existe uma seqüencia $x$ de comprimento $\delta, x=\left\langle x_{\xi}: \xi<\delta\right\rangle$, que é uma bijeçào entre $\delta$ e $X$. Podemos então usar essa bijeção para fazer uma enumeração de $X$, escrevendo $X=\left\{x_{\xi}: \xi<\delta\right\}$. Usualmente utilizaremos $\delta=\kappa$ ou $\delta=\kappa+1$ para enumerar conjuntos de cardinalidade $\kappa$.

Se $X$ é um conjunto e $\lambda$ é um cardinal, definimos

$$
[X]^{\lambda}=\{A \in \mathcal{P}(X):|A|=\lambda\}
$$

e

$$
[X]^{<\lambda}=\{A \in \mathcal{P}(X):|A|<\lambda\}
$$

Em particular, $[\omega]^{\omega}$ é o conjunto de todos os subconjuntos infinitos de $\omega$ e $[\omega]<\omega$ é o conjunto de todos os subconjuntos finitos de $\omega$.

Assumiremos conhecidas as definições de soma, produto e potência de ordinais ("aritmética ordinal") e soma, produto e potência de cardinais ("aritmética cardinal"). Também são assumidos conhecidos os resultados: $\left|[\omega]^{<\omega}\right|=\omega,|\mathcal{P}(\omega)|=\left|[\omega]^{\omega}\right|:=\left|{ }^{\omega} \omega\right|=$ $2^{\omega}$. O cardinal $2^{\omega}$ será em geral denotado por "c", o que já é tradicional.

Dado um cardinal $\kappa$, denotamos por $\kappa^{+}$o cardinal sucessor de $\kappa$, que é o menor cardinal estritamente maior que $\kappa$. Um cardinal $\kappa$ é dito um cardinal sucessor se existir um cardinal $\lambda$ para o qual $\kappa=\lambda^{+}$. Um cardinal $\kappa$ é dito um cardinal limite se $\kappa>\omega$ e $\kappa$ não é um cardinal sucessor. Considerando-se a "hierarquia" dos cardinais infinitos dada por

(1) $\aleph_{0}=\omega_{0}=\omega$

(2) $\aleph_{\alpha+1}=\omega_{\alpha+1}=\left(\omega_{\alpha}\right)^{+}$

(3) Para $\gamma$ limite, $\aleph_{\gamma}=\omega_{\gamma}=\sup \left\{\omega_{\xi}: \xi<\gamma\right\}$

temos para todo $\alpha$ que o cardinal $\omega_{\alpha}$ é cardinal sucessor ou limite conforme a seja um ordinal sucessor ou limite. Todo cardinal infinito $\kappa$ é da forma $\kappa=\omega_{\alpha}$ para algum $\alpha$. É claro também que cardinais infinitos são ordinais limite.

O célebre Teorema de Cantor nos dá que, para qualquer conjunto $X,|X|<|\mathcal{P}(X)|$. Em particular, $\omega<2^{\omega}$, isto é, $\omega_{1} \leqslant 2^{\omega}$ (aritmética cardinal). Mais geralmente, $\omega_{\alpha+1} \leqslant 2^{\omega_{x}}$ 
para todo ordinal $\alpha$. A Hipótese do Contínuo ("CH") é a asserção $2^{\omega}=\omega_{1}$. A Hipótese Generalizada do Contínuo ("GCH") é a asserção: para todo ordinal $\alpha, 2^{\omega_{\alpha}}=\omega_{\alpha+1}$.

Uma questão de lingüagem que surge de uma tradução já estabelecida e consagrada: o termo utilizado em português para "countable", que em inglês designa os conjuntos de cardinalidade $\omega$, é "enumerável". Obviamente, a ação de "enumerar" que descrevemos há alguns parágrafos não se associa ao conceito de "enumerável" enquanto "contável"; com efeito, podemos enumerar $\mathcal{P}(\omega)=\left\{C_{\alpha}: \alpha<\mathfrak{c}\right\}$, que é um conjunto não-enumerável.

Sejam $\alpha, \beta$ ordinais. Se $\beta$ é ordinal sucessor, $\beta=\zeta+1$ digamos, uma função $f: \alpha \mapsto \beta$ é dita cofinal $\in m \beta$ se $\zeta \in i m(f)$. Se $\beta$ é ordinal limite, $f: \alpha \mapsto \beta$ é dita cofinal em $\beta$ se $i m(f)$ é ilimitada em $\beta$ (i.e., $\sup (i m(f))=\beta$ ). A cofinalidade de um ordinal $\beta$ (denotada por $c f(\beta)$ ) é o menor ordinal $\alpha$ para o qual existe $f: \alpha \mapsto \beta$ cofinal. Se $\beta$ é ordinal sucessor, $c f(\beta)=1$, logo só existe interesse nas cofinalidades de ordinais limite. Se $\beta$ é limite e $c f(\beta)=\alpha$, podemos afirmar que existe $f: \alpha \mapsto \beta$ cofinal e estritamente crescente.

Um ordinal limite $\beta$ é dito regular se $c f(\beta)=\beta$, caso contrário é dito singular. Um cardinal infinito $\kappa$ é dito regular (respectivamente, singular) se o ordinal limite $\kappa$ for regular (respectivamente, singular).

Valem os seguintes fatos a respeito de cofinalidade:

(i) $c f(\beta)$ é regular para todo $\beta$ limite;

(ii) Se $\alpha$ é regular, então $\alpha$ é cardinal (em particular, cofinalidades de ordinais limite são sempre cardinais regulares);

(iii) w é regular;

(iv) Para todo cardinal infinito $\kappa, \kappa^{+}$é regular.

(v) Para todo cardinal infinito $\kappa, \kappa<\operatorname{cf}\left(2^{\kappa}\right)$.

(vi) $c f(\beta)=\min \{|A|: A$ é cofinal em $\beta\}$, onde

" $A \subseteq \beta$ é cofinal em $\beta "$ significa $\sup (A)=\beta$.

(vii) Se $A \subset \delta$ e $|A|<c f(\delta)$, então $\sup (A)<\delta$; em particular, (viii) Se $\kappa$ é regular e $A \in[\kappa]^{<\kappa}$ então $\sup (A)<\kappa$.

Para os chamados resultados de consistência em Teoria dos Conjuntos, há que se 
introduzir alguma linguagem da Teoria dos Modelos (supondo conhecida a noção de " $m o-$ delo de uma fórmula", que essencialmente consiste em estrutura com uma interpretação da linguagem na qual a fórmula é verdadeira; a noção generaliza-se naturalmente para a de "modelo de um conjunto de fórmulas"). Falemos então um pouco a respeito de consistência e independência. Seja $S$ um conjunto de sentenças e $\varphi$ uma fórmula. Dizemos que $S$ prova $\varphi$ (o que se indica por $S \vdash \varphi$ ) se houver uma dedução formal (sintática) de $\varphi$ a partir de $S$, ou seja, se existir uma seqüência finita $\varphi_{1}, \varphi_{2}, \ldots, \varphi_{n}$ de fórmulas tais que $\varphi_{n}=\varphi$ e cada $\varphi_{i}, 1 \leqslant i \leqslant n$, ou está em $S$ ou é um axioma lógico ou segue de $\varphi_{1}, \ldots, \varphi_{i-1}$ por axiomas lógicos e/ou regras de inferência válidas. No caso em que $S$ prova $\varphi, \varphi$ é dita um teorema de $S$; nesse caso, a correção dos métodos de dedução garante que $\varphi$ é verdadeira (semanticamente) em todos os modelos de $S$ (o que se indica por $S \models \varphi$ ). Reciprocamente, vale que se $S \vDash \varphi$ então $S \vdash \varphi$, pelo Teorema da Completude; isso equivale a dizer que todo conjunto consistente de fórmulas possui um modelo (um conjunto de fórmulas é dito consistente se ele não puder provar contradições.). $\varphi$ é dita consistente com $S$ se $S \cup\{\varphi\}$ for consistente (o que equivale a dizer que existe algum modelo de $S$ no qual $\varphi$ seja verdadeira; nesse caso, se $M$ é um modelo de $S$ no qual $\varphi$ é verdadeira, é usual escrever-se $M \models \varphi$ ou $\left.(\varphi)^{M}\right)$. $\varphi$ é dita independente de $S$ se tanto $\varphi$ como $\neg \varphi$ forem consistentes com $S$. Por exemplo, sabemos que o Axioma de Escolha e a Hipótese do Contínuo são independentes de $Z F$ (Gödel provou que $A C$ e $C H$ são consistentes com $Z F$, Cohen provou que a negação de ambas é consistente com $Z F$ ).

Neste trabalho, "Teorema" significa "teorema de $Z F C$ ", e uma asserção do tipo "É consistente que..." significa "É consistente com ZFC que...". Nas demonstrações de resultados de consistência que utilizem hipóteses ou axiomas adicionais, essas hipóteses e axiomas serão destacados. Freqüentemente utilizaremos resultados de consistência relativos a cardinais e estruturas combinatórias para obter resultados de consistência nas questões topológicas associadas. O linguajar básico do contexto de provas de consistência e de independência ("forcing", "adição de reais por forcing", "Axioma de Martin $(M A)$ ", "classe $L$ dos construtíveis", "Axioma da Construtibilidade $(V=L)$ ") será utilizado quando citarmos esse tipo de resultado; indicamos ao leitor o livro de Kunen ([Kun80]) para as definições desses termos. (Voltaremos ao "Axioma de Martin" na pág. 8.)

Um conceito central em nosso trabalho será o de pré-ordens. Uma pré-ordem é um par $\left\langle X, \leqslant^{*}\right\rangle$ no qual $X$ é um conjunto $e \leqslant^{*}$ é uma relação reflexiva e transitiva. Dados 
$x, y \in X$, a notação " $x<^{*} y$ " denotará " $x \leqslant \leqslant^{*} y$ e $y \mathbb{*}^{*} x$ " (em particular, $\subset$ sempre denotará inclusâo estrita.). Observamos que, nessas condições, " $x<^{*} y$ " é, em geral, mais forte do que " $x \leqslant *$ e $x \neq y$ ", pois, como não vale necessariamente a antissimetria, podemos ter $x, y \in X$ tais que $x \neq y, x \leqslant^{*} y$ e $y \leqslant^{*} x$. Uma pré-ordem $\left\langle X, \leqslant^{*}\right\rangle$ pode gerar uma ordem parcial "quocientando-se" o conjunto $X$ pela relação de equivalência $"={ }^{*}$, definida naturalmente da seguinte forma: para quaisquer $x, y \in D$,

$$
x={ }^{*} y \Longleftrightarrow\left(x \leqslant{ }^{*} y\right) \wedge(y \leqslant * x)
$$

e a relação $\leqslant_{X /=^{*}}^{*}$ no quociente de $X$ por $=^{*}$ dada por $[x]_{=*} \leqslant_{X /=^{*}}^{*}[y]_{=*} \Leftrightarrow x \leqslant \leqslant^{*} y$ é uma ordem parcial. Freqüentemente assume-se que uma determinada discussão a respeito de uma pré-ordem está restrita a representantes de classes de equivalência por $={ }^{*}$, e sob essa interpretação $\leqslant$ * comporta-se como uma ordem parcial de fato; tendo isso em mente, conclui-se que muitos resultados sobre pré-ordens podem ser estendidos para ordens.

Se $\left\langle X, \leqslant^{*}\right\rangle$ é uma pré-ordem, $B \subseteq X$ é dito ilimitado em $\left\langle X, \leqslant^{*}\right\rangle$ (ou, simplesmente, ilimitado) se $(\forall x \in X)(\exists b \in B)\left[b \mathbb{Z}^{*} x\right] . D \subseteq X$ é dito cofinal em $\left\langle X, \leqslant^{*}\right\rangle$ (ou, simplesmente, cofinal $)$ se $(\forall x \in X)(\exists d \in D)\left[x \leqslant \leqslant^{*} d\right]$. A cofinalidade de uma pré-ordem $\left\langle X, \leqslant^{*}\right\rangle$ (denotada por $c f\left(X, \leqslant^{*}\right)$ ou simplesmente $c f(X)$ se não houver dúvidas com relação à pré-ordem considerada) é a cardinalidade mínima de uma família cofinal em $\left\langle X, \leqslant^{*}\right\rangle$.

São duas as pré-ordens mais utilizadas neste trabalho: a primeira é $\left\langle\mathcal{P}(\omega), \subseteq^{*}\right\rangle$, definida da seguinte maneira: para quaisquer $A, B \subseteq \omega, A \subseteq^{*} B \Leftrightarrow A \backslash B$ é finito. Em algumas situações, consideraremos também $\left\langle\mathcal{P}(X), \subseteq^{*}\right\rangle$ para outros conjuntos enumeráveis $X$. A outra pré-ordem é $\left\langle{ }^{\omega} \omega, \leqslant^{*}\right\rangle$, definida da seguinte forma: para quaisquer $f, g \in{ }^{\omega} \omega$, $f \leqslant^{*} g \Leftrightarrow\{n<\omega: g(n)<f(n)\}$ é finito. Para a verificação da transitividade das relações dadas, basta ver que, se $A, B, C \subseteq \omega, f, g, h \in \omega_{\omega} \omega, A \backslash C \subseteq(A \backslash B) \cup(B \backslash C) \mathrm{e}$ $\{n<\omega: h(n)<f(n)\} \subseteq\{n<\omega: g(n)<f(n)\} \cup\{n<\omega: h(n)<g(n)\}$.

Os invariantes cardinais do continuum (também chamados em alguns textos de pequenos cardinais) em geral são definidos da seguinte forma: dada uma propriedade $Q$ que se aplica a subfamílias de $[\omega]^{\omega}$ ou de ${ }^{\omega} \omega$, associamos a ela um invariante cardinal $\lambda$ dado por $\lambda=\min \left\{|\mathcal{Q}|: \mathcal{Q} \subseteq[\omega]^{\omega}\right.$ satisfaz $\left.Q\right\}$ (ou $\lambda=\min \left\{|\mathcal{Q}|: \mathcal{Q} \subseteq \omega_{\omega} \omega\right.$ satisfaz $\left.Q\right\}$, conforme o caso.). O artigo [vD84] de Erick van Douwen faz uma detalhada exposição de seis invariantes cardinais do continuum, a saber: $\mathfrak{a}, \mathfrak{b}, \mathfrak{d}, \mathfrak{p}, \mathfrak{s}$ e $\mathfrak{t}$. Minha dissertaçào de 
mestrado ([Si198]) estudou também esses mesmos cardinais. Vejamos as propriedades que os definem. Uma subfamília $\mathcal{A}$ de $[\omega]^{\omega}$ é dita uma família m.a.d.(maximal almost disjoint) em $\omega$ se for uma família a.d.(almost disjoint, i.e., para quaisquer $A, B \in \mathcal{A}$ distintos temse $|A \cap B|<\omega)$ e se $\mathcal{A}$ for maximal para essa propriedade no sentido da inclusão. Observamos que $\{\omega\}$ é uma família m.a.d. finita. Se $Q$ é a propriedade "ser uma família m.a.d. infinita em $\omega "$, o invariante cardinal associado é a. $B \subseteq{ }^{\omega} \omega$ é dita uma família ilimitada se for ilimitada em $\left\langle{ }^{\omega} \omega, \leqslant^{*}\right\rangle$ e $D \subseteq{ }^{\omega} \omega$ é dita uma família dominante se for cofinal em $\left\langle{ }^{\omega} \omega, \leqslant^{*}\right\rangle$. Para as propriedades "ser uma família ilimitada em ${ }^{\omega} \omega$ " e "ser uma família dominante em " $\omega$ ", os invariantes cardinais associados são, respectivamente, $\mathfrak{b}$ e $\mathfrak{d}$; note que $\mathfrak{d}=c f\left({ }^{\omega} \omega, \leqslant^{*}\right)$. Se $\mathcal{F} \subseteq[\omega]^{\omega}$, dizemos que $A$ é uma pseudo-intersecção de $\mathcal{F}$ se $(\forall F \in \mathcal{F})\left[A \subseteq^{*} F\right]$ e dizemos que $\mathcal{F}$ satisfaz a s.f.i.p. (strong finite intersection property - propriedade forte da intersecção finita ) se toda sua subfamília finita e não vazia possui intersecção infinita. Se $\mathcal{F}$ possuir pseudo-intersecção infinita, $\mathcal{F}$ satisfaz a s.f.i.p., mas a recíproca não é verdadeira; qualquer ultrafiltro não-principal em $\omega$ é um contra-exemplo. $\mathcal{T} \subseteq[\omega]^{\omega}$ é dita uma torre se $\mathcal{T}$ é bem-ordenada por $\supset^{*}$ e não possui pseudo-intersecção infinita. Para as propriedades "ser uma subfamilia de $[\omega]^{\omega}$ que satisfaz a s.f.i.p. mas não possui pseudo-intersecção infinita" e "ser uma torre", os invariantes cardinais associados são, respectivamente, $\mathfrak{p}$ e $t$. Finalmente, $\mathcal{S} \subseteq[\omega]^{\omega}$ é dita uma família splitting ("cisante") se $\left(\forall A \in[\omega]^{\omega}\right)(\exists S \in S)[|A \cap S|=|A \backslash S|=\omega]$. Para a propriedade "ser una subfamília splitting de $[\omega]^{\omega} "$, o invariante cardinal associado é $\mathfrak{s}$. Em [vD84] e [Sil98] verifica-se que esses cardinais estão bem definidos e são não-enumeráveis - logo, todos eles valem $\mathfrak{c}$ se assumirmos $C H$ - e são apresentados os resultados conjuntísticos básicos válidos em $Z F C$, além de uma série de resultados consistentes com $Z F C$. O seguinte teorema lista os fatos básicos mais importantes a respeito desses seis pequenos cardinais:

Teorema 1.1 ([vD84]) Valem em ZFC as seguintes afirmações:

a) $\omega_{1} \leqslant \mathfrak{p} \leqslant \mathfrak{t} \leqslant \mathfrak{b} \leqslant \mathfrak{a}, \mathfrak{t} \leqslant \mathfrak{s} \leqslant \mathfrak{d}$ e $\mathfrak{b} \leqslant \mathfrak{d}$.

b) $\mathfrak{p}=\omega_{1}$ se e só se $\mathfrak{t}=\omega_{1}$.

c) Se $\omega \leqslant \kappa<\mathfrak{t}$, então $2^{\kappa}=\mathfrak{c}$.

d) $\mathfrak{t} e \mathfrak{b}$ são cardinais regulares, $e \mathfrak{b} \leqslant c f(\mathfrak{d})$.

e) pé regular. 
As relações de ordem entre os cardinais $\mathfrak{a}, \mathfrak{b}, \mathfrak{D}, \mathfrak{p}, \mathfrak{s}$ e $\mathfrak{t}$ que são descritas no primeiro item do teorema anterior podem ser visualizadas no seguinte diagrama:

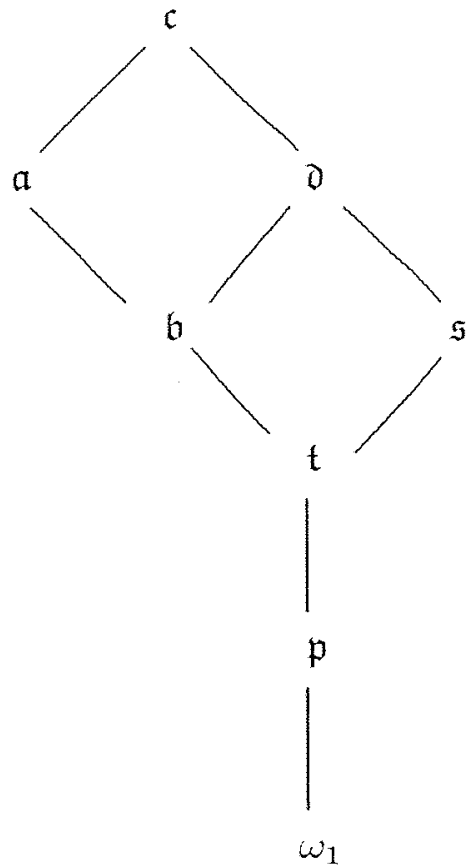

Existem ainda problemas em aberto com relaçào a resultados de consistência envolvendo esses seis cardinais: por exemplo, não sabemos se " $\mathfrak{p}<\mathfrak{t}$ " é consistente, ou se existem modelos de $Z F C$ em que a e $\mathfrak{s}$ sejam cardinais singulares. O leitor poderá encontrar também várias informações a respeito desses cardinais no artigo [Vau90] de Jerry Vaughan, onde são listados outros invariantes cardinais do continuum, sendo que alguns desses invariantes cardinais estão naturalmente relacionados com a teoria da medida (sendo definidos a partir das famílias dos subconjuntos da reta de primeira categoria ("magros") e dos subconjuntos da reta com medida de Lebesgue nula).

No contexto de resultados de consistência e independência, o cardinal p relacionase muito fortemente com o chamado Axioma de Martin (freqüentemente denotado por " $M A$ "), que é um princípio combinatório cujo enunciado pode parecer "não-intuitivo", já que o mesmo é definido em termos de argumentos bastante técnicos do tipo dos utilizados em forcing, envolvendo conceitos como densos e filtros em o.p.'s. 
Vamos introduzir rapidamente a linguagem necessária para enunciar MA. Especificamente no contexto de $M A$ e/ou forcing, uma o.p. (ordem parcial) é, essencialmente, uma "pré-ordem não-vazia" : define-se uma o.p. nesses contextos como sendo um par $\langle\mathbb{P}, \leqslant\rangle$ tal que $\mathbb{P} \neq \emptyset \mathrm{e} \leqslant$ é uma relação em $\mathbb{P}$ transitiva e reflexiva. Um subconjunto $D \subseteq \mathbb{P}$ é dito denso em $\mathbb{P}$ se $(\forall p \in \mathbb{P})(\exists d \in D)[d \leqslant p]$. Um subconjunto $G \subseteq \mathbb{P}$ é dito um filtro em $\mathbb{P}$ se: $i)(\forall g \in G)(\forall p \in \mathbb{P})[g \leqslant p \Rightarrow p \in G]$; e $i i)\left(\forall g, g^{\prime} \in G\right)(\exists r \in G)\left[(r \leqslant g) \wedge\left(r \leqslant g^{\prime}\right)\right]$. Dois elementos $p, q \in \mathbb{P}$ são ditos compativeis na o.p. se $(\exists r \in \mathbb{P})[(r \leqslant p) \wedge(r \leqslant q)]$; caso contrário, eles são ditos incompativeis. Uma anticadeia em $\mathbb{P}$ é um subconjunto de $I P$ no qual quaisquer dois elementos distintos são incompativeis. Dizemos que $\mathbb{P}$ satisfaz a propriedade c.c.c. (ou, simplesmente, $\mathbb{P}$ é c.c.c.) se qualquer anticadeia em $\mathbb{P}$ é no máximo enumerável. ("c.c.c." é a chamada countable chain condition.)

$M A(\kappa)$ é a asserção: "Se $\mathbb{P}$ é uma o.p. c.c.c. e $\mathcal{D}$ é uma família de densos de $\mathbb{P}$ tal que $|\mathcal{D}| \leqslant \kappa$, então existe um filtro $G$ tal que $G \cap D \neq \emptyset$ para todo $D \in \mathcal{D}^{\prime}$ ". Sabe-se que $M A(\omega)$ é verdadeiro e que $M A(\mathfrak{c})$ é falso ([Kun80], Lema 2.6). O Axioma de $\operatorname{Martin}(M A)$ é a asserção: " $\forall \lambda[\lambda$ é cardinal e $\omega \leqslant \lambda<\mathfrak{c} \Rightarrow M A(\lambda)] "$. CH implica $M A$, obviamente. No entanto, $M A+\neg C H$ é consistente ([Kun80], VIII $\S 6$ ).

Uma primeira relação existente entre o Axioma de Martin e o cardinal p é bastante conhecida: $M A(\kappa) \Rightarrow$ " $\kappa<\mathfrak{p}$ " (o que segue do chamado "Lema de Solovay"; veja [Kun80], pág.57), donde $M A \Rightarrow \mathfrak{p}=\mathfrak{c}(\mathrm{e}$, em conseqüencia das desigualdades do primeiro item do Teorema 1.1, sob o Axioma de Martin temos " $\kappa=\mathfrak{c}$ para $\kappa \in\{\mathfrak{a}, \mathfrak{b}, \mathfrak{d}, \mathfrak{p}, \mathfrak{s}, \mathfrak{t}\}$ "). Na

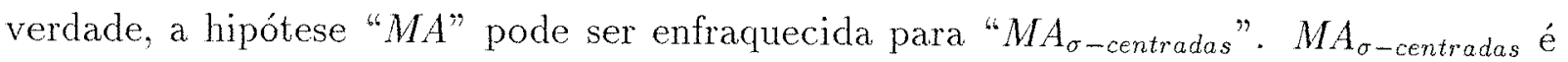
uma forma (estritamente mais fraca) do Axioma de Martin que restringe às chamadas o.p.'s $\sigma$-centradas as asserções do tipo " $M A(\lambda)$ vale" (uma o.p. IP é dita $\sigma$-centrada se puder ser escrita como uma união enumerável de subconjuntos centrados, sendo que um subconjunto $B \subseteq \mathbb{P}$ é dito centrado se todo subconjunto finito de $B$ possui limitantes inferiores em $\mathbb{P}$ ). Pode-se afirmar mais do que " $M A_{\sigma \text {-centradas }} \Rightarrow \mathfrak{p}=\mathfrak{c}$ "; Bell mostrou em 1981 que as asserções " $M A_{\sigma-c e n t r a d a s}(\kappa)$ " e " $\kappa<\mathfrak{p}$ " são equivalentes ([Bel81]), logo temos em $Z F C$ que pé o menor cardinal para o qual falha o "Axioma de Martin restrito às ordens $\sigma$-centradas".

Devido à essas relações entre o cardinal p e o Axioma de Martin, uma desigualdade do tipo " $\kappa<\mathfrak{p}$ " pode nos dar "informaçôes muito interessantes" a respeito de $\kappa$ - por exemplo, "se $\kappa<\mathfrak{p}$ então todo subconjunto de $\mathbb{R}$ de cardinalidade $\kappa$ é um $Q$-conjunto" 
(veja [Rud77] ou [Tal77]); discutiremos a noção de "Q-conjuntos" na Subseção 3.2 .1 (pág. $34)$.

Alguns dos pequenos cardinais apresentados estão fortemente relacionados com o conceito de gaps (um gap numa ordem parcial $\langle P, \leqslant\rangle$ é um par $\langle\mathcal{A}, \mathcal{B}\rangle$ tal que: $i$ ) $\mathcal{A} \subseteq P$ é bem-ordenado por $<$ e $\mathcal{B} \subseteq P$ é bem-ordenado por $>$; ii) $A<B$ sempre que $A \in \mathcal{A}$ e $B \in \mathcal{B}$; e $i i i)$ não existe $S \in P$ tal que $A<S<B$ para quaisquer $A \in \mathcal{A}$ e $B \in \mathcal{B}$. Se o tipo de ordem é de $\langle\mathcal{A},<\rangle$ é $\alpha$ e o de $\langle\mathcal{B},>\rangle$ é $\beta$, dizemos que $\langle\mathcal{A}, \mathcal{B}\rangle$ é um $\left\langle\alpha, \beta^{*}\right\rangle$-gap; usando um argumento simples de cofinalidade, sempre é possivel supor s.p.g. (sem perda de generalidade) que estamos trabalhando $\operatorname{com}\left\langle\kappa, \lambda^{*}\right\rangle$-gaps, onde $\kappa$ e $\lambda$ são cardinais regulares.). Vejamos algumas interações existentes entre invariantes cardinais do continuum e gaps: sabe-se que $\mathfrak{b}=\min \left\{\lambda \geqslant \omega\right.$ : existe $\operatorname{um}\left\langle\lambda, \omega^{*}\right\rangle$-gap $\left.\operatorname{em}\left\langle\mathcal{P}(\omega), \subset^{*}\right\rangle\right\}$ - logo, não existem $\left\langle\omega, \omega^{*}\right\rangle$-gaps em $\left\langle\mathcal{P}(\omega), C^{*}\right\rangle$ - e que $\mathfrak{t}=\min \left\{\lambda \geqslant \omega\right.$ : existe um $\left\langle\lambda, 1^{*}\right\rangle$ gap em $\left.\left\langle\mathcal{P}(\omega), \subset^{*}\right\rangle\right\}$. Um resultado clássico de Hausdorff de 1936 mostrou (em $Z F C$, sem utilizar hipóteses adicionais como $C H)$ que existem $\left\langle\omega_{1}, \omega_{1}^{*}\right\rangle$-gaps em $\left\langle\mathcal{P}(\omega), \subset^{*}\right\rangle$; gaps desse tipo são denominados atualmente gaps de Hausdorff.

Um cardinal $\kappa>\omega$ é dito fracamente inacessivel se for regular e limite, e é dito (fortemente) inacessivel se for regular e limite forte (i.e., para todo $\lambda<\kappa$ tem-se $\left.|\mathcal{P}(\lambda)|=2^{\lambda}<\kappa\right)$. Não é possivel provar em $Z F C$ que existem cardinais inacessiveis: se $\kappa$ é um cardinal inacessivel, então o conjunto de todos os conjuntos com rank menor que $\kappa$ (que é o conjunto $V_{\kappa}$ da hierarquia acumulativa do universo dada pelo Axioma da Regularidade) é um modelo de $Z F C$; segue que, se $\kappa$ é o menor cardinal inacessível, então $V_{\kappa} \vDash(Z F C+$ "Não existem cardinais inacessiveis" ) e assim $Z F C$ não pode provar que existem inacessíveis. Também não é possível obter a consistência relativa da asserção "Existem cardinais inacessiveis" com $Z F C$, pois se tivéssemos Con $(Z F C) \vdash \operatorname{Con}(Z F C$ + "Existem cardinais inacessíveis") então num modelo $M$ com inacessiveis os conjuntos da forma $\left(V_{\kappa}\right)^{M}$ para $(\kappa \text { inacessível })^{M}$ seriam modelos de $Z F C$; desse modo teríamos $C o n(Z F C+$ "Existem cardinais inacessíveis" $) \vdash C o n(Z F C)$, e conseqüentemente teríamos Con $(Z F C) \vdash \operatorname{Con}(Z F C)$, o que contradiz o Segundo Teorema da Incompletude de Gödel.

Um cardinal $\kappa$ é dito um grande cardinal (large cardinal) se a consistência de sua existência não puder ser provada nem desprovada, isto é, um grande cardinal é um cardinal que possui certas propriedades que são tais que: (i) não é possível obter um modelo de $Z F C$ em que existam cardinais com essas propriedades; e também (ii) não é possível 
provar que em qualquer modelo de $Z F C$ um tal cardinal não exista. O menor cardinal grande é, pelo menos, fracamente inacessível (convém observar que, se $\kappa$ é fracamente inacessivel, então $\left.(\kappa \text { é fortemente inacessível })^{L}\right)$. Assim, freqüentemente usaremos o termo "grande cardinal" para designar um cardinal que possua propriedades que impliquem em inacessibilidade. Em nosso trabalho, obtivemos resultados que estão associados a certos cardinais grandes denominados cardinais mensuráveis (veja o capítulo 5 de [Jec78]). Nossa principal referência sobre grandes cardinais é o livro de Kanamori ([Kan94]).

\subsection{Topologia Geral}

Nossa principal referência em Topologia Geral é o livro de Engelking ([Eng89]). Porém, em muitas situações tal livro assume hipóteses de separação na definição de alguns conceitos, o que em geral não faremos; nesse sentido, adotaremos a linha do grupo de pesquisa em Topologia Geral e Conjuntística do IME/USP, que edita regularmente notas de aula para os cursos de graduação e pós-graduação do Instituto ([T.J97]). Uma interessante referência para exemplos e contra-exemplos de espaços topológicos é o livro de Steen e Seebach ([SS95]).

Assumiremos conhecidos os conceitos básicos de topologia geral (topologia sobre um conjunto (usualmente denotada por $\tau$ ), abertos e fechados, interior e fecho, vizinhanças, homeomorfismos, pontos de acumulação, base do espaço e base num ponto.)

Se $X$ é um espaço e $A \subseteq X$, o derivado de $A$ (denotado por $A^{\prime}$ ) é o conjunto de todos os pontos de acumulação de $A$. Em particular, dado um espaço topológico $X$ temos que $X^{\prime}$ é o conjunto dos pontos não-isolados de $X$, i.e., $X^{\prime}=\{x \in X:\{x\} \notin \tau\}$.

Dizemos que um espaço $X$ é discreto se ele está munido da topologia discreta, que consiste em declarar abertos todos os subconjuntos de $X$. Se $X$ é um espaço topológico qualquer e $A \subseteq X$ é tal que $A$, com a topologia de subespaço, é um espaço discreto, então $A$ é dito um subespaço discreto de $X$. Na hipótese adicional de $A$ ser fechado em $X, A$ é dito um fechado e discreto em $X$, o que equivale a dizer que "A não possui pontos de acumulação em $X "$.

Axiomas de enumerabilidade e de separação: dizemos que um espaço $X$ satisfaz o primeiro axioma da enumerabilidade (ou é "primeiro enumerável", de "first countable") 
se todo ponto do espaço possui um sistema fundamental de vizinhanças que é enumerável; $X$ satisfaz o segundo axioma da enumerabilidade se possui uma base de abertos que é enumerável e $X$ satisfaz o terceiro axioma da enumerabilidade ( e é dito separável) se $X$ possui um subconjunto enumerável denso. Quanto aos axiomas de separação, assumiremos conhecidas as definições de espaço $T_{i}$ para $i=0,1,2,3,3 \frac{1}{2}$ e $4(\S 1.5$ de [Eng89] ) e assumiremos também que para $i \geqslant 3$ um espaço $T_{i}$ satisfaz também o axioma $T_{1}$; assumindo-se isso, podemos utilizar os termos Hausdorff para $T_{2}$, regular para $T_{3}$, completamente regular para $T_{3 \frac{1}{2}}$ e normal para $T_{4}$.

Se $\langle X, \tau\rangle$ é um espaço topológico e $A \subseteq X$, a topologia de subespaço induzida por $\tau$ é $\tau^{\prime}=\{A \cap O: O \in \tau\}$. Uma propriedade topológica (i.e., preservada por homeomorfismos) é dita hereditária se é preservada por "tomar subespaços", isto é, se um espaço $X$ satisfaz $P$ e $A$ é subespaço de $X$ então $A$ satisfaz $P$.

Se $\left\{X_{i}: i \in I\right\}$ é uma família de espaços topológicos, consideraremos que a. topologia dada ao produto cartesiano $\prod_{i \in I} X_{i}$ é a chamada topologia-produto de Tychonoff, que é gerada pela base $\left\{\prod_{i \in I} V_{i}: V_{i}\right.$ é aberto em $X_{i}$ para todo $i$ e $\left.\left|\left\{i \in I: V_{i} \neq X_{i}\right\}\right|<\omega\right\}$.

Se $X$ é um espaço topológico e $A \subseteq X$ é um subconjunto que é tanto um aberto como um fechado de $X$, dizemos que $A$ é um aberto-fechado ou clopen (por "closed and open"). Um espaço $X$ é dito zero-dimensional se possuir uma base formada por abertos-fechados. Por exemplo, um ordinal $\delta$ com a topologia da ordem é um espaço zero-dimensional, pois a família dos intervalos \{]$\alpha, \beta]: \alpha<\beta<\delta\} \cup\{[0, \beta]: \beta<\delta\}$ é uma base de abertos-fechados para $\delta$.

Sempre consideraremos ordinais com a topologia da ordem; em particular, para $\kappa \leqslant \omega, \kappa$ é o espaço discreto com $\kappa$ pontos.

Seja $X$ um espaço, $A \subseteq X$ e $x \in X ; x$ é dito um ponto de acumulaçấo completo de $A$ se para toda vizinhança aberta $U$ de $x$ vale que $|U \cap A|=|A|$.

Suporemos conhecidas as definiçôes de espaço compacto, espaço enumeravelmente compacto e espaço de Lindelöf, enunciadas a partir dos conceitos de coberturas e subcoberturas abertas (e não assumiremos aqui que um espaço compacto é Hausdorff ou $T_{1}$ ). Destacaremos agora algumas equivalências que são muitíssimo úteis.

Para a compacidade, temos que são equivalentes:

(i) $X$ é compacto. 
(ii) Toda família de fechados com a p.i.f. em $X$ possui intersecção não-vazia.

(iii) Todo subconjunto infinito de $X$ possui um ponto de acumulação completo.

Para a compacidade enumerável, temos as seguintes equivalências:

(i) $X$ é enumeravelmente compacto.

(ii) Toda família enumerável de fechados com a p.i.f. em $X$ possui intersecção não-vazia.

(iii) Todo subconjunto infinito e enumerável de $X$ possui um ponto de acumulação completo.

A compacidade e a compacidade enumerável são propriedades hereditárias para subespaços fechados. Disto - ou ainda das caracterizações acima - conclui-se que espaços compactos e espaços enumeravelmente compactos não possuem subconjuntos infinitos que sejam fechados e discretos.

Seja $\kappa$ um cardinal infinito. Um espaço $X$ é dito inicialmente $\kappa$-compacto se toda cobertura aberta de $X$ de cardinalidade menor ou igual a $\kappa$ tem subcobertura finita (assim, enumeravelmente compacto significa inicialmente $\omega$-compacto.).

Para estas propriedades, temos as seguintes equivalências:

(i) $X$ é inicialmente $\kappa$-compacto.

(ii) Toda família de $\leqslant \kappa$ fechados com a p.i.f. em $X$ possui intersecção não-vazia.

(iii) Todo subconjunto infinito de $X$ de cardinalidade menor ou igual a $\kappa$ possui um ponto de acumulação completo.

Seja $X$ um espaço topológico, $x \in X$ e $A \subseteq X$ tal que $|A|=\omega$. Dizemos que $A$ converge para $x$ se para qualquer vizinhança aberta $V$ de $x$ tem-se que $A \backslash V$ é finito.

Seja $f: \omega \mapsto X$ uma sequêencia num espaço $X . x \in X$ é dito ponto de acumulação de $f$ se, para toda vizinhança aberta $V$ de $x,|\{n<\omega: f(n) \in V\}|=\left|f^{-1}[V]\right|=\omega . f$ converge para um elemento $x \in X$ se, para toda vizinhança aberta $V$ de $x, \mid\{n<\omega$ : $f(n) \notin V\} \mid<\omega$. Em espaços de Hausdorff, os limites de uma sequência sào únicos.

Um espaço $X$ é dito localmente compacto se todo ponto $x \in X$ possui um sistema fundamental de vizinhanças compactas. Para espaços $T_{2}$, isso é equivalente a dizer que 
para cada $x \in X$ e para cada $W$ vizinhança aberta de $X$ existe uma vizinhança aberta $V$ de $x$ tal que $\bar{V}$ é um subconjunto compacto de $W$. Analogamente, podemos definir os casos localmente enumeravelmente compacto e localmente inicialmente $\kappa$-compacto para $\kappa$ cardinal infinito.

Seja $\mathcal{F}$ uma família de subconjuntos de um espaço topológico $X$. F é dita uma família ponto-finita se para cada ponto $x \in X$ o conjunto $\{A \in \mathcal{F}: x \in A\}$ é finito e $\mathcal{F}$ é dita uma família localmente finita se cada $x \in X$ possui uma vizinhança aberta $U$ para a qual o conjunto $\{A \in \mathcal{F}: U \cap A \neq \emptyset\}$ seja finito. Famílias localmente finitas são pontofinitas, mas a recíproca não é verdadeira $(\{\{\alpha\}: \alpha \in(\omega+1)\}$ é uma cobertura ponto-finita do ordinal $\omega+1$ que não é localmente finita). $\mathcal{F}$ é dita uma família discreta se todo ponto $x \in X$ possui uma vizinhança aberta $U$ satisfazendo $|\{A \in \mathcal{F}: U \cap A \neq \emptyset\}| \leqslant 1$.

Se $X$ é um espaço e $\mathcal{U}$ é uma cobertura de $X$, dizemos que uma cobertura $\mathcal{V}$ de $X$ é um refinamento de $\mathcal{U}$ se para todo $V \in \mathcal{V}$ existe $U \in \mathcal{U}$ tal que $V \subseteq U$. $\mathcal{V}$ é dito um refinamento aberto de $\mathcal{U}$ se todos os elementos de $\mathcal{V}$ são abertos de $X$.

Um espaço $X$ é dito paracompacto se toda cobertura aberta de $X$ possui um refinamento aberto localmente finito, e um espaço $X$ é dito enumeravelmente paracompacto se toda cobertura aberta enumerável de $X$ possui um refinamento aberto localmente finito.

Um espaço $X$ é dito metacompacto (ou fracamente paracompacto) se toda cobertura aberta de $X$ possui um refinamento aberto ponto-finito, e um espaço $X$ é dito enumeravelmente metacompacto se toda cobertura aberta enumerável de $X$ possui um refinamento aberto ponto-finito.

Um espaço $X$ é dito ortocompacto se toda cobertura aberta de $X$ possui um refinamento que é tal que a intersecção de qualquer subconjunto do refinamento é aberta. É fácil ver que espaços metacompactos são ortocompactos.

Dado um espaço $X, \mathcal{U}$ uma cobertura de $X$ e $F \subseteq X$ definimos a estrela com relação a $F$ e $\mathcal{U}($ denotada $S t(F, \mathcal{U})$ ) pondo

$$
S t(F, \mathcal{U})=\bigcup\{U \in \mathcal{U}: U \cap F \neq \emptyset\}
$$

No caso em que $F=\{x\}$, usualmente abusa-se da linguagem e escreve-se $\operatorname{St}(x, \mathcal{U})$ em vez de $S t(\{x\}, \mathcal{U})$. Muitas propriedades topológicas podem ser definidas ou caracterizadas usando estrelas com relação a coberturas abertas; recomendamos ao leitor o excelente "survey" de Matveev ([Mat98]) para maiores detalhes a esse respeito. A Pro- 
priedade $(a)$, da qual trataremos nos capítulos seguintes, é uma propriedade definida a partir de estrelas com relação a coberturas abertas (i.e., trata-se de uma das chamadas star covering properties).

Se $A$ é um conjunto e $X$ é um espaço, ${ }^{A} X$ será sempre considerado com a topologiaproduto de Tychonoff. Em algumas situações, esse espaço produto de suporte ${ }^{A} X$ será denotado por $X^{A}$.

$I R$ denota a "reta real" com sua topologia usual. $Q$ e IP denotam, respectivamente, o espaço dos racionais e dos irracionais com a topologia de subespaço da reta. Uma importante propriedade do espaço $\mathbb{P}$ dos irracionais é que $\mathbb{P}$ é homeomorfo ao espaçoproduto $\omega^{\omega}$.

Em trabalhos como este, em que a Topologia e a Teoria dos Conjuntos convivem, freqüentemente as chamadas funções cardinais desempenham um importante papel. Uma função cardinal é uma "função" (função-classe) $\varphi$, definida na classe dos espaços topológicos com valores na classe dos cardinais infinitos, e que é preservada por homeomorfismos, i.e., se $X$ e $Y$ são espaços homeomorfos e $\varphi$ é uma função cardinal então $\varphi(X)=\varphi(Y)$. Funções cardinais generalizam para maiores cardinalidades idéias como as que definem os três axiomas de enumerabilidade ("ser primeiro enumerável", "possuir base enumerável", "ser separável"), dentre muitas outras propriedades. Nossa principal referência para funções cardinais é o artigo de Hodel ([Hod84]). As funções cardinais às quais nos referiremos são essencialmente as seguintes:

- peso de $X$ :

$w(X)=\min \{|\mathcal{B}|: \mathcal{B}$ é uma base para $X\}+\omega$

- caráter de $X$ :

$\chi(X)=\sup \{\chi(p, X): p \in X\}+\omega$

onde $\chi(p, X)$ é o caráter de $p$ em $X$ :

$$
\chi(p, X)=\min \{|\mathcal{B}|: \mathcal{B} \text { é uma base local para } p \text { em } X\}
$$


- densidade de $X$ :

$d(X)=\min \{|D|: D$ é denso em $X\}+\omega$

- celularidade de $X$ :

$c(X)=\sup \{|\mathcal{V}|: \mathcal{V}$ é família celular em $X\}+\omega$

onde uma família celular é uma família de abertos de $X$ dois-a-dois disjuntos.

- extent de $X$ :

$e(X)=\sup \{|F|: F \subseteq X$ é fechado e discreto em $X\}+\omega$.

- tightness de $X$ :

$t(X)=\sup \{t(p, X): p \in X\}+\omega$

onde $t(p, X)$ é o tightness de $p$ em $X$ :

$$
\begin{gathered}
t(p, X)=\min \{\kappa: \text { para todo } Y \subseteq X \text { para o qual } p \in \bar{Y} \text {, existe } A \subseteq Y \text { com } \\
|A| \leqslant \kappa \text { e tal que } p \in \bar{A}\}
\end{gathered}
$$

Assim, na linguagem de funçoes cardinais, " $X$ satisfaz o primeiro axioma da enumerabilidade" traduz-se por $\chi(X)=\omega$; "X satisfaz o segundo axioma da enumerabilidade" traduz-se por $w(X)=\omega$, e "X é separável" traduz-se por $d(X)=\omega$. Um espaço $X$ que satisfaça " $t(X)=\omega$ " é dito um espaço de tightness enumerável.

A "Reta de Sorgenfrey" e o "Plano de Niemytzki" são exemplos clássicos em topologia geral e constam em nossas três referências básicas ([Eng89], [TJ97] e [SS95]), que os descrevem e discutem em vários contextos. O plano de Niemytzki é o espaço topológico cujo suporte é $X=P \cup L$ (onde $P=\left\{(x, y) \in \mathbb{R}^{2}: y>0\right\}$ e $L=\left\{(x, y) \in \mathbb{R}^{2}: y=0\right\}$ ) e cuja topologia é tal que as vizinhanças básicas para os pontos em $P$ ("semiplano superior") coincidem com as vizinhanças euclidianas usuais e as vizinhanças básicas de um ponto $x \in L$ são dadas pelos conjuntos da forma 


$$
B_{x, r}=\{x\} \cup D_{x, r}
$$

onde $D_{x, r}$ é o conjunto dos pontos interiores da circunferência de raio $r(r \in \mathbb{R}, r>0)$ que é tangente a $L$ em $x$. Já a Reta de Sorgenfrey é um refinamento da topologia usual de $\mathbb{R}$ que se obtém declarando como abertos os intervalos da forma $[x, x+\varepsilon[$ para todo $x \in \mathbb{R}$ e $\varepsilon>0$.

Finalmente, um comentário de cunho bibliográfico: durante a elaboração de um trabalho de topologia conjuntística, duas obras - coletâneas de artigos - são bastante utilizadas: o Handbook of Set Theoretic Topology ([KV84]), editado por Kenneth Kunen e Jerry Vaughan em 1984, e o Open Problems in Topology ([vMR90]), editado por Jan Van Mill e George M. Reed em 1990. Devido à constante presença de citações de artigos publicados nessas duas obras, freqüentemente nos referiremos a elas simplesmente como, respectivamente, Handbook e Open Problems. 


\section{Capítulo 2}

\section{A Propriedade (a)}

Tendo já trabalhado com relações entre cardinais e topologia no meu mestrado ([Si198]), decidi seguir pela mesma linha em meu doutoramento, e, à busca de algum tópico específico e recente no qual pudesse trabalhar, pude verificar que uma determinada "star covering property" denominada "Propriedade (a)" vinha sendo objeto (a partir da segunda metade dos anos 90) de interessantes e recentes pesquisas na área e que essa propriedade se apresentava bastante propícia para a obtenção de resultados relacionados, inicialmente, à teoria de invariantes cardinais - depois, no decorrer do trabalho de pesquisa, pude obter resultados também relacionados a cardinais, mas fora do contexto de pequenos cardinais.

\subsection{Uma propriedade definida por estrelas}

Os "primórdios" da Propriedade (a) datam de 1994, quando M. Matveev introduziu os espaços absolutamente enumeravelmente compactos ([Mat94]). Motivado por uma caracterização da compacidade enumerável (um espaço de Hausdorff $X$ é enumeravelmente compacto se e só se para toda cobertura aberta $\mathcal{U}$ de $X$ existe um subconjunto finito $F \subset X$ tal que $X=S t(F, \mathcal{U})=\bigcup\{U \in \mathcal{U}: U \cap F \neq \emptyset\}$ - ver [Eng89], 3.12.23(d)), Matveev apresentou a seguinte definição: 
Definição 2.1 ([Mat94]) Um espaço $X$ é dito absolutamente enumeravelmente compacto ou a.e.c. se para toda cobertura aberta $\mathcal{U}$ de $X$ e para todo denso $D \subseteq X$ existe um subconjunto finito $F \subseteq D$ tal que $S t(F, \mathcal{U})=X$.

Já na minha dissertação de mestrado estudei espaços a.e.c., apresentando um resultado de Jerry Vaughan ([Vau95]) que respondia negativamente uma questão de Matveev: todo espaço enumeravelmente compacto e separável é a.e.c.? O exemplo construído por Vaughan é totalmente baseado em construçôes associadas ao invariante cardinal $\mathfrak{t}$.

É fácil ver que espaços $T_{2}$ a.e.c. são enumeravelmente compactos, mas a recíproca não é verdadeira (ver exemplo 1.5 de [Mat94]). Portanto, faz sentido perguntar o que exatamente se exige a mais de um espaço enumeravelmente compacto para que este espaço possua a condição de absolutividade. Observando que, restringindo-se à classe dos espaços enumeravelmente compactos $T_{1}$, "finito" significa o mesmo que "fechado e discreto", Matveev (em comunicações por email com Mary Ellen Rudin, Ian Stares e Jerry Vaughan, cf.[RSV97]) isolou a chamada Propriedade (a), que corresponde à tal exigência a mais que garante a absolutividade de um espaço enumeravelmente compacto e que pode ser entendida como uma extensão do conceito de espaço a.e.c. para além da classe dos espaços enumeravelmente compactos.

Definição 2.2 (Matveev, apud [RSV97]) Dizemos que um espaço $X$ possui a Propriedade (a) (ou que $X$ é um (a)-espaço) se para toda cobertura aberta $\mathcal{U}$ de $X$ e para todo subconjunto denso $D \subseteq X$ existe $F \subseteq D$ que é fechado e discreto em $X$ e tal que $S t(F, \mathcal{U})=X$.

Os problemas relacionados à Propriedade (a), em geral, consistem em determinar classes de espaços que possuem tal propriedade, ou que não possuem, ou ainda determinar quais são os fatos que se podem concluir com relação a um espaço topológico a partir de certas hipóteses combinadas com a Propriedade (a). (A grosso modo, este parágrafo descreve o tipo de problema que se associa a uma propriedade topológica qualquer: é isso o que os topólogos fazem.)

A Propriedade (a) é, em muitos aspectos e de modo bastante curioso, similar à normalidade. Em artigos como [Mat97] e [JMS00] são identificadas várias situaçôes em 
que, para determinadas classes de espaços, é difícil "distingür" entre essas duas propriedades topológicas: sabe-se, por exemplo, que é muito difícil construir exemplos de espaços que sejam normais e que não possuam a Propriedade (a) (até o presente momento só existem referências sobre dois desses exemplos: um deles é um exemplo consistente que é obtido a partir de uma aplicação do Axioma de Martin ([JMS00]) e o outro é uma construção em $Z F C$ de um espaço normal, enumeravelmente compacto e não-absolutamente enumeravelmente compacto ([Pav01])). Além disso, muitos teoremas que são válidos para espaços normais têm análogos para a Propriedade $(a)$. Apresentaremos na próxima seção alguns resultados para a Propriedade (a) que são resultados do tipo do "Lema de Jones" (o Lema de Jones é um resultado clássico sobre espaços normais e limita superiormente a cardinalidade dos fechados e discretos nesses espaços por uma potência de sua densidade).

Para certas questões técnicas com relação à Propriedade $(a)$, apenas o axioma de separação $T_{1}$ já garante um "bom comportamento" dos vários objetos em questão: por exemplo, vale para espaços $T_{1}$ que os unitários são fechados, logo todos os conjuntos finitos são fechados, e também discretos, pois também vale para espaços $T_{1}$ que se $x$ é um ponto de acumulação de $A \subseteq X$ então qualquer vizinhança de $x$ possui infinitos pontos de $A$. Note também que, com esta nossa última observação, para concluirmos que um determinado conjunto $H$ é fechado e discreto num espaço $T_{1}$ basta verificarmos que todo ponto do espaço possui uma vizinhança que intercepta no máximo finitos elementos de H.

Vamos mostrar agora um exemplo de aplicação dessas propriedades presentes em espaços $T_{1}$ que é um dos mais importantes resultados positivos com relação à Propriedade $(a)$ e que foi observado por Matveev em [Mat97], no entanto sem ser exibida uma demonstração:

Proposição 2.3 Espaços paracompactos $T_{1}$ possuem a Propriedade (a).

Demonstração: Seja $X$ um espaço paracompacto $T_{1}$ e sejam dados uma cobertura aberta $\mathcal{U}$ de $X$ e $D \subseteq X$ um subconjunto denso de $X, \operatorname{com} \mathcal{U}$ e $D$ arbitrários. Por paracompacidade, existe $\mathcal{V}$ um refinamento aberto localmente finito de $\mathcal{U}$. Fixamos, para cada $V \in \mathcal{V}$, um elemento $x_{V} \in V \cap D$ e definimos $F=\left\{x_{V}: V \in \mathcal{V}\right\}$. Temos $F \subseteq D$ e 


$$
X=S t(F, \mathcal{V}) \subseteq S t(F, \mathcal{U}) \subseteq X
$$

donde $S t(F, \mathcal{U})=X$; resta verificar que $F \subseteq D$ é fechado e discreto em $X$, o que segue de $\mathcal{V}$ ser uma família localmente finita de abertos, logo todo ponto do espaço $X$ (que é $T_{1}$ ) possui uma vizinhança $W$ tal que $W \cap F$ é finito.

Alguns resultados positivos para a Propriedade $(a)$ são, na verdade, resultados positivos para espaços absolutamente enumeravelmente compactos, pois são resultados que mostram que determinadas hipóteses garantem que espaços enumeravelmente compactos sejam absolutamente enumeravelmente compactos (a.e.c.); tratam-se, assim, de resultados positivos para a Propriedade (a) na classe dos espaços enumeravelmente compactos. Por exemplo, sabe-se que espaços enumeravelmente compactos de tightness enumerável são a.e.c. ([Mat94]). Vamos tratar de alguns desses resultados positivos no Capítulo 4 deste trabalho, no contexto de uma questão de Matveev.

$\mathrm{Na}$ próxima seção, apresentaremos alguns resultados negativos que usam fortemente a teoria de cardinais; os resultados da primeira subseção são originais.

\subsection{Resultados negativos usando cardinais}

Nesta seção, apresentaremos alguns resultados negativos sobre a Propriedade $(a)$ que utilizam a teoria de cardinais: observaremos que hipóteses sobre a cardinalidade dos densos e dos fechados e discretos contidos em um espaço topológico (ou sobre a cardinalidade de famílias relacionadas a eles) influem na presença da Propriedade $(a)$.

$\mathrm{Na}$ primeira subseção, apresentamos alguns resultados originais que generalizam um lema apresentado em [JMS00]. Na segunda subseção, nossa contribuição consiste em apresentar uma demonstração para uma generalização de um teorema de Matveev que é uma versão do Lema de Jones para a Propriedade $(a)$.

\subsubsection{Um lema com cardinais regulares}

Em [JMS00], Just, Matveev e Szeptycki apresentaram (quando da construçâo de um exemplo consistente de um espaço normal sem a Propriedade (a)) um lema que garante 
que determinados espaços não possuem a Propriedade $(a)$ : mais precisamente, não são (a)-espaços os espaços topológicos que possuem um denso $D$ de cardinalidade $\omega_{1}$ e um fechado e discreto $H$ não-enumerável que sejam tais que: $(i)$ os subconjuntos enumeráveis de $D$ possuem fecho disjunto de $H$; e (ii) subconjuntos não-enumeráveis de $D$ possuem pontos de acumulação no espaço. Conseguimos estender este Lema para toda a classe dos cardinais regulares, isto é, demonstramos que o resultado análogo vale se trocarmos " $\omega_{1}$ " por " $\kappa$ cardinal regular". Nossa versão para cardinais regulares é conseqüência do resultado a seguir, que possui um cunho mais geral e é uma contribuição original deste trabalho:

Teorema 2.4 Sejam $X$ um espaço topológico $e \kappa, \lambda$ cardinais infinitos, com $\lambda=c f(\kappa)$. Suponha que existam $D \subset X$ denso e $H \subset X$ fechado e discreto em $X$ que satisfaçam as seguintes propriedades:

(1) $|D|=\kappa$

(2) $|H| \geqslant \kappa$

(3) Se $C \subset D$ é tal que $|C|<\kappa$, então $\bar{C} \cap H=\emptyset$

(4) $D$ não contém fechados e discretos de tamanho $\lambda$.

Então, $X$ não possui a Propriedade $(a)$.

Demonstração : Sejam $D$ e $H$ nas condições do enunciado; por (2), podemos tomar $H^{\prime} \subseteq H$ tal que $\left|H^{\prime}\right|=\kappa$. Enumeremos $D=\left\{d_{\alpha}: \alpha<\kappa\right\}$ e $H^{\prime}=\left\{x_{\alpha}: \alpha<\kappa\right\}$. Definimos então, para cada $\alpha<\kappa$,

$$
U_{\alpha}=X \backslash\left(\left(H^{\prime} \backslash\left\{x_{\alpha}\right\}\right) \cup \overline{\left\{d_{\xi}: \xi<\alpha\right\}}\right)
$$

Por (3), para qualquer $\alpha<\kappa$ tem-se que $x_{\alpha} \notin \overline{\left\{d_{\xi}: \xi<\alpha\right\}}$; observamos também que $H^{\prime} \backslash\left\{x_{\alpha}\right\}$ é fechado (discreto) em $X$, donde, dado $\alpha<\kappa, U_{\alpha}$ é uma vizinhança aberta de $x_{\alpha}$ e, mais ainda, $U_{\alpha}$ satisfaz $U_{\alpha} \cap H^{\prime}=\left\{x_{\alpha}\right\}$. Portanto, se considerarmos a cobertura aberta de $X$ dada por

$$
\mathcal{U}=\left\{X \backslash H^{\prime}\right\} \cup\left\{U_{\alpha}: \alpha<\kappa\right\}
$$


vale que, se fixarmos $\alpha<\kappa$, então $U_{\alpha}$ é o único elemento de $\mathcal{U}$ que contém $x_{\alpha}$.

Com isso, podemos afirmar que $\mathcal{U}$ e $D$ testemunham que $X$ não possui a Propriedade $(a)$. De fato: seja $F \subset D$ fechado e discreto em $X$. Então a condição (4) nos garante que $|F|<\lambda=c f(\kappa), \operatorname{logo} \sup \left(\left\{\gamma<\kappa: d_{\gamma} \in F\right\}\right)<\kappa$ e portanto existe $\zeta<\kappa$ tal que $F \subseteq\left\{d_{\xi}: \xi<\zeta\right\}$ e, nessas condições, $F \cap U_{\zeta}=\emptyset$. Segue que $x_{\zeta} \notin S t(F, \mathcal{U})$. Como o fechado e discreto $F \subset D$ foi escolhido arbitrariamente, conclui-se que $X$ não é um (a)-espaço.

No caso particular em que $\kappa$ é um cardinal regular, a demonstração do Teorema anterior nos fornece o seguinte Lema, que é a versão para cardinais regulares do Lema para " $\kappa=\omega_{1} "$ em [JMSO0].

Lema 2.5 Sejam $X$ um espaço topológico e $\kappa$ um cardinal regular. Suponha que existam $D \subset X$ denso e $H \subset X$ fechado e discreto em $X$ que satisfaçam as seguintes propriedades:

(1) $|D|=\kappa$

(2) $|H| \geqslant \kappa$

(3) Se $C \subset D$ é tal que $|C|<\kappa$, então $\bar{C} \cap H=\emptyset$

(4) D não contém fechados e discretos de tamanho $\kappa$.

Então, $X$ não possui a Propriedade $(a)$.

Como $\omega$ é um cardinal regular, o resultado acima também vale para densos enumeráveis e fechados e discretos infinitos. Em particular, para $X T_{1}$, vale o seguinte

Corolário 2.6 (Corolário do Lema) Seja X um espaço topológico $T_{1}$ e separável. Suponha que $X$ contenha subconjuntos disjuntos $D$ e $H$ tais que $D$ é um enumerável denso $e$ $H$ é um fechado e discreto infinito. Suponha ainda que $D$ não contém fechados e discretos infinitos. Então, $X$ não possui a Propriedade $(a)$.

O Corolário acima será utilizado e citado muitas vezes durante este trabalho; quando o fizermos, nos referiremos a ele usualmente como sendo "o Corolário do Lema". 


\subsubsection{Uma versão do Lema de Jones para $(a)$-espaços}

Conforme já comentamos, existe uma versão para (a)-espaços do "Lema de Jones", que é um célebre resultado (de 1937) sobre espaços normais; existem muitas maneiras de enunciar o Lema de Jones, e na verdade dedicamos um apêndice de nosso trabalho (o Apêndice A) para discutir certas comparações entre a versão para (a)-espaços da qual trataremos nesta subseção e os diversos enunciados possíveis com que o Lema de Jones aparece na literatura. Para trabalharmos nesta subseção, basta assumirmos a seguinte versão "separável" do Lema de Jones:

"Se $X$ é um espaço normal e separável, então $X$ não pode conter um fechado e discreto de cardinalidade maior ou igual a $2^{\omega}$."

O seguinte resultado análogo para (a)-espaços foi obtido por Matveev:

Teorema 2.7 (Matveev, [Mat97]) Se um (a)-espaço separável $X$ possui um fechado e discreto de cardinalidade $\kappa$, entâo $\kappa<2^{\omega}$.

O resultado de Matveev restringe-se à classe dos espaços separáveis, mas pode ser generalizada para o caso $d(X)=\kappa$; isso já foi observado por Szeptycki e Vaughan em [SV98], mas não foi exibida uma demonstração. Apresentaremos a seguir uma demonstração de que a generalização pode ser feita, como uma contribuição deste trabalho:

Teorema 2.8 Seja $X$ um espaço topológico que possui um fechado e discreto de cardinalidade maior ou igual a $2^{d(X)}$. Então $X$ não possui a Propriedade $(a)$.

Demonstração : Seja $D \subseteq X$ um subconjunto denso, $|D|=d(X)$. Definimos

$$
\mathcal{F}_{D}=\{G \subseteq D: G \text { é fechado e discreto em } X\}
$$

Seja então $H$ um fechado e discreto em X de cardinalidade maior ou igual a $2^{d(X)}$. Como subconjuntos de fechados e discretos são fechados e discretos e $|H| \geqslant 2^{|D|}>|D| \geqslant$ $|H \cap D|$, podemos supor sem perda de generalidade que $H \cap D=\emptyset$. 
Enumerando $\mathcal{F}_{D}=\left\{G_{\alpha}: \alpha<\lambda\right\}$, temos $\lambda \leqslant 2^{d(X)} \leqslant|H|$, logo é possível tomar um subconjunto de $H$ de cardinalidade $\lambda$; consideremos então $H^{\prime}=\left\{x_{\alpha}: \alpha<\lambda\right\}, H^{\prime} \subseteq H$. Definimos agora para cada $\alpha<\lambda$ um aberto

$$
U_{\alpha}=X \backslash\left(G_{\alpha} \cup\left(H^{\prime} \backslash\left\{x_{\alpha}\right\}\right)\right)
$$

e (como $D$ e $H$ são disjuntos e $\left.G_{\alpha} \subset D\right)$ é fácil ver que, dado $\alpha<\lambda, U_{\alpha}$ é uma vizinhança aberta de $x_{\alpha}$ que satisfaz as condições

$$
\begin{aligned}
& \text { (1) } U_{\alpha} \cap H^{\prime}=\left\{x_{\alpha}\right\} \\
& \text { (2) } U_{\alpha} \cap G_{\alpha}=\emptyset
\end{aligned}
$$

logo, se considerarmos a cobertura aberta de $X$ dada por

$$
\mathcal{U}=\left\{X \backslash H^{\prime}\right\} \cup\left\{U_{\alpha}: \alpha<\lambda\right\}
$$

então (1) nos garante que $U_{\alpha}$ é o único aberto em $\mathcal{U}$ que contém $x_{\alpha}$; com isso, $\mathcal{U}$ testemunha, juntamente com $D$, que $X$ não possui a Propriedade $(a)$, pois, dado $F \subset D$ um fechado e discreto arbitrário então (pela nossa enumeração de $\mathcal{F}_{D}$ ) existe $\xi<\lambda$ tal que $F=G_{\xi}$ e, por (2), $U_{\xi} \cap G_{\xi}=\emptyset$. Portanto

$$
S t(F, \mathcal{U})=S t\left(G_{\xi}, \mathcal{U}\right) \subseteq X \backslash\left\{x_{\xi}\right\}
$$

e, como $F \subset D$ foi tomado arbitrariamente, $X$ não é um (a)-espaço.

Analisando a demonstração apresentada, podemos ver que o argumento utilizado para "destruir" a Propriedade (a) de um determinado espaço foi essencialmente o seguinte: "Seja dado um espaço $X$ que contenha um denso $D$ e um fechado e discreto $H$. Se for possível injetar a família $\mathcal{F}_{D}$ dos fechados e discretos contidos em $D$ em um subconjunto de $H$ que seja disjunto do denso $D$, então $X$ não possui a Propriedade (a)." Assim, podemos apresentar o seguinte Corolário, que é um corolário da demonstração do Teorema 2.8 e, colocado nestes termos, é uma contribuição original:

Corolário 2.9 Seja $X$ um espaço topológico que contenha subconjuntos $D$ e $H$ tais que $D$ é um denso e $H$ é um fechado e discreto $e m X$. Se $\left|\mathcal{F}_{D}\right| \leqslant|H \backslash D|$, então $X$ náo possui a Propriedade (a). 
O Corolário 2.9 tenta fazer uma "estimativa mais apurada" da cardinalidade que um fechado e discreto não pode exceder num (a)-espaço; a estimativa " $2^{d(X)}$ " para limite superior de $\left|\mathcal{F}_{D}\right|$ pode, a princípio, ser melhorada. Resultados nesse sentido foram introduzidos por Szeptycki e Vaughan em [SV98], e utilizaremos no Capítulo 5 deste trabalho algumas idéias semelhantes às utilizadas por esses autores: no caso, tratam-se de idéias relativas à cardinalidade de certas famílias cofinais em $\mathcal{F}_{D}$ e que também se prestam a tentar estimar melhor os limites superiores para a cardinalidade dos fechados e discretos em um (a)-espaço, além de outros aspectos que serão discutidos detalhadamente.

Note que do Corolário 2.9 pode-se deduzir também o "Corolário do Lema" (Corolário 2.6): se, num determinado espaço $X T_{1}, H$ é um fechado e discreto infinito que é disjunto de um denso enumerável $D$ que não contém fechados e discretos infinitos, então $\mathcal{F}_{D}=[D]^{<\omega}$ donde $\omega=\left|\mathcal{F}_{D}\right| \leqslant|H|$ e portanto $X$ não é um $(a)$-espaço.

Como já observamos, dedicamos um apêndice deste nosso trabalho (Apêndice A) para determinadas comparações entre vários enunciados possíveis do Lema de Jones e a sua versão para (a)-espaços. Dessas comparações surgiram algumas questões, as quais motivaram o aparecimento de certos resultados no Capítulo 5 que nos levam a tratar de grandes cardinais. Portanto, ainda voltaremos ao assunto "Lema de Jones". 


\section{Capítulo 3}

\section{Os espaços $\Psi(\mathcal{A})$}

Certos espaços construídos a partir de famílias a.d. de subconjuntos infinitos de $\omega$ e que são genericamente denominados como espaços $\Psi(\mathcal{A})$ são espaços muito interessantes para o estudo da Propriedade (a). Esses espaços foram introduzidos nos anos 50 por Mrówka, e às vezes são chamados de "espaços de Mrówka-Isbell"; também existem denominações como " $\Psi$-espaços" ou "espaços $\Psi$-like" (neste trabalho, optamos pelas denominações "espaços $\Psi(\mathcal{A})$ " ou ainda "espaços $\Psi$-like"). Vejamos como é a construção de um espaço $\Psi(\mathcal{A})$. Seja dada $\mathcal{A}$ uma família a.d. (almost disjoint) de subconjuntos infinitos de $\omega$ (lembrando que uma família $\mathcal{A}$ de subconjuntos infinitos de $\omega$ é dita uma família a.d. se para quaisquer $X, Y \in \mathcal{A}$ distintos tem-se $|X \cap Y|<\omega)$. O espaço $\Psi(\mathcal{A})$ associado tem como suporte o conjunto $\mathcal{A} \cup \omega$. Os pontos de $\omega$ são declarados isolados e as vizinhanças básicas de um elemento $A$ de $\mathcal{A}$ são da forma $\{A\} \cup(A \backslash F)$ para $F \in[\omega\}^{<\omega}$ (isso é equivalente a declarar que $\{\{A\} \cup(A \backslash n): n<\omega\}$ é uma base para $A$ ). Com isso, já fica claro que $\Psi(\mathcal{A})$ é primeiro-enumerável e também separável (pois $\omega$ é um conjunto denso de pontos isolados em $\Psi(\mathcal{A})$ ) e, como as vizinhanças básicas de um ponto $A \in \mathcal{A}$ não interceptam $\mathcal{A} \backslash\{A\}, \mathcal{A}$ é um fechado e discreto em $\Psi(\mathcal{A})$. É fácil verificar também que $\Psi(\mathcal{A})$ é um espaço de Hausdorff: dados dois pontos distintos do espaço, ou ambos são números naturais que são separados por seus unitários, ou um é um natural $m<\omega$ e outro é um elemento $A \in \mathcal{A}$ que são separados pelos abertos $\{m\}$ e $\{A\} \cup(A \backslash\{m\})$ ou eles são dois elementos distintos $A_{1}, A_{2}$ de $\mathcal{A}$ que são separados pelos abertos $\left\{A_{1}\right\} \cup\left(A_{1} \backslash\left(A_{1} \cap A_{2}\right)\right)$ e $\left\{A_{2}\right\} \cup A_{2}$. As mesmas verificações mostram que os abertos básicos são fechados, por- 
tanto $\Psi(\mathcal{A})$ é zero-dimensional e conseqüentemente completamente regular, pois espaços $T_{1}$ zero-dimensionais são $T_{3 \frac{1}{2}}([$ Eng89], 6.2.16). Além disso, as vizinhanças básicas dos pontos de $\Psi(\mathcal{A})$ são todas compactas: isso é óbvio para os pontos de $\omega$ e, dado $A \in \mathcal{A}$ e uma vizinhança básica arbitrária $\{A\} \cup(A \backslash F)$ de $A$ observamos que dada uma cobertura aberta $\mathcal{U}$ de $\{A\} \cup(A \backslash F)$, com $\mathcal{U}$ formada por abertos básicos, podemos fixar $U \in \mathcal{U}$ tal que $A \in U$, com $U$ dado por, digamos, $U=\{A\} \cup(A \backslash G)$; teremos então $(\{A\} \cup(A \backslash F)) \backslash U=A \cap(G \backslash F)$ que é finito. Portanto $\Psi(\mathcal{A})$ é um espaço zero-dimensional, primeiro-enumerável, localmente compacto, completamente regular e separável (no qual o conjunto dos pontos isolados é um denso enumerável cujo complementar é discreto). Essas propriedades de $\Psi(\mathcal{A})$ são, de certo modo, bastante específicas; veremos na seção seguinte que um espaço com estas características é homeomorfo a um espaço $\Psi(\mathcal{A})$. Esse resultado será muito útil no decorrer deste trabalho.

Nas seçôes seguintes, apresentamos as demonstrações de alguns resultados que, mesmo que em alguns casos sejam "folklore" em topologia conjuntística, não são apresentadas na literatura. Neste capítulo, trataremos basicamente de duas propriedades que já vimos estarem relacionadas em muitos contextos: a normalidade e a Propriedade (a). Com relação à normalidade, veremos que certos espaços (homemomorfos a espaços) $\Psi(\mathcal{A})$ podem ser facilmente relacionados a questões clássicas da Topologia Geral, como a existência de espaços de Moore não-metrizáveis. O capítulo encerra-se com a apresentação de algumas questões e conjecturas.

Outras propriedades interessantes, notadamente a presença da paracompacidade enumerável nos espaços " $\Psi$-like", serão discutidas no próximo capítulo, onde apresentaremos resultados originais sobre espaços $\Psi(\mathcal{A})$.

\subsection{Uma caracterização dos espaços " $\Psi$-like"}

A seguinte proposição é "folklore" em topologia conjuntística, e trata-se, essencialmente, de um resultado que consta sem demonstração em [vD84]. Fizemos algumas modificações no enunciado do seguinte resultado, tornando-o mais aplicável aos nossos 
propósitos, e apresentamos uma demonstração como uma contribuição do nosso trabalho.

Proposição 3.1 Se $X$ é um espaço de Hausdorff primeiro-enumerável, localmente compacto e separável tal que $X^{\prime}$ é discreto e não-vazio, então $X$ é homeomorfo a um espaço $\Psi(\mathcal{A})$ para alguma família a.d. $\mathcal{A} \subseteq[\omega]^{\omega}$.

Demonstração: Seja $\langle X, \tau\rangle$ um espaço topológico nas condições do enunciado. Como $\emptyset \neq X^{\prime} \neq X$ então, considerando o subconjunto próprio de $X$ dado por $D=X \backslash X^{\prime}$ tem-se que $D$ é o conjunto dos pontos isolados de $X$ (i.e., $D=\{d \in X:\{d\} \in \tau\}$ ) e, mais ainda, como $X^{\prime}$ é discreto temos que $D$ é um subconjunto denso de $X$ que está claramente contido em qualquer subconjunto denso de $X$. Como $X$ é um espaço de Hausdorff que possui pontos de acumulação e é separável, segue que $|D|=\omega$.

As hipóteses " $X$ é primeiro-enumerável" e " $X$ é localmente compacto" nos permitem enunciar e provar o seguinte Lema, que nos auxiliará nas demais verificações:

Lema 3.2 Nas condiçóes do enunciado, $X$ é zero-dimensional e cada ponto $x \in X^{\prime}$ possui um sistema fundamental enumerável de vizinhanças abertas-fechadas compactas.

Prova do Lema: Como $X$ é $T_{2}$ e localmente compacto e $X^{\prime}$ é discreto, então (trabalhando rotineiramente com bases locais enumeráveis e arbitrárias de pontos de $X^{\prime}$, usando que $X$ é primeiro-enumerável) podemos afirmar que cada ponto $x \in X^{\prime}$ possui uma base local enumerável de vizinhanças abertas $\mathcal{V}_{x}=\left\{V_{x, n}: n<\omega\right\}$ que é tal que seus abertos satisfazem as condiçōes

(1) $(\forall n<\omega)\left[x \in V_{x, n+1} \subseteq \overline{V_{x, n+1}} \subseteq V_{x, n}\right]$

(2) $(\forall n<\omega)\left[\overline{V_{x, n}}\right.$ é compacto e $\left.\overline{V_{x, n}} \cap X^{\prime}=\{x\}\right]$

Com isso, podemos afirmar que

(3) $(\forall n<\omega)\left[V_{x, n}\right.$ é um fechado]

pois os pontos de $D$ são isolados e de $\overline{V_{x, n}} \cap X^{\prime}=\{x\}$ segue que se $y \in X^{\prime} \backslash\{x\}$ então $y \notin \overline{V_{x, n}}$. Logo, dado $x \in X^{\prime}$ arbitrário, $\mathcal{V}_{x}=\left\{V_{x, n}: n<\omega\right\}$ é uma base local 
enumerável formada por vizinhanças abertas-fechadas e compactas. Como os abertos $\{d\}$ para $d \in D$ são também abertos-fechados, $X$ é um espaço zero-dimensional (e, portanto, completamente regular).

Segue do Lema que, dado $x \in X^{\prime}$ arbitrário, os abertos de $\mathcal{V}_{x}$ satisfazem a condição

(4) $(\forall n<\omega)\left[V_{x, n} \backslash V_{x, n+1}\right.$ é finito $]$

pela compacidade de cada um dos conjuntos $V_{x, n}$ : se tivéssemos $V_{x, m} \backslash V_{x, m+1}$ infinito para algum $m<\omega$, a cobertura de $V_{x, m}$ dada por

$$
\mathcal{U}=\left\{V_{x, m+1}\right\} \cup\left\{\{d\}: d \in V_{x, m} \backslash V_{x, m+1}\right\}
$$

não admitiria subcobertura finita. Ou, equivalentemente, basta notar que para qualquer $n<\omega$ temos que $V_{x, n} \backslash V_{x, n+1}$ é um fechado e discreto contido num compacto.

Definimos agora, para cada $x \in X^{\prime}$, um subconjunto infinito $A_{x} \subset D$ pondo

$$
A_{x}=V_{x, 0} \backslash\{x\}
$$

e observamos que vale, para cada $x \in X^{\prime}$, a seguinte afirmação:

(5) $A_{x}$ converge para $x$

De fato: dada uma vizinhança arbitrária $W$ de um ponto $x \in X^{\prime}$, existe então $m<\omega$ (que podemos supor satisfazer $1 \leqslant m<\omega$ ) tal que $x \in V_{x, m} \subseteq W$ donde

$$
A_{x} \backslash W \subseteq A_{x} \backslash V_{x, m}=\bigcup_{k<m} V_{x, k} \backslash V_{x, k+1}
$$

e este último conjunto é finito por ser uma união finita de conjuntos que são finitos (pela asserção (4) ). Como $X$ é um espaço de Hausdorff, segue imediatamente que

(6) $\mathcal{A}=\left\{A_{x}: x \in X^{\prime}\right\}$ é uma família a.d. de subconjuntos de $D$.

Identificando $D \operatorname{com} \omega$ e $X^{\prime} \operatorname{com} \mathcal{A}$ na maneira "óbvia", mostraremos que a topologia $\tau$ de $X$ coincide com a topologia $\tau^{\prime}$ que se obtém considerando-se $X=\Psi(\mathcal{A})$.

Verificaçào de $\tau \subseteq \tau^{\prime}:$ Sejam $U \in \tau$ e $p \in X$ tal que $p \in U$. Se $p \in D,\{p\}$ é um aberto de $\tau^{\prime}$ (pois os pontos de $D$ foram declarados isolados nessa topologia) e assim, nesse caso 
existe um aberto de $\tau^{\prime}$ contido em $U$. Se $p \in X^{\prime}$, então existe $n<\omega$ tal que $p \in V_{p, n} \subseteq U$ donde

$$
p \in\left(\{p\} \cup\left(A_{p} \backslash\left(A_{p} \backslash V_{p, n}\right)\right)\right) \subseteq V_{p, n} \subseteq U
$$

e $\{p\} \cup\left(A_{p} \backslash\left(A_{p} \backslash V_{p, n}\right)\right)$ é um aberto de $\tau^{\prime}$ já que $A_{p} \backslash V_{p, n}$ é finito (o que pode se verificar de modo análogo ao que foi feito quando da verificação de (5)). Portanto $U$ também é um aberto em $\tau^{\prime}$, logo $\tau \subseteq \tau^{\prime}$.

Verificação de $\tau^{\prime} \subseteq \tau$ : Basta verificar que os abertos básicos de $\tau^{\prime}$ são também abertos de $\tau$. Dado $d \in D$, o aberto básico de $\tau^{\prime}$ dado por seu unitário $\{d\}$ também é aberto em $\tau$ (pois temos $D=X \backslash X^{\prime}$ ). Se $x \in X^{\prime}$ e $F \subset D$ é finito então o aberto básico de $\tau^{\prime}$ dado por $\{x\} \cup\left(A_{x} \backslash F\right)$ é um aberto de $\tau$ pois $\{x\} \cup\left(A_{x} \backslash F\right)=V_{x, 0} \backslash F$ que é um aberto de $\tau$ porque $V_{x, 0} \in \tau$ e $F$ é finito num espaço $T_{2}$, donde $V_{x, 0} \backslash F=\{x\} \cup\left(A_{x} \backslash F\right) \in \tau$.

Portanto $\tau=\tau^{\prime}$ e as topologias coincidem, conforme desejado; segue que $X$ é homeomorfo a um espaço da forma $\Psi(\mathcal{A})$ para $\mathcal{A} \subseteq[\omega]^{\omega}$.

$\mathrm{Na}$ verdade, podemos definir espaços análogos para famílias a.d. contidas na. família dos subconjuntos infinitos e enumeráveis de um conjunto infinito qualquer : são os chamados $\Psi(D, \mathcal{A})$ (para $\mathcal{A} \subseteq[D]^{\omega}$ a.d., $D$ infinito) descritos em [vD84]. Se $D=\omega$, escrevemos $\Psi(\omega, \mathcal{A})=\Psi(\mathcal{A})$. Na proposição anterior, se retirarmos a hipótese " $X$ é separável" obteremos um espaço $\Psi(D, \mathcal{A})$ para $D$ o conjunto (infinito) dos pontos isolados em $X$ : basta observar que os conjuntos $A_{x}$ (mesmo numa situação mais geral em que $|D|>$ w) são necessariamente enumeráveis, por serem uma reunião enumerável de subconjuntos finitos: note que, para $p \in X^{\prime}$ fixado, $\cap \mathcal{V}_{p}=\{p\}$ por $\mathcal{V}_{p}$ ser uma base local para $p$ e por ser $X$ um espaço de Hausdorff. Segue que

$$
A_{p}=V_{p, 0} \backslash\{p\}=\bigcup_{n \geqslant 1} V_{p, 0} \backslash V_{p, n}=\bigcup_{n<\omega} V_{p, n} \backslash V_{p, n+1}
$$

e cada um dos conjuntos $V_{p, n} \backslash V_{p, n+1}$ é finito, por (4).

Dito isto, podemos observar que nossa Proposição 3.1 é a "versão separável" do resultado de "folklore" em topologia conjuntistica que consta no artigo de van Douwen sobre pequenos cardinais([vDS4]), conforme já destacamos; nesse mesmo artigo, o leitor 
poderá obter referências sobre os trabalhos iniciais de Mrówka e Isbell a respeito dos espaços $\Psi(\mathcal{A})$.

\subsection{Caracterização combinatória da normalidade para espaços $\Psi(\mathcal{A})$}

Os resultados "técnicos" do começo desta seção constam, essencialmente, na seção 11 do artigo de van Douwen sobre pequenos cardinais no Handbook, porém sem demonstração; apresentamos aqui as demonstrações como uma contribuição do nosso trabalho. Com relação à subseção em seguida (que trata de um resultado de consistência), os resultados que ali constam seguem dos resultados técnicos do começo da seção e do estudo da ação de $Q$-conjuntos em certos subespaços do Plano de Niemytzki; nos propusemos a dar enunciados coerentes e claros para uma série de resultados que não constam de forma "organizada" na literatura, mesmo porque o "foco" principal desses resultados está relacionado a um problema de grande peso na história da Topologia Geral, que é a questão da existência de espaços de Moore normais (no caso, separáveis) e não-metrizáveis.

O Lema de Jones já garante que um espaço $\Psi(\mathcal{A})$ não é normal no caso em que $|\mathcal{A}|=\mathfrak{c}$; basta observar que $\mathcal{A}$ é um subespaço fechado e discreto de $\Psi(\mathcal{A})$. Para os casos mais gerais, a normalidade de um espaço $\Psi(\mathcal{A})$ tem uma caracterização combinatória bastante específica e, de certo modo, simples. Inicialmente, uma definição de cunho bastante geral:

Definição 3.3 Sejam $\mathcal{F}$ e $\mathcal{G}$ famílias de conjuntos enumeráveis infinitos. Dizemos que $\mathcal{F} \in \mathcal{G}$ podem ser separados se existir um conjunto $S$ tal que

$$
(\forall F \in \mathcal{F})\left[F \subseteq \subseteq^{*}\right] \wedge(\forall G \in \mathcal{G})[|S \cap G|<\omega] .
$$

O seguinte lema mostra que para subfamílias de uma família a.d. o conceito de "podem ser separados" (de acordo com a definição anterior) significa "podem ser separados" (por abertos de $\Psi(\mathcal{A})$ ). 
Lema 3.4 Sejam $\mathcal{A} \subseteq[\omega]^{\omega}$ uma familia a.d. e $\mathcal{F}, \mathcal{G} \subset \mathcal{A}, \mathcal{F} \cap \mathcal{G}=\emptyset$. Então $\mathcal{F}$ e $\mathcal{G}$ podem ser separados se e somente se $\mathcal{F}$ e $\mathcal{G}$ possuem vizinhanças disjuntas em $\Psi(\mathcal{A})$.

Prova do Lema: Sejam $\mathcal{A}, \mathcal{F}$ e $\mathcal{G}$ como no enunciado e suponhamos inicialmente que exista um conjunto $S \in[\omega]^{\omega}$ que separe $\mathcal{F}$ e $\mathcal{G}$; então $\mathcal{F} \cup S$ e $\mathcal{G} \cup(\omega \backslash S)$ são vizinhanças disjuntas de $\mathcal{F}$ e $\mathcal{G}$ em $\Psi(\mathcal{A})$ (os abertos da forma $\{A\} \cup(A \backslash(A \backslash S)$ ) para $A \in \mathcal{F}$ e da forma $\{A\} \cup(A \backslash(A \cap S))$ para $A \in \mathcal{G}$ mostram que $\mathcal{F} \cup S$ e $\mathcal{G} \cup(\omega \backslash S)$ "fazem o trabalho"). Para a recíproca, suponhamos que existam $X$ e $Y$ em $[\omega]^{\omega}$ tais que $\mathcal{F} \cup X$ e $\mathcal{G} \cup Y$ sejam vizinhanças disjuntas de $\mathcal{F}$ e de $\mathcal{G}$; pode-se supor s.p.g. que $Y=\omega \backslash X$. É fácil verificar nessas condições que $X$ separa $\mathcal{F}$ e $\mathcal{G}$.

Com isso, temos o seguinte

Fato 3.5 Um espaço $\Psi(\mathcal{A})$ é normal se e somente se quaisquer duas subfamílias disjuntas de $\mathcal{A}$ podem ser separadas.

Com isso, informações sobre a estrutura combinatória de famílias a.d. (basicamente, informações usando cardinais) podem definir se os espaços " $\Psi$-like" correspondentes são ou não normais. Por exemplo, valem as seguintes igualdades (ver, respectivamente, o Teorema 3.3 e Corolário 4.2 de [vD84]):

Fato $3.6 \mathfrak{b}=\min \left\{|\mathcal{B}|: \mathcal{B} \subseteq[\omega]^{\omega}\right.$ e $\exists \mathcal{C} \subseteq[\omega]^{\omega}[|\mathcal{C}|=\omega, \mathcal{B} \cap \mathcal{C}=\emptyset, \mathcal{B} \cup \mathcal{C}$ é família a.d. e $\mathcal{B}$ e $\mathcal{C}$ não podem ser separados]\}

Fato $3.7 \omega_{1}=\min \left\{|\mathcal{B}|: \mathcal{B} \subseteq[\omega]^{\omega}\right.$ é a.d. e $(\exists \mathcal{C} \subseteq \mathcal{B})[\mathcal{C}$ e $\mathcal{B} \backslash \mathcal{C}$ não podem ser separados ]\}

Segue do Fato 3.6, portanto, que $\Psi(\mathcal{A})$ é normal se $|\mathcal{A}| \leqslant \omega$ (como $\omega<\mathfrak{b}$, segue da. caracterização de $\mathfrak{b}$ dada por 3.6 que no caso de $|\mathcal{A}|=\omega$ não existem subfamílias que não possam ser separadas) e, mais ainda, $\Psi(\mathcal{A})$ é pseudonormal se $|\mathcal{A}|<\mathfrak{b}$ (um espaço $X$ é dito pseudonormal se a separação de dois fechados disjuntos por abertos é garantida sempre que pelo menos um dos fechados disjuntos for um conjunto enumerável). Já o Fato 3.7 nos garante que existe, em $Z F C$, uma família a.d. $\mathcal{A}$ tal que $|\mathcal{A}|=\omega_{1}$ e $\Psi(\mathcal{A})$ não é normal; 
3.7 é conseqüência da existência dos chamados gaps de Luzin (ver [vD84]). Devido ao Lema de Jones, não se pode provar em ZFC que existam famílias a.d. não-enumeráveis tais que o respectivo espaço seja normal; tal fenômeno não pode ocorrer em modelos de CH (ou, mais geralmente, não pode ocorrer em modelos de " $2^{\omega}<2^{\omega_{1}}$ ). Uma questão óbvia no momento é: é consistente a existência de alguma família a.d. não-enumerável tal que o respectivo espaço " $\Psi$-like" seja normal ? Esse é o assunto da próxima subseção.

\subsection{1 "Existe um espaço $\Psi(\mathcal{A})$ normal com $\mathcal{A}$ não-enumerável" é independente de $Z F C$}

A consistência da existência de um espaço $\Psi(\mathcal{A})$ normal com $\mathcal{A}$ não-enumerável segue da consistência da existência de certos "subconjuntos especiais da reta", que são os $Q$-conjuntos não-enumeráveis; um subconjunto $B \subseteq \mathbb{R}$ é dito um $Q$-conjunto se todo subconjunto de $B$ é um $F_{\sigma}$ relativo, isto é, se $S \subseteq B$ então $S=F \cap B$ para algum $F$ subconjunto $F_{\sigma}$ da reta (um $F_{\sigma}$ é uma reunião enumerável de fechados).

Para uma compreensão melhor do contexto em que "aparece" o nosso espaço $\Psi(\mathcal{A})$ devemos dedicar algumas palavras ao chamado "Problema do Espaço de Moore Normal": um espaço topológico $X$ é dito um espaço de Moore se $X$ for regular e possuir um desenvolvimento, sendo que um desenvolvimento de $X$ é uma família de coberturas abertas $\left\{\mathcal{U}_{n}: n<\omega\right\}$ que seja tal que para todo ponto $p \in X$ e para toda vizinhança aberta $V$ de $p$ existe $n<\omega$ tal que $\bigcup\left\{U \in \mathcal{U}_{n}: p \in U\right\} \subseteq V$. Um espaço $X$ que possua um desenvolvimento é, portanto, primeiro-enumerável. É fácil ver que, se $X$ é um espaço métrico, então a seqüência de famílias de bolas abertas $\mathcal{U}_{n}=\{B(p, 1 / n): p \in X\}$ é um desenvolvimento de $X$. Assim, todo espaço métrico é de Moore, mas a recíproca não é verdadeira (o plano de Niemytzki é um espaço de Moore não-normal: voltaremos a falar do Plano de Niemytzli em breve). Em 1937, Jones conjecturou que espaços de Moore normais seriam metrizáveis e nesse sentido ele provou um resultado notável: "Se $2^{\omega}<2^{\omega_{1}}$, então espaços de Moore normais separáveis são metrizáveis" (trata-se do mesmo trabalho no qual ele demonstrou o chamado Lema de Jones ([Jon37])). No entanto, o Problema do Espaço de Moore Normal - que consiste em determinar se espaços de Moore normais são metrizáveis - continuou em aberto e foi alvo de ataque de inúmeros topólogos nas três 
décadas seguintes. Bing, no início dos anos 50, demonstrou que a "condição essencial" que é equivalente à metrizabilidade de um espaço de Moore é a normalidade coletiva (um espaço $X$ é dito coletivamente normal se toda família discreta de fechados de $X$ pode ser separada por uma família de abertos dois-a-dois disjuntos). A Chamada Conjectura do Espaço de Moore Normal (NMSC) é a afirmação "Espaços de Moore normais são metrizáveis"; sabe-se atualmente que a discussão dessa conjectura envolve grandes cardinais, pois Fleissner demonstrou que "Se todos os espaços de Moore normais são metrizáveis, então existe um modelo interno com um cardinal mensurável"([Fle82]). Referências mais completas sobre os primórdios da discussão do Problema do Espaço de Moore Normal podem ser encontradas na tese de doutorado de Frank Tall, de 1969, publicada em [Tal77]; a partir deste ponto, vamos inclusive utilizar as notações da tese de Tall para discutirmos certos espaços que são subespaços do chamado Plano de Niemytzki (ver descrição desse espaço na página 16): dado $B \subset \mathbb{R}$, seja $M(B)$ o espaço de Moore derivado de $B$, que é o subespaço do plano de Niemytzki que se obtém deletando-se todos os pontos do eixo $O x$ ("reta $L$ ") que não pertençam a. $B \times\{0\} . M(B)$ é claramente um espaço de Moore, separável; se $|B| \geqslant \omega_{1},\{\{\langle x, 0\rangle\}: x \in B\}$ é uma família discreta de fechados que não pode ser separada, donde, se $B \subset \mathbb{R}$ for não-enumerável e tal que $M(B)$ é normal, então nesse caso $M(B)$ é um espaço de Moore normal separável e não-metrizável. No entanto, pode-se mostrar que vale a equivalência " $M(B)$ é normal $\Longleftrightarrow B$ é $Q$-conjunto" ([Tal77]), e é consistente que existam $Q$-conjuntos não-enumeráveis; isso segue de " $\omega_{1}<\mathfrak{p}$ é consistente", ou do Axioma de Martin (mais precisamente, de " $M A+\neg C H$ é consistente"; a informação crucial aqui é que "se $\kappa<\mathfrak{p}$ então todo subconjunto de $I R$ de cardinalidade $\kappa$ é um $Q$-conjunto", o que é um resultado clássico de Rothberger nos anos 40: veja [Tal77], pág.43, e as discussões sobre p e MA na pág.9 de nosso trabalho). Assim, a tese de Tall (utilizando modelos de Solovay e Silver e um resultado de Heath) mostrou que a existência de espaços de Moore normais, separáveis e não-metrizáveis é independente de $Z F C$.

O espaço $\Psi(\mathcal{A})$ normal com $\mathcal{A}$ não-enumerável que exibiremos é construído a partir de um espaço $M(B)$ no qual $B$ é um $Q$-conjunto não-enumerável; como trata-se de uma construção que iremos utilizar outras vezes neste trabalho, vamos descrevê-la com um pouco mais de generalidade. Antes, vamos fazer algumas definições e fixar algumas notaçôes para facilitar referências futuras. 
Definição 3.8 Seja dado um subconjunto $Y \subseteq \mathbb{R}$ e considere $X=M(Y)$ o espaço de Moore derivado de $Y$ (que é o subespaço do plano de Niemytzki que se obtém deletando-se todos os pontos da reta que não pertençam a $Y \times\{0\}$.). Definem-se nessas condições os seguintes espaços topológicos:

(i) $X_{Y}$ é o espaço topológico que é o refinamento da topologia de $X$ que se obtém isolando todos os pontos que pertencem ao semiplano superior.

(ii) Para $D$ um denso enumerável contido no semiplano superior, consideraremos sempre $(Y \times\{0\}) \cup D$ com a topologia de subespaço de $X_{Y}$.

A construção do espaço $X_{Y}$ é usual em topologia: estamos isolando todos os pontos que não pertencem ao subespaço $Y \times\{0\}$ (ver [Eng89], 5.1.22).

Proposição 3.9 Sejam $Y \subset \mathbb{R}$ e $M(Y)$ o espaço de Moore derivado de $Y$. Suponha que $M(Y)$ é normal. Então existe um espaço $\Psi(\mathcal{A})$ com $|\mathcal{A}|=|Y|$ tal que $\Psi(\mathcal{A})$ é normal.

Demonstração : Considere $Y$ e $M(Y)$ como no enunciado e sejam $X=M(Y), X_{Y}$ e (para $D$ um denso enumerável contido no semiplano superior) $(Y \times\{0\}) \cup D$ como na Definição 3.8. Por hipótese, $X$ é normal, e como $Y \times\{0\}$ é subespaço fechado de $X, X_{Y}$ é normal ([Eng89], 5.1.22). Note agora que $(Y \times\{0\}) \cup D$ contém todos os seus pontos de acumulaçào, portanto $(Y \times\{0\}) \cup D$ é um subespaço fechado do espaço normal $X_{Y}$, sendo portanto normal também. $(Y \times\{0\}) \cup D$ é homeomorfo a um espaço $\Psi(\mathcal{A})$ com $|\mathcal{A}|=|Y|$ por ser um espaço $T_{2}$ primeiro-enumerável, localmente compacto e separável no qual os pontos de acumulação formam um conjunto discreto cujo complementar é um conjunto enumerável denso de pontos isolados; basta aplicar a Proposição 3.1.

Com a Proposição 3.9, já é possível enunciar o resultado que é título desta subseção:

Teorema 3.10 A existência de um espaço $\Psi(\mathcal{A})$ normal com $\mathcal{A}$ não-enumerável é independente de $\mathrm{ZFC}$. 
Demonstração : Em modelos de $C H$ (ou mesmo de " $2^{\omega}<2^{\omega_{1}}$ ") não existem espaços $\Psi(\mathcal{A})$ normais com $|\mathcal{A}|>\omega$ em virtude do Lema de Jones. Em modelos que satisfaçam " $\omega_{1}<\mathfrak{p}$ " ou " $M A+\neg C H$ " existem $Q$-conjuntos não-enumeráveis, logo o respectivo espaço de Moore derivado é normal e basta aplicar a Proposição 3.9.

É importante destacarmos desde já que em modelos nos quais existam $Q$-conjuntos não-enumeráveis vale a igualdade " $2^{\omega}=2^{\omega_{1}}$ "; isso segue facilmente das construções que mostramos e do Lema de Jones. No Capítulo 5 deste trabalho estaremos interessados em procurar certos exemplos de espaços em modelos que satisfaçam " $2^{\omega}<2^{\omega_{1}}$ ", logo nesses modelos não podem existir $Q$-conjuntos não-enumeráveis, Note que, mais geralmente, num modelo em que tenhamos a desigualdade estrita " $2^{\omega}<2^{\omega_{1}}$ " não podem existir espaços normais com fechados e discretos não-enumeráveis (ver Apêndice A).

\subsection{Caracterização combinatória da Propriedade $(a)$ para espaços $\Psi(\mathcal{A})$}

Uma das condições mais simples que garantem que um dado espaço $\Psi(\mathcal{A})$ não possui a Propriedade $(a)$ é $|\mathcal{A}|=\mathfrak{c}$; nesse caso o espaço não possui a Propriedade $(a)$ em virtude da versão de Matveev para o Lema de Jones (pág. 24). Outra condição facilmente identificável na qual um espaço $\Psi(\mathcal{A})$ não possui a Propriedade $(a)$ é dada pelo seguinte

Fato 3.11 Se $\mathcal{A} \subseteq[\omega]^{\omega}$ é uma família a.d. maximal, então $\Psi(\mathcal{A})$ não possui a Propriedade $(a)$.

Justificativa: Observe que, se $\mathcal{A}$ é maximal, qualquer subconjunto infinito de $\omega$ deve ter intersecção infinita com algum $A \in \mathcal{A}$, e conseqüentemente sua intersecçào com esse conjunto $A$ convergirá para o elemento $A$ de $\Psi(\mathcal{A})$; segue que os fechados e discretos contidos em $\omega$ são finitos. Aplica-se então o "Corolário do Lema" (Corolário 2.6) para $D=\omega$ e $H=\mathcal{A}$. 
No artigo [SV98], Szeptycki e Vaughan apresentaram uma caracterização combinatória para os espaços $\Psi(\mathcal{A})$ que possuem a Propriedade $(a)$, em termos da família a.d. $\mathcal{A}$. Como não foi exibida uma demonstração dessa caracterização, apresentaremos uma demonstração aqui como uma contribuição do nosso trabalho.

Fato 3.12 ([SV98]) Se $\mathcal{A} \subseteq[\omega]^{\omega}$ é uma família a.d., então o espaço $\Psi(\mathcal{A})$ correspondente é um (a)-espaço se e somente se

$$
(\forall f: \mathcal{A} \mapsto \omega)(\exists P \subset \omega)(\forall A \in \mathcal{A})[0<|P \cap(A \backslash f(A))|<\omega]
$$

Justificativa: Suponha que $\mathcal{A}$ seja tal que $\Psi(\mathcal{A})$ é um $(a)$-espaço; dada $f: \mathcal{A} \mapsto \omega$ arbitrária, considere a cobertura de $\mathcal{A}$ dada por

$$
\mathcal{U}=\{\{A\} \cup(A \backslash f(A)): A \in \mathcal{A}\} \cup\{\{n\}: n \in \omega\}
$$

Observamos que, dado $A \in \mathcal{A},\{A\} \cup(A \backslash f(A))$ é o único aberto de $\mathcal{U}$ que contém o elemento $A \in \mathcal{A}$.

A Propriedade $(a)$ implica na existência de $P \subset \omega$ fechado e discreto satisfazendo $S t(P, \mathcal{U})=\Psi(\mathcal{A})$; então $P$ intersecta todos os conjuntos da forma $(A \backslash f(A))$ para $A \in \mathcal{A}$ (garantindo que estes pontos estejam na estrela de $P$ com relação a $\mathcal{U}$ ) e $P$ tem intersecção finita com todos os elementos $A \in \mathcal{A}$, caso contrário $P$ possuiria pontos de acumulação.

Reciprocamente, suponha que $\mathcal{A}$ satisfaça a condição descrita no enunciado. Considere $\mathcal{U}$ uma cobertura arbitrária de $\Psi(\mathcal{A})$. Tomamos um refinamento $\mathcal{U}^{\prime}$ de $\mathcal{U}$ formado por abertos básicos, digamos

$$
\mathcal{U}^{\prime}=\left\{\{A\} \cup\left(A \backslash n_{A}\right)\right\} \cup\{\{n\}: n<\omega\}
$$

Podemos então definir uma função $f: \mathcal{A} \mapsto \omega$ pondo $f(A)=n_{A}$ para todo $A \in \mathcal{A}$. Por hipótese, existe $P \subset \omega$ tal que $0<|P \cap(A \backslash f(A))|<\omega$ para todo $A \in \mathcal{A}$; segue que $P$ não possui pontos de acumulação e que $S t\left(P, \mathcal{U}^{\prime}\right)$ cobre $\mathcal{A}$. Seja $S=\Psi(\mathcal{A}) \backslash S t\left(P, \mathcal{U}^{\prime}\right)$; então $P \cup S$ é fechado e discreto, $P \cup S \subset \omega \mathrm{e}$

$$
\Psi(\mathcal{A})=S t\left(P \cup S, \mathcal{U}^{\prime}\right) \subseteq S t(P \cup S, \mathcal{U}) \subseteq \Psi(\mathcal{A})
$$


e como $\omega$ é um conjunto denso de pontos isolados (sendo portanto um subconjunto de qualquer denso de $\Psi(\mathcal{A})$ ) e $\mathcal{U}$ é arbitrária, $\Psi(\mathcal{A})$ é um $(a)$-espaço.

Essa caracterização combinatória leva naturalmente a estudar as chamadas famílias a.d. do tipo "soft", introduzidas também em [SV98]. Uma família a.d. $\mathcal{A}$ é dita soft se existe $X \subseteq \omega$ infinito tal que $0<|X \cap A|<\omega$ para todo $A \in \mathcal{A}$. É fácil ver que a caracterização combinatória dada pelo Fato 3.12 equivale a dizer que um espaço $\Psi(\mathcal{A})$ é um (a)-espaço se e somente se todas as modificações finitas de $\mathcal{A}$ são soft ([Sze02]). Note que, com esta última observação, uma asserção do tipo "Todas as famílias a.d. $\mathcal{A}$ com uma determinada cardinalidade $\kappa$ são soft" implicaria que "Todas as famílias a.d. $\mathcal{A}$ de cardinalidade $\kappa$ são tais que o espaço $\Psi(\mathcal{A})$ associado possui a Propriedade $(a)$ ".

\subsection{1 "Existe um $(a)$-espaço $\Psi(\mathcal{A}) \operatorname{com} \mathcal{A}$ não-enumerável" é independente de $Z F C$}

Antes de discutirmos o caso não-enumerável, é importante observarmos que, se $|\mathcal{A}| \leqslant \omega$, então $\Psi(\mathcal{A})$ possui a Propriedade $(a)$; esse resultado é imediato se observarmos que, nesse caso, $\Psi(\mathcal{A})$ é metrizável (por ser um espaço regular de base enumerável) e portanto paracompacto, e assim o resultado segue então da Proposição 2.3. Pode-se também demonstrar que $\Psi(\mathcal{A})$ tem a Propriedade (a) no caso enumerável usando a seguinte Proposição, que é uma contribuição original deste trabalho e que fornece uma interessante propriedade dos espaços " $\Psi$-like" enumeráveis:

Proposição 3.13 Seja $\mathcal{A} \subseteq[\omega]^{\omega}$ uma familia a.d. que satisfaça $|\mathcal{A}| \leqslant \omega$. Nessas condiçoes, qualquer cobertura aberta do espaço $\Psi(\mathcal{A})$ correspondente possui um refinamento aberto que particiona $\Psi(\mathcal{A})$.

Demonstração: Faremos a argumentação para o caso $|\mathcal{A}|=\omega$, mas adaptar os argumentos para o caso finito é simples. Seja $\mathcal{A}=\left\{A_{n}: n<\omega\right\}$ uma família a.d. e considere $\mathcal{U}$ uma cobertura aberta arbitrária do espaço $\Psi(\mathcal{A})$. $\mathcal{U}$ possui um refinamento $\mathcal{U}^{\prime}$ formado por abertos básicos, digamos 


$$
\mathcal{U}^{\prime}=\left\{\left\{A_{n}\right\} \cup\left(A_{n} \backslash F_{n}\right)\right\} \cup\{\{n\}: n<\omega\}
$$

onde $F_{n} \in[\omega]^{<\omega}$ para todo $n<\omega$.

Por ser $\mathcal{A}$ uma família a.d., podemos definir uma família disjunta $\left\{B_{n}: n<\omega\right\} \subseteq$ $[\omega]^{\omega}$ pondo

$$
B_{n}=A_{n} \backslash\left(\bigcup_{k<n} A_{k}\right)=A_{n} \backslash\left(\bigcup_{k<n}\left(A_{n} \cap A_{k}\right)\right)
$$

e esses conjuntos $B_{n}$ para $n<\omega$ são tais que, se definirmos para cada $n<\omega$ um conjunto $V_{n}=\left\{A_{n}\right\} \cup B_{n}$ então cada um dos $V_{n}$ é um aberto de $\Psi(\mathcal{A})$.

Segue que, definindo para cada $n<\omega$ um aberto da forma

$$
W_{n}=\left(\left\{A_{n}\right\} \cup\left(A_{n} \backslash F_{n}\right)\right) \cap V_{n}
$$

então a cobertura aberta de $\Psi(\mathcal{A})$ dada por

$$
\mathcal{W}=\left\{W_{n}: n<\omega\right\} \cup\left\{\{n\}: n \in \Psi(\mathcal{A}) \backslash\left(\bigcup_{n<\omega} W_{n}\right)\right\}
$$

é um refinamento aberto de $\mathcal{U}^{\prime}$ (e, portanto, de $\mathcal{U}$ ) que safisfaz as condições desejadas.

A partir da Proposição apresentada, pode verificar-se facilmente que $\Psi(\mathcal{A})$ possui a Propriedade (a) sempre que $\mathcal{A}$ é enumerável: dada uma cobertura arbitrária $\mathcal{U}$, tomamos um refinamento aberto dessa cobertura que particione $\Psi(\mathcal{A})$ e escolhemos um elemento de $\omega$ em cada um dos abertos da partição; o conjunto formado por esses pontos é um fechado e discreto contido num conjunto denso de pontos isolados cuja estrela com relação à cobertura original cobre todo o espaço.

Tratemos então do caso não-enumerável: analogamente à normalidade, na presença de $C H$ não existem espaços $\Psi(\mathcal{A})$ que sejam $(a)$-espaços com $\mathcal{A}$ não-enumerável: segue da versão de Matveev para o Lema de Jones (pág. 24). Com relação ao caso nãoenumerável, resultados de Szeptycki e Vaughan ([SV98]) garantem que é consistente que exista uma família a.d. $\mathcal{A}$ não-enumerável tal que $\Psi(\mathcal{A})$ seja um $(a)$-espaço: usando o resultado de Bell que envolve uma certa versão restrita do Axioma de Martin e o cardinal $\mathfrak{p}$ ([Bel81]; veja comentários na pág.9), os autores mostraram que um espaço $\Psi(\mathcal{A})$ possui a Propriedade (a) sempre que $|\mathcal{A}|<\mathfrak{p}$ (resultado que também cuida do caso enumerável, portanto). Consideremos então um modelo no qual tenhamos " $\omega_{1}<\mathfrak{p}$ ": nessas condiçōes, 
tomando qualquer família a.d. que satisfaça $|\mathcal{A}|=\omega_{1}$ tem-se que o respectivo espaço $\Psi(\mathcal{A})$ possui a Propriedade $(a)$. Observamos ainda que a "escolha" de $\mathcal{A}$ pode ser feita de modo que $\Psi(\mathcal{A})$ também seja normal; se $\omega_{1}<\mathfrak{p}$, todo subconjunto de $\mathbb{R}$ de tamanho $\omega_{1}$ é um $Q$-conjunto, conforme já comentamos, e portanto o respectivo espaço de Moore $M(Y)$ é normal; aplicando-se a Proposição 3.9 obtém-se um espaço $\Psi(\mathcal{A})$ que é normal $\operatorname{com}|\mathcal{A}|=|Y|=\omega_{1}<\mathfrak{p}$, o que implica que ele também é um $(a)$-espaço. No mesmo trabalho citado, os autores mostraram que existe um modelo de $Z F C$ no qual existe um espaço $\Psi(\mathcal{A})$ que possui a Propriedade $(a)$ e é tal que $|\mathcal{A}|=\mathfrak{p}$ num modelo em que $\mathfrak{p}=\omega_{1}$ e $\mathfrak{d}=\omega_{2}=\mathfrak{c}$. Voltaremos a discutir com mais detalhes esses resultados de Szeptycki e Vaughan no Apêndice A de nosso trabalho (página 94).

\subsection{Questões e conjecturas}

Como já destacamos no capítulo anterior, existe um grande interesse na discussão das similaridades entre a Propriedade $(a)$ e a normalidade; essa discussão também vem ocorrendo no contexto dos espaços $\Psi(\mathcal{A})$. Em [SV98] foi demonstrado que um espaço $\Psi(\mathcal{A})$ normal com $|\mathcal{A}|<\mathfrak{d}$ possui a Propriedade $(a)$; um dos autores apresentou em seguida a seguinte questão, que surge da conjectura que essa restrição cardinal possa ser retirada:

Questão 3.14 (Szeptycki, [Sze02]) Se $\Psi(\mathcal{A})$ é normal, $\mathcal{A}$ é soft ?

Observamos que uma resposta positiva para a questão de Szeptycki implicaria que todo espaço $\Psi(\mathcal{A})$ normal possui a Propriedade $(a)$; basta observar que a condição de normalidade dada pelo Fato 3.5 vale para qualquer modificação finita da família a.d. em questão.

Apresentamos aqui uma questão, como contribuição de nosso trabalho. Conforme discussão a ser apresentada no próximo capítulo, nossa questão pode possuir uma resposta (se positiva) consistentemente mais forte (pois espaços $\Psi(\mathcal{A})$ normais são enumeravelmente paracompactos, mas é consistente que não valha a reciproca): 
Questão 3.15 Se $\Psi(\mathcal{A})$ é enumeravelmente paracompacto, $\Psi(\mathcal{A})$ é um $(a)$-espaço?

A questão da existência de espaços enumeravelmente paracompactos e primeiroenumeráveis que não possuam a Propriedade $(a)$ é o cerne de uma questão em aberto de Matveev, a qual também discutiremos no capítulo seguinte. Assim, nossa questão é uma restrição de uma questão de Matveev que, se tiver resposta positiva, soluciona uma questão de Szeptycki.

Com o intuito de fornecer mais elementos para a discussão de questões que envolvam a paracompacidade enumerável de espaços $\Psi(\mathcal{A})$, apresentamos no Apêndice $B$ de nosso trabalho uma caracterização das famílias a.d. $\mathcal{A} \subseteq[\omega]^{\omega}$ para as quais o respectivo espaço $\Psi(\mathcal{A})$ é enumeravelmente paracompacto. 


\section{Capítulo 4}

\section{Espaços metacompactos e enumeravelmente metacompactos}

Espaços paracompactos $T_{1}$ possuem a Propriedade (a) (Proposição 2.3), portanto é natural verificar se existem implicações análogas para versões mais fracas dessa propriedade. Uma maneira de enfraquecermos a paracompacidade é analisar o que ocorre para os espaços enumeravelmente paracompactos. Trataremos desse caso quando discutirmos uma questão apresentada por Matveev; no contexto dessa questão, a paracompacidade enumerável também é encarada como uma versão mais fraca da compacidade enumerável. Outra maneira de enfraquermos a condição de paracompacidade é considerar os espaços metacompactos, e nesse sentido, é muito natural nos perguntarmos se vale o resultado análogo da Proposição 2.3 : espaços metacompactos $T_{1}$ possuem a Propriedade $(a)$ ?

As propriedades de metacompacidade e metacompacidade enumerável aparecem em dois exemplos que construímos (usando torres) que foram motivados pelas questões que acabamos de comentar; um dos exemplos é metacompacto e o outro é enumeravelmente metacompacto. O exemplo metacompacto que construímos não possui a Propriedade $(a)$, portanto esse exemplo responde negativamente à pergunta sobre metacompactos do final do parágrafo anterior.

Lembramos que as propriedades do tipo da metacompacidade são mais fracas que as do tipo da paracompacidade porque nào se garante (dado uma cobertura aberta enumerável, para os enumeravelmente metacompactos, e uma cobertura aberta qualquer 
para os metacompactos) um refinamento aberto localmente finito, e sim ponto-finito. É interessante observarmos, porém, que a propriedade da metacompacidade enumerável, que é, em geral, mais fraca que a da paracompacidade enumerável, vem a ser equivalente a esta última quando restringe-se a discussão aos espaços normais ([Eng89], 5.2.6), ou seja, podese dizer que a "diferença" que existe entre essas duas propriedades relaciona-se fortemente às propriedades de separação de um espaço topológico. Como a questão de Matveev para enumeravelmente paracompactos permanece em aberto, é natural discutirmos como se comportam as situações análogas para enumeravelmente metacompactos.

A primeira seção deste capítulo consiste numa apresentação da questão de Matveev. Em seguida, apresentamos os exemplos que construímos usando o cardinal $\mathfrak{t}$; uma das construções, realizada sob " $\mathfrak{t}=\omega_{1}$ ", "inspira" uma construção em $Z F C$ de um espaço metacompacto $T_{1}$ que não possui a Propriedade $(a)$. Temos uma seção dedicada ao Plano de Nyemitzki, que fornece um exemplo em ZFC com muitas propriedades interessantes. $\mathrm{Na}$ última seção voltamos a discutir os espaços $\Psi(\mathcal{A})$, e como contribuição original apresentamos o primeiro exemplo consistente de um espaço $\Psi(\mathcal{A})$ que é anti-Dowker, isto é, enumeravelmente paracompacto e não-normal.

Antes de iniciarmos as seções, apresentemos mais uma contribuição original deste trabalho: um resultado sobre funções cardinais que vale para espaços metacompactos (e, conseqüentemente, para os paracompactos também). É um resultado interessante, pois trata de funções cardinais e não faz nenhuma suposição sobre a presença de axiomas de separação, o que é o usual (ver [Hod84]): usa-se apenas a metacompacidade do espaço (para espaços não-metacompactos, podemos ter $\epsilon(X)>d(X)$ : tome o quadrado da reta de Sorgenfrey ou o plano de Niemytzki).

Antes de apresentarmos a demonstração, lembremos que a função cardinal extent é definida como $e(X)=\sup \{|F|: F \subseteq X$ é fechado e discreto em $X\}+\omega$.

Teorema 4.1 Se $X$ é um espaço metacompacto, então $e(X) \leqslant d(X)$.

Demonstração : Seja $X$ um espaço metacompacto e $D \subseteq X$ um subconjunto denso, com $|D|=\kappa=d(X)$ : vamos mostrar que se $F \subseteq X$ é um fechado e discreto então $|F| \leqslant \kappa$, o que nos é suficiente. De fato: seja $F \subseteq X$ um fechado e discreto. Podemos então 
escolher, para cada $x \in F, U_{x}$ uma vizinhança aberta de $x$ que satisfaça $U_{x} \cap F=\{x\}$. Consideremos agora a cobertura aberta dada por

$$
\mathcal{U}=\left\{U_{x}: x \in F\right\} \cup\{X \backslash F\}
$$

Como $X$ é metacompacto, existe um refinamento aberto pontualmente finito $\mathcal{V}$ de $\mathcal{U}$, e portanto para cada $x \in F$ existe uma vizinhança aberta $V_{x}$ de $x$ que satisfaz $x \in V_{x} \subseteq U_{x} \operatorname{com} V_{x} \in \mathcal{V}$; obviamente, vale também que $V_{x} \cap F=\{x\}$ para todo $x \in F$.

Para cada $d \in D$, seja

$$
F_{d}=\left\{x \in F: d \in V_{x}\right\}
$$

Como $D$ é denso e $\mathcal{V}$ cobre $X$, temos $F=\bigcup_{d \in D} F_{d}$, e, como $\mathcal{V}$ é pontualmente finito, cada $F_{d}$ é finito, e portanto $|F| \leqslant|D|=\kappa$, conforme desejado.

\subsection{Uma questão de Matveev}

Expliquemos qual foi a questão que motivou a construção de nossos exemplos. No artigo [Mat94], no qual foi introduzido o conceito de espaços absolutamente enumeravelmente compactos, Matveev identificou algumas hipóteses que, restritas à classe dos espaços enumeravelmente compactos, implicam a Propriedade (a) (isto é, ele identificou hipóteses que implicam que um espaço enumeravelmente compacto é, também, absolutamente enumeravelmente compacto). Por exemplo, para que um espaço $X$ enumeravelmente compacto possua a Propriedade $(a)$ basta que todo subconjunto denso de $X$ seja $\omega$-denso (um subconjunto $Y \subset X$ é dito $\omega$-denso se para todo $a \in X$ existe $A \subset Y$ enumerável tal que $a \in \bar{A}$ ). Em particular, espaços enumeravelmente compactos de tightness enumerável possuem a Propriedade $(a)$, sendo portanto absolutamente enumeravelmente compactos. É importante destacarmos aqui que essa implicação vale na classe dos espaços $T_{1}$

Em 1997, Matveev ([Mat97]) listou esta e mais algumas outras propriedades (obtidas por Rudin, Stares e Vaughan em [RSV97]) que implicam a Propriedade (a) - desde que restritas à classe dos espaços enumeravelmente compactos. Ele entào observou que 
é bastante natural perguntar o que acontece se a compacidade enumerável é substituida por paracompacidade enumerável.

Questão 4.2 (Matveev ([Mat97])) Seja X enumeravelmente paracompacto e que satisfaça mais alguma das seguintes propriedades:
(A) tightness enumerável;
(B) primeiro axioma da enumerabilidade;
(C) ortocompacidade; e
(D) radialidade.

Pode-se afirmar que $X$ satisfaz a Propriedade $(a)$ ?

Observamos aqui que um contra-exemplo para o item $(B)$ seria também um contraexemplo para $(A)$ e $(D)$, já que vale a desigualdade $t(X) \leqslant \chi(X)$ (donde "primeiro enumerável" $\Rightarrow$ "tightness enumerável") e espaços primeiro-enumeráveis são espaços de Fréchet (um espaço topológico $X$ é dito um espaço de Fréchet se para todo $A \subseteq X$ e todo $x \in \bar{A}$ existe uma seqüencia de pontos de $A$ que converge para $x$ ) e espaços de Fréchet são claramente radiais (um espaço $X$ é dito radial se para todo $A \subseteq X$ e todo $x \in \bar{A}$ existe um cardinal infinito e regular $\kappa$ e uma sequêencia de comprimento $\kappa$ de pontos de $A$ que converge para $x$; como $\kappa$ é regular, define-se a convergência de uma seqüência de comprimento $\kappa$ de modo análogo ao caso enumerável).

Numa tentativa de apresentar um contra-exemplo (consistente) para os itens $(B)$, $(A)$ e $(D)$ da questão de Matveev, construímos um espaço $T_{1}$ que é enumeravelmente metacompacto e não possui a Propriedade $(a)$ e que, sob a hipótese " $\mathfrak{t}=\omega_{1}$ ", é primeiroenumerável. A implicação que motivou a questão de Matveev ("enumeravelmente compacto + tightness enumerável" $\Rightarrow$ "Propriedade $(a)$ ") vale na classe dos espaços $T_{1}, \operatorname{logo}$ seria interessante verificar que existe um exemplo consistente que fornecesse uma resposta negativa para enumeravelmente paracompactos nessa classe: o exemplo que construímos mostra que é consistente uma resposta negativa para uma "versão mais fraca" da questão de Matveev, restrita aos espaços $T_{1}$. Esse exemplo, porém, perdeu um pouco de seu interesse como resultado de consistência porque veremos na seção seguinte que existem exemplos em $Z F C$ de espaços enumeravelmente metacompactos e primeiro-enumeráveis 
que não possuem a Propriedade (a); no entanto, suas características combinatórias puderam ser utilizadas para, sob pequenas alterações, produzir um exemplo em $Z F C$ que responde (negativamente) a uma questão que surge naturalmente: espaços metacompactos $T_{1}$ possuem a Propriedade (a) ?

\subsection{Exemplos usando o cardinal $\mathfrak{t}$}

Os exemplos que construímos utilizam torres. Uma torre é uma família $\mathcal{T}$ de subconjuntos infinitos de $\omega, \mathcal{T}=\left\{T_{\alpha}: \alpha<\xi\right\}$, que é bem-ordenada por $\supset^{*}$ (isto é, para quaisquer $\alpha<\beta<\xi$ vale que $T_{\alpha} \supset^{*} T_{\beta}$ - ou seja, para $\alpha<\beta<\xi \operatorname{temos} T_{\alpha} \backslash T_{\beta}$ infinito e $T_{\beta} \backslash T_{\alpha}$ finito) e que não possui pseudo-intersecção infinita (não existe $X \in[\omega]^{\omega}$ tal que $X \subseteq^{*} T_{\alpha}$ para todo $\left.\alpha<\xi\right)$. Um dos invariantes cardinais do continuum com o qual trabalhamos freqüentemente é exatamente o cardinal $t$, onde

$$
t=\min \{|\mathcal{T}|: \mathcal{T} \text { é uma torre }\}
$$

Sabe-se que $t$ é um cardinal regular e não-enumerável, e que a asserção " $t=\omega_{1}$ " é independente de $C H$ ( obviamente, $C H \Rightarrow \mathfrak{t}=\omega_{1}$, no entanto a adição de $\kappa \geqslant \omega_{2}$ reais de Cohen ou reais aleatórios sobre um modelo de $C H$ nos fornece um modelo de $\left." \neg C H+\mathfrak{t}=\omega_{1} "\right)$.

Existem na literatura espaços naturalmente associados a torres, que fornecem exemplos dos chamados espaços de Franklin-Rajagopalan ou, simplesmente, FR-espaços. Esses espaços vêm sendo estudados desde o início da década de 70 por vários topólogos, entre eles Peter Nyikos e Jerry Vaughan. Um $F R$-espaço é, por definição, um espaço de Hausdorff, localmente compacto, com um subconjunto denso enumerável de pontos isolados cujo complementar é homeomorfo a um ordinal munido da topologia da ordem (se esse ordinal é $\omega_{1}$, esses espaços são chamados genericamente de " $\gamma$ IN"). Em [NV87], Nyikos e Vaughan caracterizaram os $F R$-espaços seqüencialmente compactos e não-compactos como sendo exatamente esses espaços "naturais" associados às torres. O interesse desses espaços é que, sob a hipótese $t=\omega_{1}$, pode-se construir um tal espaço com as propriedades: Hausdorff, enumeravelmente compacto, primeiro-enumerável, separável e não-compacto. Uma questão que permanece em aberto na área de Topologia Conjuntística é exatamente a 
seguinte: existem em $Z F C$ exemplos de espaços $T_{2}$, enumeravelmente compactos, primeiroenumeráveis, separáveis e não-compactos? Indicamos o artigo [Nyi90] de Nyikos para uma discussão completa a respeito desse tópico.

Os exemplos que construímos são inspirados nos espaços naturalmente associados a torres, mas ao invés de trabalhar com apenas uma torre $\mathcal{T}$ trabalharemos com uma família enumerável infinita de torres $\left\{\mathcal{T}_{n}: n<\omega\right\}$. Não poderemos separar por abertos disjuntos certos elementos que estarão em torres distintas, por isso nossos exemplos não satisfazem o axioma de separação $T_{2}$, mas satisfazem o axioma $T_{1}$, o que ainda é interessante, conforme já comentamos.

Como os espaços paracompactos $T_{1}$ possuem a Propriedade (a) (Proposição 2.3), é natural perguntarmos o que acontece com relação aos metacompactos $T_{1}$, já que parece ser uma conjectura razoável que os espaços metacompactos também possuam a Propriedade (a). No entanto, podemos afirmar em $Z F C$ o seguinte:

Teorema 4.3 Existem espaços metacompactos $T_{1}$ que näo possuem a Propriedade $(a)$.

Demonstração : Demonstraremos o teorema construindo um exemplo de um espaço metacompacto $T_{1}$, não-Hausdorff e que não possui a Propriedade (a); tal exemplo também é localmente compacto e separável mas como essas propriedades não estão presentes na discussão da questão de Matveev, não vamos nos ater a elas.

Construção do Exemplo: A rigor, as famílias de subconjuntos infinitos de $\omega$ com as quais trabalharemos não são torres, mas sim familias de complementares de elementos de torres. Para cada $n<\omega$, seja então $\mathcal{T}_{n}=\left\{T_{n, \alpha}: \alpha<\mathfrak{t}\right\}$ uma família de subconjuntos de $\omega$ satisfazendo as condições:

(1) $\alpha<\beta \Rightarrow T_{n, \alpha} \subset^{*} T_{n, \beta}$

(2) $\left(\forall X \in[\omega]^{\omega}\right)(\exists \alpha<\mathfrak{t})\left[\left|T_{n, \alpha} \cap X\right|=\omega\right]$

(3) $\left(\forall T \in \mathcal{T}_{n}\right)[T \cap n=\emptyset]$

Para que as condições (1) e (2) sejam satisfeitas, basta tomar torres de tamanho mínimo te considerar a familia dos complementares dos elementos dessas torres: passando 
aos complementares, cada família fica bem-ordenada por $C^{*}$ e a não-existência de pseudointersecções infinitas nas torres é traduzida para os complementares pela condição (2). Podemos supor ainda, sem perda de generalidade, que a condição (3) está satisfeita, pois essa condição pode ser obtida por simples modificações finitas nos elementos das torres.

Definimos, para cada $n<\omega$,

$$
T_{n, \mathrm{t}}=\omega \backslash n
$$

e observamos que, para $n<\omega$ fixado, $\mathcal{T}_{n} \cup\left\{T_{n, t}\right\}$ é um $\left\langle\mathfrak{t}, 1^{*}\right\rangle$-gap em $\left\langle\mathcal{P}(\omega), \subset^{*}\right\rangle$. Um parênteses aqui: conforme destacamos no capítulo de preliminares, vários fatos básicos a respeito de cardinais como $\mathfrak{t}$ e $\mathfrak{b}$ podem ser expressos na linguagem de gaps; o próprio cardinal $\mathfrak{t}$ pode ser definido como $\mathfrak{t}=\min \left\{\lambda:\right.$ existe $u \operatorname{m}\left\langle\lambda, 1^{*}\right\rangle$-gap em $\left.\left\langle\mathcal{P}(\omega), \subset^{*}\right\rangle\right\}$. Dedicamos um capítulo de nossa dissertação de mestrado ([Sil98]) para apresentar alguns desses fatos básicos.

Para fins exclusivos de notação, admitiremos $T_{n,-1}=\emptyset$ para qualquer $n<\omega$. Também abusaremos eventualmente da linguagem e chamaremos de "torres" a essas famílias formadas por complementares de elementos de torres.

Seja então

$$
X=\omega \cup\left(\bigcup_{n<\omega}\left(\mathcal{T}_{n} \cup\left\{T_{n, t}\right\}\right)\right)
$$

Damos a $X$ a seguinte topologia: os pontos de $\omega$ são declarados isolados. As vizinhanças básicas para os pontos $T_{n, \zeta}, n<\omega$ e $\zeta \leqslant t$, são da forma

$$
B_{n}(\beta, \zeta, F)=\left\{T \in \mathcal{T}_{n}: T_{n, \beta} \subset^{*} T \subseteq^{*} T_{n, \zeta}\right\} \cup\left(\left(T_{n, \zeta} \backslash T_{n, \beta}\right) \backslash F\right)
$$

onde $\beta \in \zeta \cup\{-1\}$ e $F \in[\omega]^{<\omega}$.

Verificações rotineiras garantem que a topologia dada está bem definida. Para verificarmos que a topologia em questão é $T_{1}$, observamos inicialmente que é imediato separarmos um natural $k \in \omega$ de qualquer outro elemento de $X$, já que $\{k\}$ é aberto, todos os naturais $m \neq k$ também são isolados e, se $T=T_{n, \zeta} \in \mathcal{T}_{n} \cup\left\{T_{n, \mathrm{t}}\right\}$ então $B_{n}(-1, \zeta,\{k\})$ é uma vizinhança aberta de $T$ disjunta de $\{k\}$. Para separarmos dois elementos $T, T^{\prime} \in$ $\bigcup_{n<\omega}\left(\mathcal{T}_{n} \cup\left\{T_{n, \mathrm{t}}\right\}\right)$, temos que analisar dois casos: se $T$ e $T^{\prime}$ pertencem a torres diferentes, então qualquer vizinhança básica de um deles nào contém o outro, e se $T=T_{n, \alpha}$ e $T^{\prime}=T_{n, \beta}$ $\operatorname{com} \alpha<\beta \leqslant \zeta$ então $B_{n}(-1, \alpha, \emptyset)$ e $B_{n}(\alpha, \beta, \emptyset) \operatorname{separam} T_{n, c}$ e $T_{n, \beta}$. 
No entanto, tal espaço não é Hausdorff. Para verificarmos isso, inicialmente destacamos uma asserção a respeito do espaço $X$ que é central na verificação de suas propriedades:

(4) Subconjuntos infinitos de $\omega$ possuem pontos de acumulação em todas as torres.

Ou seja: dado $E \subseteq \omega$ infinito existe para cada $n<\omega$ um ponto de acumulação $x_{n}$ de $E$ em $\mathcal{T}_{n}$. De fato: seja $E$ um subconjunto infinito de $\omega$ e fixemos $n<\omega$. Por (2), $E$ possui intersecção infinita com algum elemento de $\mathcal{T}_{n}$. Seja $\alpha$ mínimo para essa propriedade, isto é, consideremos o elemento $T_{n, \alpha} \in \mathcal{T}_{n}(\alpha<\mathfrak{t})$ que seja tal que $T_{n, \alpha} \cap E$ é infinito e $T_{n, \beta} \cap E$ é finito para todo $\beta \in \alpha \cup\{-1\}$. É imediato então que qualquer vizinhança básica de $T_{n, \alpha}$ contém todos a menos de no máximo finitos elementos de $T_{n, \alpha} \cap$ $E$, donde $T_{n, \alpha} \cap E$ converge para. $T_{n, \alpha}$ e $T_{n, \alpha}$ é um ponto de acumulação de $E$.

Com isso, é imediato ver que nosso espaço não pode ser Hausdorff, pois existem sequências com limites distintos em $X$ : fixados $n \neq m$ em $\omega$, temos que o subconjunto de $\omega$ dado por $T_{n, 0}$ converge para o elemento de $\mathcal{T}_{n}$ dado por $T_{n, 0}$ - enquanto que uma subseqüência de $T_{n, 0}$ converge para um elemento $T_{n, \alpha}$ para algum $\alpha<\mathfrak{t}$ (a saber, a subseqüência $T_{n, 0} \cap T_{m, \alpha}$ converge para $T_{m, \alpha}$ onde $\alpha=\min \left\{\beta: T_{n, 0} \cap T_{m, \beta}\right.$ é infinito $\left.\}\right)$.

Verifiquemos agora que $X$ é metacompacto. Para isso, precisaremos de um "lema de refinamento":

Lema 4.4 ("Lema de Refinamento") Seja $m<\omega$ fixado e suponha que V seja um aberto não-vazio de $X$ que possa ser decomposto numa união disjunta

$$
V=V_{m} \cup E
$$

onde $\emptyset \neq V_{m} \subseteq \mathcal{T}_{m} \cup\left\{T_{m, \ell}\right\}$ e $E \subseteq \omega$. Existe então um aberto $W$ de $X$ tal que $W$ é uma vizinhança de $V_{m}, W \subseteq V \in W \cap m=\emptyset$.

Prova do Lema: Observamos que, se $x \in V_{m}$, então qualquer vizinhança básica $B_{x}$ de $x$ satisfaz $B_{x} \cap m=\emptyset$ (isso segue de (3), da definição de $T_{m, \mathfrak{t}}$ e da definição dos abertos básicos). Tomamos então para cada $x \in V_{m}$ um aberto básico $B_{x} \subseteq V$ e definimos

$$
W=\bigcup_{s \in V_{m}} B_{x}
$$


É imediato que $W$ satisfaz as condições desejadas.

Seja então $\mathcal{U}$ uma cobertura aberta arbitrária de $X$. Dado $U \in \mathcal{U} \operatorname{com} U \backslash \omega \neq \emptyset$, podemos aplicar o "Lema de Refinamento" para todos os abertos da forma $U \cap\left(\left(\mathcal{T}_{n} \cup\right.\right.$ $\left.\left\{T_{n, l}\right\}\right) \cup \omega$ ) para $n<\omega$, o que nos permite supor (tomando unitários em $\omega$, se necessário, para compensar qualquer perda nesse refinamento inicial) que a cobertura arbitrária $\mathcal{U}$ é tal que

(*) Se $U \in \mathcal{U}$ e $U \backslash \omega \neq \emptyset$, então existe $m<\omega$ tal que $U \backslash \omega \subseteq\left(\mathcal{T}_{m} \cup\left\{T_{m, \mathfrak{l}}\right\}\right)$ e $U \cap m=\emptyset$.

Consideremos agora, para cada $n<\omega$ fixado, a família

$$
\mathcal{U}_{n}=\left\{U \in \mathcal{U}: U \cap\left(\mathcal{T}_{n} \cup\left\{T_{n, \ell}\right\}\right) \neq \emptyset\right\}
$$

$\mathcal{U}_{n}$ é uma cobertura aberta de $\mathcal{T}_{n} \cup\left\{T_{n, t}\right\}$. Como esse subespaço é claramente homeomorfo a $\mathfrak{t}+1$, que é um ordinal sucessor, $\mathcal{T}_{n} \cup\left\{T_{n, \mathbf{t}}\right\}$ é compacto, donde existe uma subfamília finita $\mathcal{U}_{n}^{\prime} \subseteq \mathcal{U}_{n} \subseteq \mathcal{U}$ tal que $\mathcal{U}_{n}^{\prime}$ cobre $\mathcal{T}_{n} \cup\left\{T_{n, \mathrm{t}}\right\}$.

Note agora que, dado $m \in \omega$, vale (por $(*)$ ) que se $n>m$ então $m \notin U$ para todo $U \in \mathcal{U}_{n}$, logo os únicos abertos da família $\bigcup\left\{\mathcal{U}_{i 2}^{\prime}: n<\omega\right\}$ que podem intersectar $\{m\}$ são os abertos de $\bigcup_{k \leqslant m} \mathcal{U}_{k}^{\prime}$, que é uma união finita de famílias finitas de abertos. Se $x \in \mathcal{T}_{j} \cup\left\{T_{j, \mathrm{t}}\right\}$ para algum $j<\omega$, os únicos abertos que podem intersectar $\{x\}$ são os da familia finita $\mathcal{U}_{j}^{\prime}$. Segue portanto que

$$
\mathcal{V}=\bigcup_{n<\omega} \mathcal{U}_{n}^{\prime} \cup\left\{\{n\}: n \in X \backslash\left(\bigcup_{n<\omega} \mathcal{U}_{n}^{\prime}\right)\right\}
$$

é um refinamento aberto ponto-finito de $\mathcal{U}$. Como $\mathcal{U}$ foi tomada como cobertura aberta arbitrária, segue que $X$ é metacompacto.

Verifiquemos agora que $X$ não é um (a)-espaço. Seja então $\mathcal{U}$ uma cobertura aberta de $X$ formada por abertos básicos. Mostraremos que $\mathcal{U}$ e o denso $\omega$ testemunham que $X$ não possui a Propriedade $(a)$. De fato: seja $F \subseteq \omega$ um fechado e discreto arbitrário. Por (4), F é finito, logo a condição (3) nos garante que

$$
S t(F, \mathcal{U}) \cap\left(\bigcup_{n>\max F} \mathcal{T}_{n} \cup\left\{T_{n, \mathbf{l}}\right\}\right)=\emptyset
$$


donde, da arbitrariedade de $F, X$ não é um $(a)$-espaço.

É interessante observarmos que o "Corolário do Lema" (Corolário 2.6, página 23) também poderia ser utilizado na verificação de que nosso exemplo não possui a Propriedade (a).

Observação 4.5 Pelo "Corolário do Lema", se $X$ é um espaço $T_{1}$ que contenha subconjuntos disjuntos $D$ e $H$ tais que $D$ é enumerável denso, $H$ é um fechado e discreto infinito e subconjuntos infinitos de $D$ possuem pontos de acumulação no espaço, então $X$ não possui a Propriedade (a). Para o espaço $X$ que construímos, basta tomar $D=\omega e$ $H=\left\{T_{n, 0}: n<\omega\right\} ;$ é fácil ver que $D$ e $H$ satisfazem as condiçoes dadas, donde segue também que $X$ não é um (a)-espaço.

Nosso exemplo não possui a Propriedade $(a)$, o que já garante que ele não é paracompacto. No entanto, não é difícil verificar que mesmo a condição de paracompacidade enumerável não pode ser satisfeita: dado um ponto $x$ que pertença a uma das torres, tomando-se uma vizinhança básica $B_{x}$ de $x$ tem-se que existe $E_{x}$ subconjunto infinito de $\omega$ tal que $E_{x} \subset B_{x}$; esse subconjunto infinito de $\omega$ terá pontos de acumulação em todas as outras torres (conforme destacamos em (4)) e portanto $B_{x}$ intersecta obrigatoriamente infinitos abertos de qualquer cobertura aberta de $X$ que seja formada por abertos básicos (a saber, $B_{x}$ possui intersecção não-vazia com qualquer vizinhança aberta básica dos pontos de acumulação de $E_{x}$ nas outras torres). Logo, coberturas abertas de $X$ formadas por abertos básicos não podem possuir refinamentos localmente finitos. Em particular, existem coberturas enumeráveis de $X$ formadas por abertos básicos, portanto $X$ não é enumeravelmente paracompacto.

O exemplo que construímos sob " $\mathfrak{t}=\omega_{1}$ " é o subespaço do exemplo que acabamos de construir; mais precisamente, trata-se do subespaço que se obtém deletando-se os pontos $T_{n, t}$ para $n<\omega$. Com isso, cada uma das torres correspondentes aos níveis ficam, nesse subespaço, homeomorfas ao cardinal $t$ com a topologia da ordem; como $t$ é regular e não-enumerável, cada um dos níveis $\mathcal{T}_{n}$ é enumeravelmente compacto. Segue que esse subespaço é enumeravelmente metacompacto e não- $(a)$ e, supondo se " $t=\omega_{1}$ ", é primeiroenumerável. Na próxima seção, no entanto, apresentamos um exemplo que, além de ser um 
exemplo em $Z F C$, possui mais propriedades, sendo, por exemplo, completamente regular.

\subsection{O Plano de Niemytzki}

Iniciamos esta subseção mostrando que existem em $Z F C$ espaços completamente regulares que são enumeravelmente metacompactos, primeiro-enumeráveis e que não são (a)-espaços.

Exemplo 4.6 Um espaço topológico completamente regular, separável, primeiro-enumerável, enumeravelmente metacompacto e que não possui a Propriedade (a).

Antes de descrever o exemplo, observamos que não existem sequer exemplos consistente de espaços normais que possuam as demais propriedades listadas, já que a metacompacidade enumerável e a paracompacidade enumerável são propriedades equivalentes na classe dos espaços normais, conforme já destacamos: assim, um exemplo consistente de um espaço normal com as demais propriedades do próximo exemplo forneceria uma resposta consistente negativa para a questão (ainda em aberto) de Matveev (Questão 4.2) que discutimos no início desta seção. Ainda com relação à questão de Matveev: o exemplo que descreveremos em seguida não é enumeravelmente paracompacto.

Descrição do Exemplo: O exemplo em questão é um exemplo clássico de topologia geral, o chamado "Plano de Niemytzki", cuja descrição apresentamos no capítulo de preliminares (página 16) e com o qual já trabalhamos no capítulo anterior.

Seja então $X$ o Plano de Niemytzki e utilizemos a nomenclatura da página 16 . Como os pontos do semiplano superior $P$ mantêm suas vizinhanças euclidianas usuais e para cada $x$ na reta $L$ tem-se que $\left\{B_{x, \frac{1}{n}}: n<\omega\right\}$ é uma base local enumerável para $x, o$ espaço $X$ satisfaz o primeiro axioma da enumerabilidade.

É bastante conhecido o fato de que $X$ é completamente regular: na verdade, o Plano de Niemytzki é muitas vezes apresentado como um primeiro exemplo de um espaço completamente regular e não-normal (exemplo 1.5.10 de [Eng89]). $X$ não é normal porque 
$L$ é um fechado e discreto de cardinalidade $\mathfrak{c}$ em $X$, que é um espaço separável (o conjunto dos pontos $(x, y)$ em $P$ com ambas as coordenadas racionais é denso em $X$ ); basta aplicar o Lema de Jones. Aplicando-se o resultado de Matveev (Teorema 2.7, o análogo do Lema de Jones para (a)-espaços), segue também que $X$ não possui a Propriedade $(a)$.

Como $X$ não é normal, $X$ não é paracompacto (pois paracompactos Hausdorff são normais). $X$ também não é enumeravelmente paracompacto. Poderíamos apresentar aqui uma verificação direta desse fato, argumentando especificamente para $X$, mas o fato de $X$ não ser enumeravelmente paracompacto segue diretamente de um resultado bastante geral de Fleissner ([Fle78]), o qual garante que espaços enumeravelmente paracompactos e separáveis não podem conter um fechado e discreto de cardinalidade c. O "tamanho" do fechado e discreto $L$ também garante que $X$ não é metacompacto; para metacompactos devemos ter $e(X) \leqslant d(X)$ (Teorema 4.1, pág. 44).

Resta verificar que $X$ é enumeravelmente metacompacto. Pois bem: seja $\mathcal{U}$ uma cobertura aberta enumerável e arbitrária de $X$. Decompomos $\mathcal{U}=\mathcal{U}_{P} \cup \mathcal{U}_{L}$, onde $\mathcal{U}_{P}$ e $\mathcal{U}_{L}$ são dados por

$$
\begin{aligned}
& \mathcal{U}_{P}=\{U \in \mathcal{U}: U \cap L=\emptyset\} \\
& \mathcal{U}_{L}=\{U \in \mathcal{U}: U \cap L \neq \emptyset\}
\end{aligned}
$$

Temos que $\mathcal{U}_{P} \cup\left\{U \backslash L: U \in \mathcal{U}_{L}\right\}$ é uma cobertura aberta de $P$, o semi-plano superior euclidiano usual; logo, $P$ é um espaço métrico, e, em particular, paracompacto. Existe então $\mathcal{V}_{P}$ um refinamento aberto localmente finito (e, portanto, ponto-finito) de $\mathcal{U}_{P} \cup\left\{U \backslash L: U \in \mathcal{U}_{L}\right\}$ que cobre $P$.

Se $\mathcal{U}_{L}$ for finito, então $\mathcal{V}_{P} \cup \mathcal{U}_{L}$ é um refinamento aberto ponto-finito de $\mathcal{U}$. Se $\mathcal{U}_{L}$ for infinito, enumeramos $\mathcal{U}_{L}=\left\{U_{n}: n<\omega\right\}$ e definimos para cada $n<\omega$ subconjuntos $L_{n}$ e $M_{n}$ de $L$ pondo

$$
L_{n}=U_{n} \cap L
$$

e

$$
M_{n}=L_{n} \backslash\left(\bigcup_{k<n} L_{k}\right)
$$

Como $\mathcal{U}_{L}$ cobre $L$, segue das definições que $\left\{M_{n}: n<\omega\right\}$ é uma partição de $L$ (i.e., $\left\{M_{n}: n<\omega\right\}$ é uma família dois-a-dois disjunta de subconjuntos de $L$ tais que $\left.\bigcup_{n<\omega} M_{n}=L\right)$. Para cada $n<\omega$, definimos uma vizinhança aberta de $M_{n}$ pondo 


$$
V_{n}=U_{n} \cap\left(\bigcup_{x \in M_{n}} B_{x, \frac{1}{n}}\right)
$$

e definimos $\mathcal{V}_{L}=\left\{V_{n}: n<\omega\right\}$; é imediato que $\mathcal{V}_{L}$ refina $\mathcal{U}_{L}$. Afirmamos que $\mathcal{V}=\mathcal{V}_{P} \cup \mathcal{V}_{L}$ "faz o serviço desejado", isto é, refina $\mathcal{U}$ e é ponto-finito. Já temos que $\mathcal{V}_{P}$ é ponto-finito, refina $\mathcal{U}_{P} \cup\left\{U \backslash L: U \in \mathcal{U}_{L}\right\}$ e cobre $P$. Com relação a $\mathcal{V}_{L}$, temos que cada ponto de $L$ pertence a um único aberto de $\mathcal{V}_{L}$ (pois vale que " $x \in M_{n} \Longleftrightarrow x \in V_{n}$ " para todo $x \in L$ ) e se $p=(x, y) \in P$ então $p \notin V_{n}$ para todo $n$ tal que $\frac{2}{n}<y$, logo cada ponto do semi-plano superior intersecta no máximo finitos abertos em $\mathcal{V}_{L}$. Segue que $\mathcal{V}$ satisfaz o desejado, e, como $\mathcal{U}$ foi tomada como cobertura aberta enumerável arbitrária, $X$ é enumeravelmente metacompacto.

\subsection{Resultados envolvendo os espaços $\Psi(\mathcal{A})$}

A argumentação que fizemos no final da seção anterior para verificar a metacompacidade enumerável do Plano de Niemytzki segue as linhas gerais de um caso análogo apresentado em [SS95]. Adaptando novamente esses argumentos, pode-se verificar que um espaço da forma $\Psi(\mathcal{A})$ é sempre enumeravelmente metacompacto, sem a necessidade de nenhuma hipótese adicional a respeito da respectiva família a.d. $\mathcal{A}$; como a metacompacidade enumerável é equivalente à paracompacidade enumerável para espaços normais, segue que espaços $\Psi(\mathcal{A})$ que sejam normais são também enumeravelmente paracompactos. Esta seção é dedicada aos espaços $\Psi(\mathcal{A})$, e destacamos que nesta seção apresentamos uma contribuição original, que é a exibição do primeiro exemplo consistente de um espaço $\Psi(\mathcal{A})$ enumeravelmente paracompacto e não-normal.

\subsubsection{Metacompacidade e paracompacidade enumeráveis "versus" normalidade}

Iniciemos esta subseção com a seguinte 
Proposição 4.7 Para qualquer família a.d. $\mathcal{A} \subseteq[\omega]^{\omega}, \Psi(\mathcal{A})$ é um espaço enumeravelmente metacompacto.

Demonstração : Seja dada $\mathcal{A}$ a.d. arbitrária, $X=\Psi(\mathcal{A})$ o espaço associado à essa família e $\mathcal{U}$ uma cobertura aberta enumerável e arbitrária de $X$. Consideremos a família de abertos de $X$ dada por

$$
\mathcal{U}_{\mathcal{A}}=\{U \in \mathcal{U}: U \cap \mathcal{A} \neq \emptyset\}
$$

É óbvio que $\mathcal{U}_{\mathcal{A}}$ é uma cobertura aberta de $\mathcal{A}$. Se $\mathcal{U}_{\mathcal{A}}$ for finito, $\mathcal{U}_{\mathcal{A}} \cup\{\{n\}: n \in$ $\left.X \backslash \bigcup\left(\mathcal{U}_{\mathcal{A}}\right)\right\}$ é um refinamento aberto ponto-finito de $\mathcal{U}$. Se $\mathcal{U}_{\mathcal{A}}$ for infinito, enumeramos $\mathcal{U}_{\mathcal{A}}=\left\{U_{n}: n<\omega\right\}$ e definimos para cada $n<\omega$ subconjuntos $L_{n}$ e $M_{n}$ de $\mathcal{A}$ pondo

$$
L_{n}=U_{n} \cap \mathcal{A}
$$

e

$$
M_{n}=L_{n} \backslash\left(\bigcup_{k<n} L_{k}\right)
$$

Como $\mathcal{U}_{\mathcal{A}}$ cobre $\mathcal{A}$, segue das definições que $\left\{M_{n}: n<\omega\right\}$ é uma partição de $\mathcal{A}$. Para cada $n<\omega$, definimos uma vizinhança aberta de $M_{n}$ pondo

$$
V_{n}=U_{n} \cap\left(\bigcup_{A \in M_{n}}\{A\} \cup(A \backslash n)\right)
$$

e definimos $\mathcal{V}_{\mathcal{A}}=\left\{V_{n}: n<\omega\right\}$; é imediato que $\mathcal{V}_{\mathcal{A}}$ refina $\mathcal{U}_{\mathcal{A}}$. Segue que, definindo-se

$$
\mathcal{V}=\mathcal{V}_{\mathcal{A}} \cup\left\{\{n\}: n \in X \backslash\left(\cup \mathcal{V}_{\mathcal{A}}\right)\right\}
$$

então $\mathcal{V}$ é um refinamento aberto ponto-finito de $\mathcal{U}$, pois cada elemento $A \in \mathcal{A}$ pertence a um único aberto de $\mathcal{V}_{\mathcal{A}}$ e um natural $m<\omega$ é tal que $m \notin V_{n}$ para todo $n>m$.

Já destacamos que a metacompacidade enumerável e a paracompacidade enumerável são equivalentes na classe dos espaços normais ([Eng89], 5.2.6). Com isso, segue da Proposiçào 4.7 que podemos enunciar o seguinte 
Fato 4.8 Se um determinado espaço $\Psi(\mathcal{A})$ é normal, esse espaço também é enumeravelmente paracompacto.

Com isso, fica justificada a nossa afirmação de que uma resposta positiva para a nossa questão sobre espaços " $\Psi$-like" (Questão 3.15 ) responde também à questão de Szeptycki (Questão 3.14).

Observamos agora que o Fato 3.11 e o Teorema 2.7 nos permitem exibir mais exemplos $Z F C$ de espaços que possuem as mesmas propriedades do Plano de Niemytzki descritas no Exemplo 4.6.

Fato 4.9 Seja $\mathcal{A} \subseteq[\omega]^{\omega}$ uma família a.d. que satisfaça pelo menos uma entre as hipóteses:

(1) $\mathcal{A}$ é maximal; ou

(2) $|\mathcal{A}|=\mathfrak{c}$

Então, o espaço associado $X=\Psi(\mathcal{A})$ é um espaço completamente regular, separável, primeiro-enumerável, enumeravelmente metacompacto e que não possui a Propriedade $(a)$.

"Ser maximal" ou "possuir cardinalidade c" não são as únicas condições sob as quais uma família a.d. A é tal que seu espaço associado não possui a Propriedade $(a)$; sabemos (devido à caracterização combinatória descrita no Fato 3.12 ) que a asserção " $\Psi(\mathcal{A})$ não possui a Propriedade $(a)$ " é equivalente ao fato combinatório

$$
(\exists f: \mathcal{A} \mapsto \omega)(\forall P \subseteq \omega)(\exists A \in \mathcal{A})[(P \cap(A \backslash f(A))=\emptyset) \vee(P \cap(A \backslash f(A)) \text { é infinito })]
$$

mas os exemplos $Z F C$ mais "evidentes" são obtidos com uma das duas condições citadas no Fato 4.9.

Tanto o Plano de Nyemitzki como os espaços $\Psi(\mathcal{A})$ nas condições do Fato 4.9 são exemplos de espaços enumeravelmente metacompactos, separáveis e primeiro-enumeráveis que contêm fechados e discretos não-enumeráveis e que não possuem a Propriedade $(a)$. No entanto, podemos apresentar o seguinte resultado de consistência: 
Proposição 4.10 É consistente que exista um espaço enumeravelmente paracompacto, separável e primeiro-enumerável que contenha um fechado e discreto não-enumerável e que possua a Propriedade (a).

Demonstração : Basta considerar um modelo de " $\omega_{1}<\mathfrak{p}$ "; nessas condições, podemos tomar $Y \subseteq \mathbb{R}$ que seja um $Q$-conjunto de cardinalidade $\omega_{1}$. O respectivo espaço de Moore $M(Y)$ é normal (conforme discutimos com bastante destaque no Capítulo 3) e, aplicando a Proposição 3.9 obtemos um espaço $\Psi(\mathcal{A})$ normal (portanto, enumeravelmente paracompacto) $\operatorname{com}|\mathcal{A}|=|Y|=\omega_{1}<\mathfrak{p}$; a desigualdade estrita $|\mathcal{A}|<\mathfrak{p}$ garante que $\Psi(\mathcal{A})$ é um $(a)$-espaço (veja o Teorema A.4, de Szeptycki e Vaughan, no Apêndice A deste trabalho (página 94), ou veja os comentários finais da subseção 3.3.1).

Observamos que se trocarmos a condição "não-enumerável" pela condição "de cardinalidade c" na Proposição anterior, a asserção análoga é inconsistente, pois tanto espaços enumeravelmente paracompactos como $(a)$-espaços, se separáveis, não podem ter um fechado e discreto de cardinalidade $\mathfrak{c}$ ([Fle78] para enumeravelmente paracompactos e Teorema 2.7, pág. 24).

Com relação a resultados de consistência, podemos ainda destacar o seguinte

Proposição 4.11 Seja dada uma família a.d. $\mathcal{A} \subseteq[\omega]^{\omega}$ e considere o espaço $\Psi(\mathcal{A})$ associado. Considere as seguintes asserções sobre $\Psi(\mathcal{A})$ :

(i) $\Psi(\mathcal{A})$ é normal.

(ii) $\Psi(\mathcal{A})$ é enumeravelmente paracompacto.

(iii) $\Psi(\mathcal{A})$ possui a Propriedade $(a)$.

Então, é consistente que as três asserções acima sejam equivalentes.

Demonstração : Em modelos de $C H$, as três asserções acima são equivalentes a " $\mathcal{A}$ é enumerável".

Considerando as três asserções da Proposição 4.11 , temos que (i) $\Rightarrow$ (ii) vale em ZFC (Fato 4.8); nossa próxima subseção se dedica a exibir um exemplo consistente de 
que não vale a recíproca. As relações entre (i) e (iii) vêm sendo estudadas principalmente por Szeptycki; a pergunta "(i) implica (iii) ?" é essencialmente a Questão 3.14 que comentamos no final do capítulo anterior, e mesmo uma versão mais fraca da recíproca ainda consta como um problema em aberto em [Sze02]; voltaremos a tratar disso no final deste capítulo. Com relação a (ii) e (iii), apresentamos uma questão referente à existência de uma implicação entre elas como uma contribuição do nosso trabalho (Questão 3.15, pág. 42).

\subsection{2 "Existe um espaço $\Psi(\mathcal{A})$ que é anti-Dowker" é independente de $Z F C$}

Conforme vimos na subseção anterior, a normalidade de um espaço $\Psi(\mathcal{A})$ implica em sua paracompacidade enumerável, e ambas propriedades não podem ocorrer em modelos de $C H$ para $\mathcal{A}$ não-enumerável; poderíamos conjecturar, então, que essas propriedades fossem equivalentes na classe dos espaços $\Psi(\mathcal{A})$. No entanto, essa equivalência não pode ser provada em $Z F C$, pois exibiremos agora o primeiro exemplo consistente de um espaço $\Psi(\mathcal{A})$ que é enumeravelmente paracompacto e não-normal, ou seja, um primeiro exemplo consistente de um espaço $\Psi(\mathcal{A})$ que é anti-Dowker. Como é consistente que as propriedades de normalidade e paracompacidade enumerável sejam equivalentes para espaços $\Psi(\mathcal{A})$, nosso exemplo consistente justifica o título da subseção.

Uma rápida apresentação do conceito de "espaço anti-Dowker": esse é um tópico que está natural e claramente associado aos espaços de Dowker. Nos anos 50, Dowker caracterizou os espaços $X$ cujo produto com o intervalo unitário [0,1] é normal: um espaço $X$ é tal que $X \times[0,1]$ é normal se e somente se $X$ é normal e enumeravelmente paracompacto. Define-se espaço de Dowker como sendo um espaço normal e não-enumeravelmente paracompacto; equivalentemente, um espaço de Dowker é um espaço normal cujo produto com $[0,1]$ não é normal. São espaços de difícil construção; em quarenta anos, apenas dois exemplos ZFC foram exibidos (um devido a Mary Ellen Rudin, em 1972, outro a Zoltan Balogh, em 1994). O leitor pode encontrar referências sobre os espaços de Dowker no survey de Szeptycki e Weiss ([SW93]) ou no artigo de Mary Ellen Rudin no Handbook([Rud84]). Os 
espaços anti-Dowker são espaços não-normais (mas regulares) e enumeravelmente paracompactos: seu estudo relaciona-se muitas vezes com o estudo dos espaços de Moore. Em seu artigo no Handbook, Mary Ellen Rudin dedica alguns comentários aos anti-Dowker, citando resultados de Wage, Fleissner e Reed a esse respeito; por exemplo, destaca-se que Wage criou uma "máquina" que, dado um espaço de Moore normal e não-metrizável, "produz" um espaço de Moore que é anti-Dowker.

Para exibirmos nosso exemplo, trabalharemos novamente com espaços da forma $M(Y)$, o subespaço do plano de Niemytzki que se obtém deletando-se os pontos de $L$ ("eixo $O x ")$ que não pertencem a $Y \times\{0\}$. Já observamos no Capítulo 3 que $M(Y)$ é normal se e somente se $Y$ é um $Q$-conjunto; para a paracompacidade enumerável, precisaremos de um "outro tipo de conjunto":

Definição 4.12 Um subconjunto $Y \subseteq \mathbb{R}$ é dito um $\Delta$-conjunto se para toda seqüência decrescente $\left\langle D_{n}: n<\omega\right\rangle$ de subconjuntos de $Y$ com intersecção vazia existe uma seqüência $\left\langle E_{n}: n<\omega\right\rangle$ de abertos de $Y$ (na topologia de subespaço de IR) também de intersecção vazia e satisfazendo $D_{n} \subseteq E_{n}$ para todo $n<\omega$.

Na definição acima, a noção de "decrescente" refere-se, como de costume, à ordem pela inclusão.

A noção de $\Delta$-conjunto foi introduzida por Reed em [Ree80]; nesse trabalho ele observou que dado $Y \subseteq \mathbb{R}$ o espaço de Moore $M(Y)$ é enumeravelmente paracompacto se e somente se $Y$ é um $\Delta$-conjunto. Nesse mesmo artigo o autor colocou a seguinte questão: há algum modelo de $Z F C$ no qual exista um $\Delta$-conjunto que não seja um $Q$-conjunto ? Nesse modelo, existiria um espaço de Moore $M(Y)$ enumeravelmente paracompacto e nãonormal. Antes de voltarmos a discutir a consistência desse espaço, vamos demonstrar a seguinte proposição (original) que garante que, se for consistente a existência de um espaço $M(Y)$ enumeravelmente paracompacto e não-normal, então é consistente a existência de um espaço $\Psi(\mathcal{A})$ enumeravelmente paracompacto e não-normal.

Proposição 4.13 Sejam $Y \subseteq \mathbb{R}, X=M(Y)$ o espaço de Moore derivado de $Y$ e $X_{Y}$ e $(Y \times\{0\}) \cup D$ espaços satisfazendo a Definição 3.8. Valem então as seguintes asserções:

(i) Se $M(Y)$ não é normal, então $(Y \times\{0\}) \cup D$ não é normal. 
(ii) Se $M(Y)$ é enumeravelmente paracompacto, então $(Y \times\{0\}) \cup D e ́$ enumeravelmente paracompacto.

Demonstração: Antes de demonstrarmos os itens (i) e (ii), observamos que dado um aberto $U$ em $X_{Y}$ podemos afirmar que se $U \cap L \neq \emptyset$ então existe um aberto de $X=M(Y)$ que contém $U \cap L$ e está contido em $U$ : basta tomar o interior de $U$ em $X$ (denotado por int $t_{X}(U)$ ), pois as vizinhanças dos pontos de $L$ ("eixo $O x$ ") não se alteram quando isolamos os pontos do semiplano superior.

Prova de (i): Seja $X=M(Y)$. Se $X$ não é normal, então existem $F$ e $G$ subconjuntos fechados de $L$ que não podem ser separados por abertos de $X$; disso já segue que $X_{Y}$ não é normal, pois abertos de $X_{Y}$ que contenham respectivamente $F$ e $G$ irão se intersectar em seus interiores com relação a $X$. Suponha agora $W$ e $Z$ abertos em $(Y \times\{0\}) \cup D$ que contenham respectivamente $F$ e $G$; existem então abertos $U$ e $V$ em $X_{Y}$ tais que $W=U \cap((Y \times\{0\}) \cup D), Z=V \cap((Y \times\{0\}) \cup D)$. Temos então que int $\ln _{X}(U)$ e $\operatorname{int}_{X}(V)$ tem interseç̧ão não-vazia, conforme comentado: como int $t_{X}(U) \cap i n t_{X}(V)$ é um aberto não-vazio de $X$ e $D$ é denso em $X$, segue que

$$
\emptyset \neq\left(i n t_{X}(U) \cap i n t_{X}(V)\right) \cap D \subseteq(U \cap V) \cap D \subseteq W \cap Z
$$

o que mostra que $(Y \times\{0\}) \cup D$ não é normal, conforme desejado.

Prova de (ii): Seja dada $\mathcal{U}$ uma cobertura aberta enumerável e arbitrária de $(Y \times\{0\}) \cup D$. Consideremos a família de abertos de $(Y \times\{0\}) \cup D$ dada por

$$
\mathcal{U}_{Y}=\{U \in \mathcal{U}: U \cap(Y \times\{0\}) \neq \emptyset\}
$$

Temos que $\mathcal{U}_{Y}$ cobre $Y \times\{0\}$ e observamos que se $\mathcal{U}_{Y}$ for finito então $\mathcal{U}_{Y} \cup\{\{d\}$ : $\left.d \in D \backslash\left(\bigcup_{\mathcal{U}_{Y}}\right)\right\}$ é um refinamento aberto localmente finito de $\mathcal{U}$. Suponhamos então $\mathcal{U}_{Y}$ infinito e enumeremos $\mathcal{U}_{Y}=\left\{U_{n}: n<\omega\right\}$. Para cada $n<\omega$ o aberto $U_{n}$ de $(Y \times\{0\}) \cup D$ pode ser escrito como $U_{n}=V_{n} \cap((Y \times\{0\}) \cup D)$, para $V_{n}$ um aberto de $X_{Y}$; definimos agora para cada $n<\omega u$ m aberto $W_{n}$ de $X$ pondo

$$
W_{n}=i n t_{X}\left(V_{n}\right)
$$

e segue dos fatos já observados sobre esses interiores e de $Y \times\{0\}$ ser fechado em $X$ que 


$$
\mathcal{W}=\{X \backslash(Y \times\{0\})\} \cup\left\{W_{n}: n<\omega\right\}
$$

é uma cobertura aberta e enumerável de $X$. Por hipótese $X$ é enumeravelmente paracompacto, então $\mathcal{W}$ admite um refinamento aberto localmente finito $\mathcal{W}^{\prime}$. Consideramos agora

$$
\mathcal{Z}=\left\{W \in \mathcal{W}^{\prime}: W \cap(Y \times\{0\}) \neq \emptyset\right\}
$$

Temos agora que $\{Z \cap((Y \times\{0\}) \cup D): Z \in \mathcal{Z}\}$ é uma família localmente finita. de abertos de $(Y \times\{0\}) \cup D$ que cobre $Y$. Como $\mathcal{W}^{\prime}$ é um refinamento de $\mathcal{W}$ temos que para cada $Z \in \mathcal{Z}$ existe $n<\omega$ tal que $Z \subseteq W_{n}$, donde

$$
\begin{aligned}
& \left.Z \cap(Y \times\{0\}) \cup D) \subseteq\left(W_{n} \cap(Y \times\{0\}) \cup D\right) \subseteq\left(V_{n} \cap(Y \times\{0\}) \cup D\right)\right)=U_{n} \\
& \text { Portanto }
\end{aligned}
$$

$$
\mathcal{U}^{\prime}=\mathcal{Z} \cup\{\{d\}: d \in D \backslash(\bigcup \mathcal{Z})\}
$$

é um refinamento aberto localmente finito de $\mathcal{U}$, conforme desejado.

Como na Proposição 3.9 verificamos que o espaço $(Y \times\{0\}) \cup D$ é homeomorfo a um espaço $\Psi(\mathcal{A}) \operatorname{com}|\mathcal{A}|=|Y|$, vale o seguinte corolário para a Proposição 4.13:

Corolário 4.14 Se existe $Y \subset \mathbb{R}$ tal que $M(Y)$ é anti-Dowker, então existe um espaço $\Psi(\mathcal{A}) \operatorname{com}|\mathcal{A}|=|Y|$ que é anti-Dowker.

Já podemos então apresentar o principal resultado desta subseção:

Teorema 4.15 É consistente que exista um espaço $\Psi(\mathcal{A})$ anti-Dowker.

Demonstração : Conforme comentado no início da subseção, basta exibir um modelo de $Z F C$ no qual exista um $\Delta$-conjunto que não seja $Q$-conjunto; um modelo nessas condições foi construído por Knight em [Kni93]. A construção foi realizada por forcing, e o autor comentou em seu trabalho que em modelos obtidos por $M A$ ou por " $V=L "$ (Axioma da Construtibilidade) não se consegue diferenciar um $Q$-conjunto de um $\Delta$-conjunto.

No modelo de Knight, existe $Y \subset \mathbb{R}$ que é um $\Delta$-conjunto e não é um $Q$-conjunto; o respectivo espaço $M(Y)$ é enumeravelmente paracompacto e não-normal, portanto o resultado desejado segue do Corolário 4.14. 


\subsubsection{Questões e conjecturas}

Como não sabemos se existem outras implicações em $Z F C$ entre as asserções que constam da Proposição 4.11 (além de " $\Psi(\mathcal{A})$ normal $\Rightarrow \Psi(\mathcal{A})$ enumeravelmente paracompacto" (Fato 4.8)), a princípio não sabemos se o espaço $\Psi(\mathcal{A})$ apresentado na subseção anterior possui necessariamente a Propriedade $(a)$; se houver uma resposta positiva para a nossa Questão 3.15, ele deve possuir.

Observamos também que, até o presente momento, não existe um exemplo de um modelo de ZFC no qual exista uma familia a.d. $\mathcal{A}$ com $|\mathcal{A}|=\mathfrak{o}$ e tal que $\Psi(\mathcal{A})$ possui a Propriedade (a); de fato, o único exemplo de um espaço $\Psi(\mathcal{A})$ com a Propriedade $(a)$ e tal que $|\mathcal{A}| \geqslant \mathfrak{p}$ é o modelo que consta no resultado de Szeptycki e Vaughan (consta em nosso Apêndice A, pág. 94) em que $|\mathcal{A}|=\mathfrak{p}=\omega_{1}<\mathfrak{d}=\omega_{2}=\mathfrak{c}$. Apresentamos as seguintes questões, como contribuições do nosso trabalho:

Questão 4.16 É consistente que exista um espaço $\Psi(\mathcal{A})$ que possua a Propriedade $(a)$ $\operatorname{com}|\mathcal{A}|=\mathfrak{d}$ ?

A seguinte questão é, obviamente, relacionada à anterior:

Questão 4.17 Alguma das seguintes asserções pode ser demonstrada em ZFC?

(i) "Se $\Psi(\mathcal{A})$ é um (a)-espaço, então $|\mathcal{A}|<\mathfrak{d}$ ".

(ii) "Se $\Psi(\mathcal{A})$ é um $($ a) -espaço normal, então $|\mathcal{A}|<\mathfrak{D}$ ".

(iii) "Se $\Psi(\mathcal{A})$ é um (a)-espaço enumeravelmente paracompacto, então $|\mathcal{A}|<\mathfrak{d}$ ".

Observamos que a condição (iii) envolve uma condição de enumerabilidade, o que pode ser "atacado" a partir de funções de $\omega$ em $\omega$, se convenientemente construídas. Note também que uma resposta positiva para (iii) responde positivamente a (ii). É interessante observarmos também que uma resposta positiva para qualquer uma entre elas dá uma resposta negativa consistente para a questão de Matveev (Questão 4.2): é consistente que exista um $Q$-conjunto $Y \subseteq \mathbb{R} \operatorname{com}|Y|=\omega_{1}=\mathfrak{d}$ (Judah e Shelah obtiveram um modelo nessas condições em [JS91]). Se alguma das asserçôes da questão anterior tiver resposta 
positiva, então o espaço $\Psi(\mathcal{A})$ que se constrói a partir de $Y$ nos moldes da Proposição 3.9 seria enumeravelmente paracompacto e não possuiria a Propriedade $(a)$; seria também mais um exemplo consistente de um espaço normal sem a Propriedade $(a)$. Recordamos ao leitor que no Apêndice $B$ deste trabalho consta uma caracterização das famílias $\mathcal{A} \subseteq[\omega]^{\omega}$ para as quais o respectivo espaço $\Psi(\mathcal{A})$ é enumeravelmente paracompacto.

Voltando a uma questão que comentamos rapidamente: ainda é um problema em aberto se um espaço $\Psi(\mathcal{A})$ possuir a Propriedade $(a)$ implica que a respectiva família a.d. $\mathcal{A}$ seja fracamente separada ([Sze02]). Uma família a.d. $\mathcal{A}$ é dita fracamente separada se para quaisquer subfamilias $\mathcal{F}, \mathcal{G} \subseteq \mathcal{A}$ existe $S \in[\omega]^{\omega}$ tal que

$$
(\forall F \in \mathcal{F})[|F \cap S|=\omega] \wedge(\forall G \in \mathcal{G})[|S \cap G|<\omega]
$$

Note que essa condição é mais fraca do que a que caracteriza a normalidade de um espaço $\Psi(\mathcal{A})$ (Fato 3.5). Assim, uma pergunta como "Se $\Psi(\mathcal{A})$ possui a Propriedade $(a)$ então $\Psi(\mathcal{A})$ é normal ?" só pode ser feita de modo mais incisivo se a questão das famílias fracarnente separadas for resolvida positivamente. 


\section{Capítulo 5}

\section{Propriedade (a) e famílias dominantes:}

\section{casos com alguma compacidade local}

Neste capítulo, discutimos os (a)-espaços localmente compactos, e introduzimos a noção de famílias dominantes de funções nessa discussão (o que já é uma contribuição original deste trabalho). Com esse instrumental, e com o auxilio de alguns resultados de consistência que constam na literatura, provamos o seguinte resultado: sob as hipóteses "2 $2^{\omega}<2^{\omega_{1}}$ " e "2 $2^{\omega}$ é regular", a existência de um $(a)$-espaço $T_{1}$ localmente compacto e separável que contenha um fechado e discreto não-enumerável implica a existência de modelos internos com cardinais mensuráveis (um modelo interno é uma classe própria que modela $Z F C$ - com a interpretação usual de $\in$ - e que contém os ordinais; por exemplo, qualquer classe própria transitiva que modele $Z F C$ é um modelo interno).

A primeira seção deste capítulo apresenta, de modo sucinto, duas questões a respeito da versão do Lema de Jones para (a)-espaços (Teorema 2.7 e sua generalização, Teorema 2.8): justificaremos a relevância dessas questões no Apêndice A deste trabalho. Na segunda seção, tratamos do caso dos (a)-espaços localmente compactos e separáveis e provamos o resultado que comentamos no parágrafo anterior. Na terceira seção, observaremos que é bastante útil trabalharmos com subfamílias cofinais (com respeito à ordem dada pela inclusão) na família dos fechados e discretos contidos num determinado subcon- 
junto denso de um dado espaço, e apresentamos a definição de dois invariantes cardinais (devidos a Szeptycki e Vaughan ([SV98])) associados a essas famílias cofinais. Na quarta seção, usamos a noção de famílias dominantes e certos invariantes cardinais associados a elas para apresentar resultados negativos para a Propriedade $(a)$ que, restritos à classe dos localmente compactos e localmente enumeravelmente compactos, constituem resultados negativos mais fortes do que aqueles que constam na Subseção 2.2 do Capítulo 2. Na quinta seção, apresentamos algumas questões e discutimos um exemplo devido a Watson.

A menos dos exemplos e resultados que são explicitamente creditados a outros autores, todos os resultados deste capítulo são originais.

\subsection{Duas questões a respeito da versão do Lema de Jones}

Existe um resultado do tipo do Lema de Jones para espaços normais de celularidade e caráter enumeráveis (ver Apêndice A) que pode ser estendido para o caso geral $\kappa=c(X) \cdot \chi(X)$; demonstra-se que se $X$ é um espaço normal, $\kappa=c(X) \cdot \chi(X)$ e $2^{\kappa}<2^{\kappa^{+}}$ então $X$ nào pode conter um fechado e discreto de cardinalidade $\kappa^{+}$. Diante das similaridades entre certos resultados para (a)-espaços e espaços normais, e dado que existem diferenças nas técnicas de demonstração dos resultados do tipo do Lema de Jones para esses espaços (ver Apêndice A), é bastante razoável considerarmos a seguinte questão (devida à Profa. Ofélia Teresa Alas):

Questão 5.1 Vale o resultado análogo para a Propriedade (a), isto é, se $X$ é um (a)espaço, $\kappa=c(X) \cdot \chi(X)$ e $2^{\kappa}<2^{\kappa^{+}}$então $X$ não pode conter um fechado e discreto de cardinalidade $\kappa^{+}$?

Os espaços $\Psi(\mathcal{A})$ são espaços de celularidade e caráter enumeráveis; assim, um espaço $\Psi(\mathcal{A})$ que possua a Propriedade $(a) \operatorname{com}|\mathcal{A}|=\omega_{1}$ num modelo em que $2^{\omega}<2^{\omega_{1}}$ forneceria um contra-exemplo consistente para a Questão 5.1. Mas, esses espaços também săo separáveis! Assim, um espaço $\Psi(\mathcal{A})$ que desse uma resposta consistente negativa para 
a Questão 5.1 também daria uma resposta consistente (no caso, positiva) para a seguinte questão:

Questão 5.2 É possivel construir um modelo de ZFC no qual exista um espaço $X$ com a Propriedade (a) que possua um fechado e discreto de cardinalidade $d(X)^{+} \operatorname{com} 2^{d(X)}<$ $2^{d(X)^{+}}$? (Obviamente, em tal modelo devem valer as desigualdades $d(X)^{+}<2^{d(X)}<$ $\left.2^{d(X)^{+}}\right)$

Toda a discussão que justifica as Questões 5.1 e 5.2 consta no Apêndice A deste trabalho. Essencialmente, o que estamos tentando verificar é se as diferenças existentes entre as técnicas de demonstração dos resultados para espaços normais e dos resultados para (a)-espaços do tipo do Lema de Jones podem fazer com que certas versões do Lema de Jones para espaços normais não possuam análogos para a Propriedade $(a)$.

A procura de um espaço $\Psi(\mathcal{A})$ que respondesse negativamente a Questão 5.1 e positivamente a Questão 5.2 nos levou a tratar de famílias dominantes. O seguinte resultado provém de uma observação de Piotr Koszmider a respeito da ordem parcial $\left\langle\omega_{1} \omega, \leqslant\right\rangle$; nessa ordem parcial, para $f, g \in\left\langle{ }^{\omega_{1}} \omega, \leqslant\right\rangle$ tem-se que " $f \leqslant g$ " significa $f(\alpha) \leqslant$ $g(\alpha)$ para todo $\alpha<\omega_{1}$. Conforme destacamos no capítulo de preliminares, uma família dominante de funções é uma família de funções que é cofinal numa dada ordem ou préordem; o resultado a seguir trata de famílias dominantes em $\left\langle\omega_{1} \omega, \leqslant\right\rangle$.

Teorema 5.3 Se existir uma família a.d. $\mathcal{A}$ com $|\mathcal{A}|=\omega_{1}$ e tal que $\Psi(\mathcal{A})$ possui a Propriedade $(a)$, então existe $\mathcal{F} \subseteq{ }^{\omega_{1}} \omega$ tal que $\mathcal{F}$ é uma familia dominante em $\left\langle\omega_{1} \omega, \leqslant\right\rangle$ e $|\mathcal{F}|=2^{\omega}$.

Demonstração: Seja. $\mathcal{A}=\left\{A_{\alpha}: \alpha<\omega_{1}\right\}$ como no enunciado. Para cada $P \subseteq \omega$ definimos $f_{P}: \omega_{1} \mapsto \omega$ pondo

$$
f_{P}(\alpha)= \begin{cases}\max \left(A_{\alpha} \cap P\right) & \text { se } 0<\left|A_{\alpha} \cap P\right|<\omega \\ 0 & \text { caso contrário }\end{cases}
$$


Afirmamos que $\mathcal{F}=\left\{f_{P}: P \subseteq \omega\right\}$ é dominante em $\left\langle\omega_{1} \omega, \leqslant\right\rangle$, o que é fácil de verificar: da hipótese de $\Psi(\mathcal{A})$ ser um $(a)$-espaço, sabemos (pelo Fato 3.12) que para cada $h: \mathcal{A} \mapsto \omega$ existe uma testemunha. $P_{h} \subseteq \omega$ que satisfaz $0<\left|P_{h} \cap\left(A_{\alpha} \backslash h\left(A_{\alpha}\right)\right)\right|<\omega$ para todo $\alpha<\omega_{1}$, donde (identificando naturalmente ${ }^{\mathcal{A}} \omega \operatorname{com}^{\omega_{1}} \omega$ a partir de nossa enumeração de $\mathcal{A})$ segue que $\left\{f_{P_{h}}: h \in^{\mathcal{A}} \omega\right\} \subseteq \mathcal{F}$ domina $\left\langle{ }^{\omega_{1}} \omega, \leqslant\right\rangle$ conforme desejado.

Corolário 5.4 Se for consistente que exista uma família a.d. $\mathcal{A} \operatorname{com}|\mathcal{A}|=\omega_{1}$ satisfazendo " $\Psi(\mathcal{A})$ possui a Propriedade $(a) "+\cdots 2^{\omega}<2^{\omega_{1}}$, então é consistente que exista uma familia dominante em $\left\langle\omega_{1} \omega, \leqslant\right\rangle$ de cardinalidade menor que $2^{\omega_{1}}$.

É exatamente neste ponto que os grandes cardinais surgem em nossa discussão.

\subsection{Resultados e questões envolvendo hipóteses sobre grandes cardinais}

A existência (ou não) de famílias dominantes $\operatorname{em}\left\langle\omega_{1} \omega, \leqslant\right\rangle$ de cardinalidade menor que $2^{\omega_{1}}$ foi objeto de estudo de Jech, Prikry e Steprans, entre outros. Sabe-se, por exemplo, que "2 $2^{\omega}<2^{\omega_{1}} "+{ }^{\omega}$ regular" + "Não existe um modelo interno com um cardinal mensurável" implica que "Não existe $\mathcal{F}$ dominante em $\left\langle\omega_{1} \omega, \leqslant\right\rangle$ de cardinalidade $2^{\omega}$; ver [JP84]. Os autores mostraram ainda em [JP84] que não pode existir uma família dominante de tamanho menor que $2^{\omega_{1}} \mathrm{em}\left\langle{ }^{\omega_{1}} \omega, \leqslant\right\rangle$ se $\mathfrak{c}$ for real mensurável, ou se $" 2^{\omega}<2^{\omega_{1}}$ e $2^{\omega}<\aleph_{\omega_{1}}$ ". Com relação aos grandes cardinais, os autores demonstram que a existência de famílias dominantes pequenas nessa ordem parcial de funções implica, via resultados de Jensen, a existência de modelos com cardinais mensuráveis (o principal resultado de Jensen utilizado pelos autores é o "Jensen's covering lemma" para o core model; ver [DJ82a] e [DJ82b]). Em particular, se assumirmos que não existem modelos com cardinais mensuráveis e cf $\left(2^{\omega}\right)=2^{\omega}<2^{\omega_{1}}$ segue que não pode existir um espaço $\Psi(\mathcal{A})$ que responda afirmativamente à Questão 5.2. A questão das "famílias dominantes pequenas" na préordem $\left\langle{ }^{\omega_{1}} \omega, \leqslant\right\rangle$ aparece também nos problemas 56 e 35.5 do Open Problems ([vMR90]). 
Destacamos que, a partir desses resultados que relacionam famílias dominantes em $\left\langle{ }^{\omega_{1}} \omega, \leqslant\right\rangle$ com grandes cardinais, segue do Corolário 5.4 que a existência de modelo com um espaço $\Psi(\mathcal{A})$ que responda positivamente à Questão 5.2 implica a existência de modelos com cardinais mensuráveis.

Existe um outro resultado na literatura que relaciona explicitamente a existência de uma família dominante de cardinalidade $\mathfrak{c}$ em $\left\langle\omega_{1} \omega, \leqslant\right\rangle$ com um fato topológico. Em [Wat85], Watson apresentou um teorema no qual a existência de uma tal família dominante relaciona-se a uma hipótese envolvendo espaços enumeravelmente paracompactos:

Teorema 5.5 (Watson, [Wat85]) Existe um espaço enumeravelmente paracompacto e separável com um fechado e discreto não-enumerável se e somente se existe uma família dominante $\mathrm{em}\left\langle\boldsymbol{\omega}_{1} \omega, \leqslant\right\rangle$ de cardinalidade $\mathfrak{c}$.

É natural apresentar-se a seguinte questão:

Questão 5.6 Existe( $m$ ) análogo(s) do resultado de Watson para a Propriedade $(a)$ ?

No caso da Questão 5.6 acima, obtivemos um análogo para o "somente se", usando a hipótese adicional " $X$ é localmente compacto". O resultado a seguir mostra também que, sob certas hipóteses, a seguinte afirmação pode ser feita: "se houver um modelo com um (a)-espaço localmente compacto e separável $X$ que possua a Propriedade $(a)$ e que responda positivamente à Questão 5.2 então existem modelos internos com cardinais mensuráveis".

Teorema 5.7 A existência de um espaço topológico $T_{1}$ que seja um (a)-espaço localmente compacto separável e que contenha um fechado e discreto não enumerável implica a existência de uma família dominante em $\left\langle{ }^{\omega_{1}} \omega, \leqslant\right\rangle$ de cardinalidade menor ou igual a $\mathfrak{c}$.

Demonstração : Seja $X$ um espaço topológico como no enunciado, com subconjuntos $H$ fechado e discreto não-enumerável e $D$ enumerável denso. Como $|H|>|D|$, podemos 
supor s.p.g. que $H=\omega_{1} \backslash \omega$ e que $D=\omega$; note que, nessas condições, $\omega_{1} \backslash \omega$ não possui pontos isolados em $X$. Seja $\left\{P_{\alpha}: \alpha<\kappa\right\}, \kappa \leqslant \mathfrak{c}$, uma enumeração dos subconjuntos fechados e discretos de $\omega$. Para cada $\beta \in \omega_{1} \backslash \omega$ tomamos $U_{\beta}$ uma vizinhança aberta de $\beta$ que satisfaça

(1) $U_{\beta} \cap\left(\omega_{1} \backslash \omega\right)=\{\beta\}$

(2) $U_{\beta} \subseteq K_{\beta}$, onde $K_{\beta}$ é um subconjunto compacto de $X$.

Como $\omega_{1} \backslash \omega$ não contém pontos isolados em $X$, é fácil ver que $U_{\beta}$ e $U_{\beta} \cap \omega$ são infinitos. Para cada $\alpha<\kappa$ definimos uma função $f_{\alpha}:\left(\omega_{1} \backslash \omega\right) \mapsto \omega$ pondo, para cada $\beta \in\left(\omega_{1} \mid \omega\right)$

$$
f_{\alpha}(\beta)= \begin{cases}\max \left(U_{\beta} \cap P_{\alpha}\right) & \text { se } U_{\beta} \cap P_{\alpha} \neq \emptyset \\ 0 & \text { caso contrário }\end{cases}
$$

Cada uma das funções de $\mathcal{F}=\left\{f_{\alpha}: \alpha<\kappa\right\}$ está bem definida: tomemos $\alpha<\kappa$ e $\beta \in \omega_{1} \backslash \omega$ tais que $U_{\beta} \cap P_{\alpha} \neq \emptyset$. Como $\emptyset \neq U_{\beta} \cap P_{\alpha} \subseteq K_{\beta} \cap P_{\alpha}$ (por (2)) e $K_{\beta} \cap P_{\alpha}$ é um conjunto finito (por ser um fechado e discreto contido num compacto), segue que $U_{\beta} \cap P_{\alpha}$ é um finito não-vazio e portanto tem máximo.

Afirmamos que $\mathcal{F}=\left\{f_{\alpha}: \alpha<\kappa\right\}$ é dominante em $\left\langle\left(\omega_{1} \backslash \omega\right) \omega, \leqslant\right\rangle$, o que nos é suficiente. De fato: seja dada $g:\left(\omega_{1} \backslash \omega\right) \mapsto \omega$ arbitrária. Consideremos a cobertura aberta $\mathcal{U}$ de $X$ dada por

$$
\mathcal{U}=\left\{X \backslash\left(\omega_{1} \backslash \omega\right)\right\} \cup\left\{U_{\beta} \backslash(g(\beta)+1): \beta \in\left(\omega_{1} \backslash \omega\right)\right\}
$$

(Note que, para cada $\beta \in\left(\omega_{1} \backslash \omega\right), g(\beta)+1=\{0, \ldots, g(\beta)\}$ é um subconjunto finito e portanto fechado de $X$, portanto $U_{\beta} \backslash(g(\beta)+1)$ é uma vizinhança aberta de $\beta$, e, mais ainda, segue de $(1)$ que $U_{\beta} \backslash(g(\beta)+1)$ é o único aberto de $\mathcal{U}$ que contém $\beta$.)

Como $X$ é um $(a)$-espaço, existe $F \subset D$ fechado e discreto tal que $S t(F, \mathcal{U})=X$. Seja agora $\alpha<\kappa$ tal que $F=P_{\alpha}$; temos que $f_{\alpha}$ domina $g$, pois para cada $\beta \in\left(\omega_{1} \backslash \omega\right)$ vale que

$$
\left(U_{\beta} \backslash(g(\beta)+1)\right) \cap P_{\alpha} \neq \emptyset
$$


donde $f_{\alpha}(\beta) \geqslant g(\beta)$, conforme desejado.

Aplicando novamente os resultados sobre grandes cardinais que comentamos, podemos apresentar o seguinte

Corolário 5.8 Assuma que $2^{\omega}$ é regular e que $2^{\omega}<2^{\omega_{1}}$. Nessas condiçôes, se existir um (a)-espaço $T_{1}$ localmente compacto e separável que contenha um fechado e discreto não-enumerável então existe um modelo interno com um cardinal mensurável.

Assim, a discussão da Questão 5.2, quando restrita à classe dos espaços localmente compactos separáveis, necessariamente envolve discutir a presença de grandes cardinais.

\subsection{Famílias cofinais e os invariantes $d d c(X)$ e $d d c_{1}(X)$}

No Teorema 5.7 garante-se que se existir um espaço $X$ satisfazendo as hipóteses " $X$ $T_{1}(a)$-espaço localmente compacto e separável com um fechado e discreto não-enumerável" então existe uma familia dominante em $\left\langle\omega^{*} \omega, \leqslant\right\rangle$ de cardinalidade menor ou igual a c; poderíamos nos perguntar se é possível estimar melhor essa limitação superior (observamos que o cardinal $\mathfrak{c}$ é utilizado na demonstração do teorema em questão para limitar superiormente uma enumeração de todos os fechados e discretos contidos no denso enumerável.). Já tivemos essa preocupação em "oferecer uma limitação superior mais apurada" no final do Capítulo 2 (Corolário 2.9, página 25): ali, substituímos uma limitação superior dada por $2^{d(X)}$ para uma dada por $\left|\mathcal{F}_{D}\right|$, onde

$$
\mathcal{F}_{D}=\{G \subseteq D: G \text { é fechado e discreto em } X\}
$$

No entanto, para o caso em que $D$ é enumerável, a cardinalidade de $\mathcal{F}_{D}$ (que é nesse caso obviamente menor ou igual a $\mathfrak{c}$ ) não permite em geral uma limitação superior mais apurada, já que $\left|\mathcal{F}_{D}\right|=2^{\omega}=\mathfrak{c}$ ou $\left|\mathcal{F}_{D}\right|=\omega$ conforme $D$ contenha um fechado e discreto infinito ou não (já que todos os subconjuntos de um fechado e discreto são igualmente fechados e discretos). Assim, simplesmente "enumerar" todos os fechados e discretos contidos no denso enumerável não vai, em geral, melhorar a estimativa para o 
caso separável. Podemos, porém, obter limitações melhores usando famílias cofinais em $\left\langle\mathcal{F}_{D}, \subseteq\right\rangle$. Observamos que mesmo no caso em que $\left|\mathcal{F}_{D}\right|=\mathfrak{c}$, é possível que $\mathcal{F}_{D}$ contenha. famílias cofinais de cardinalidades estritamente menores que $\mathfrak{c}$.

Exemplo 5.9 Um espaço metrizável $X$ que possui um subconjunto enumerável denso $D$ que satisfaz:
(1) $\left|\mathcal{F}_{D}\right|=2^{\omega}$
(2) Existe $\mathcal{C} \subset \mathcal{F}_{D}$ cofinal em $\left\langle\mathcal{F}_{D}, \subseteq\right\rangle$ com $|\mathcal{C}|=\omega$.

Construção do Exemplo: Seja $X=(\omega \times \omega) \cup\{\omega \times \omega\}$. Damos a $X$ a seguinte topologia: os pontos de $\omega \times \omega$ são declarados isolados e as vizinhanças básicas do ponto $\omega \times \omega$ são da forma

$$
B_{n}=\{\omega \times \omega\} \cup\{\langle k, i\rangle: k<\omega \text { e } i>n\}
$$

Verificações rotineiras garantem que a topologia dada está bem definida, e $X$ (por ser claramente um espaço regular de base enumerável) é um espaço metrizável. $D=\omega \times \omega$ é denso em $X$, e para cada $1 \leqslant n<\omega$ tem-se que $\omega \times n$ é um subconjunto fechado e discreto infinito de $X$ que "contribui" (via seus subconjuntos) com $2^{\omega}$ fechados e discretos para $\mathcal{F}_{D}$, donde $\left|\mathcal{F}_{D}\right|=2^{\omega}$. No entanto, $\mathcal{C}=\{\omega \times n: 1 \leqslant n<\omega\}$ é cofinal em $\mathcal{F}_{D}$ (note que se $G \subseteq D$ é fechado e discreto em $X$ então $G$ não pode interceptar infinitos "níveis" $\omega \times\{n\}$, já que se $H \subseteq D$ satisfaz $|\{n<\omega: H \cap(\omega \times\{n\}) \neq \emptyset\}|=\omega$ então $\omega \times \omega$ é um ponto de acumulação de $H$ ).

Neste trabalho, consideraremos sempre, para um denso dado $D, \mathcal{F}_{D}$ ordenado pela inclusão, assim $c f\left(\mathcal{F}_{D}\right)=c f\left(\mathcal{F}_{D}, \subseteq\right)$. Como $\left|\mathcal{F}_{D}\right|$ "omite" cardinais entre $\omega$ e $\mathfrak{c}$ no caso separável, a idéia de trabalhar com famílias cofinais em $\mathcal{F}_{D}$ é bastante natural, e foi objeto de estudo por Szeptycki e Vaughan em [SV98]. Nesse trabalho, os autores introduziram os seguintes invariantes cardinais:

Definição 5.10 ([SV98]) Dado um espaço topológico $X$, os invariantes cardinais ddc $X)$ 
$\epsilon d d c_{1}(X)$ são definidos da seguinte forma:

$$
\begin{aligned}
& d d c(X)=\min \left\{c f\left(\mathcal{F}_{D}\right): D \text { é denso em } X\right\}+\omega \\
& d d c_{1}(X)=\min \left\{c f\left(\mathcal{F}_{D}\right): D \text { é denso em } X \text { e }|D|=d(X)\right\}+\omega
\end{aligned}
$$

Note que para o espaço $X$ do Exemplo 5.9 temos $d d c(X)=d d c_{1}(X)=\omega \mathrm{e}$ $\left|\mathcal{F}_{D}\right|=\mathfrak{c}$ (é fácil ver que para um espaço $X$ arbitrário tem-se $d d c(X) \leqslant d d c_{1}(X) \leqslant 2^{d(X)}$, mas destacamos que $d d c(X)<d d c_{1}(X)$ é consistente ([SV98])).

Podemos agora apresentar uma estimativa mais apurada para a cardinalidade da família dominante no Teorema 5.7.

Proposição 5.11 Suponha que exista um espaço $X$ que seja um (a)-espaço $T_{1}$ separável e localmente compacto que contenha um fechado e discreto não-enumerável. Nessas condições, existe uma familia dominante $e m\left\langle\omega^{\omega_{1}} \omega, \leqslant\right\rangle$ de cardinalidade $d d c_{1}(X)$.

Demonstração: Basta fazer algumas modificações na demonstração do Teorema 5.7. Se $H$ é um fechado e discreto não-enumerável, podemos supor s.p.g. que ele é disjunto de um subconjunto denso enumerável $D$ que satisfaça $c f\left(\mathcal{F}_{D}\right)=d d c_{1}(X)=\kappa$, e consideramos $\mathcal{C}=\left\{C_{\alpha}: \alpha<\kappa\right\}$ uma família cofinal em $\mathcal{F}_{D}$ de cardinalidade mínima. Supondo $H=\omega_{1} \backslash \omega$ e $D=\omega$ e definindo "vizinhanças $U_{\beta}$ e funções $f_{\alpha}$ " exatamente como na demonstração de 5.7 (substituindo a enumeração dos $P_{\alpha}$ 's pela enumeração dos $C_{\alpha}$ 's) então é fácil verificar que a família $\mathcal{F}=\left\{f_{\alpha}: \alpha<\kappa\right\}$ construida é dominante em $\left.\left\langle{ }^{(\omega}{ } \backslash \omega\right) \omega, \leqslant\right\rangle$, pois dada dada $g:\left(\omega_{1} \backslash \omega\right) \mapsto \omega$ arbitrária podemos considerar a mesma cobertura aberta $\mathcal{U}$ de $X$ dada por

$$
\mathcal{U}=\left\{X \backslash\left(\omega_{1} \backslash \omega\right)\right\} \cup\left\{U_{\beta} \backslash(g(\beta)+1): \beta \in\left(\omega_{1} \backslash \omega\right)\right\}
$$

e, de $X$ ser um (a)-espaço, podemos tomar $F \subset D$ fechado e discreto tal que $S t(F, \mathcal{U})=X$. Como $\mathcal{C}$ é cofinal em $\mathcal{F}_{D}$ podemos tomar $\alpha<\kappa$ tal que $F \subseteq C_{\alpha}$ e assim $f_{\alpha}$ domina $g$, pois para cada $\beta \in\left(\omega_{1} \backslash \omega\right)$ vale que

$$
\left(U_{\beta} \backslash(g(\beta)+1)\right) \cap C_{\alpha} \neq \emptyset
$$


donde $f_{\alpha}(\beta) \geqslant g(\beta)$, conforme desejado.

Observamos também que o invariante $d d c(X)$ pode "substituir $\left|\mathcal{F}_{D}\right|$ " em um resultado semelhante ao do Corolário 2.9 (veja a segunda parte do item (1) do Teorema 5.15 a seguir). Analisando as demonstrações de 5.7 e 5.11, podemos ainda destacar o seguinte

Fato 5.12 No Teorema 5.7 e na Proposição 5.11, podemos substituir a hipótese "o espaço é localmente compacto" por "todos os pontos do fechado e discreto não-enumerável possuem uma vizinhança compacta",

De fato, os únicos pontos para os quais precisamos de vizinhanças compactas são os pontos do fechado e discreto não-enumerável. Assim, nossos resultados valem numa classe que contém a classe dos (a) espaços localmente compactos e separáveis. No entanto, possivelmente é na classe dos localmente compactos que serão procurados exemplos para a aplicação desses resultados, e por isso preferimos enunciar esses resultados para essa classe. Na próxima seção também enunciaremos uma série de resultados para localmente compactos e localmente enumeravelmente compactos nos quais a mesma substituição de hipóteses pode ser feita, e manteremos esses enunciados pelos mesmos motivos.

Com relação aos invariantes $d d c(X)$ e $d d c_{1}(X)$, eles desempenharão um papel auxiliar na próxima seção (na qual ainda trataremos de casos separáveis utilizando famílias dominantes) pois, trabalhando-se com uma hipótese do tipo " $X T_{1}$, separável, com fechado e discreto infinito e sem pontos isolados", poderemos obter bons resultados apenas trabalhando com cardinais do tipo $c f\left(\mathcal{F}_{D}\right)$, no sentido de que "se já temos um denso enumerável $D$ para o qual $\mathcal{F}_{D}$ cumpre determinadas condições desejadas, não é necessário calcular $d d c_{1}(X)$ ". Assim, $d d c_{1}(X)$ cuidará apenas de "casos particulares".

\subsection{Resultados envolvendo o cardinal do e invariantes cardinais assemelhados}

O objetivo desta seção é provar resultados envolvendo a Propriedade $(a)$ e certos invariantes cardinais associados a famílias dominantes. Apresentaremos resultados nega- 
tivos para a Propriedade $(a)$ que, restritos à classe dos localmente compactos e localmente enumeravelmente compactos, constituem resultados negativos mais fortes do que aqueles que constam na Subseção 2.2 do Capítulo 2. Trabalharemos no geral com cardinais do tipo $c f\left(\mathcal{F}_{D}\right)$ para. $D$ um enumerável denso. É importante destacar também, neste momento, que o cardinal $\mathfrak{D}$, definido como a cardinalidade mínima de uma família dominante (i.e., cofinal) em $\left\langle{ }^{\omega} \omega, \leqslant^{*}\right\rangle$ satisfaz também $\mathfrak{d}=\min \left\{D \subseteq{ }^{\omega} \omega: D\right.$ é dominante em $\left.\left\langle{ }^{\omega} \omega, \leqslant\right\rangle\right\}(\mathrm{cf}$. [vD84], [Si198]).

Teorema 5.13 Seja $X$ um espaço $T_{1}$ localmente compacto e separável que contenha subconjuntos disjuntos $D$ e $H$ tais que $D$ é um denso enumerável e $H$ é um fechado e discreto infinito. Suponha que

$$
c f\left(\mathcal{F}_{D}\right)<\mathfrak{0}
$$

Então, X não possui a Propriedade $(a)$.

Demonstração: Seja $\kappa=c f\left(\mathcal{F}_{D}\right)$. Enumeramos $D=\left\{d_{n}: n<\omega\right\}$ e $H^{\prime}=\left\{x_{n}: n<\omega\right\}$, $H^{\prime} \subseteq H$. Para cada $x_{n} \in H^{\prime}$ tomamos $U_{n}$ vizinhança aberta de $x_{n}$ satisfazendo

(1) $U_{n} \cap H^{\prime}=\left\{x_{n}\right\}$

(2) $U_{n} \subseteq K_{n}$, onde $K_{n}$ é um subconjunto compacto de $X$.

Seja $\mathcal{C}=\left\{C_{\alpha}: \alpha<\kappa\right\}, \kappa<\mathfrak{o}$, uma família cofinal em $\mathcal{F}_{D}$ de cardinalidade mínima. De modo análogo ao que fizemos nos resultados da seção anterior, definimos para cada $\alpha<\kappa$ uma função $f_{\alpha}: H^{\prime} \mapsto D$ pondo, para cada $x_{n} \in H^{\prime}$,

$$
f_{\alpha}\left(x_{n}\right)= \begin{cases}d_{j} & \text { onde } j=\max \left\{i: d_{i} \in U_{n} \cap C_{\alpha}\right\}, \text { se } U_{n} \cap C_{\alpha} \neq \emptyset \\ d_{0} & \text { caso contrário }\end{cases}
$$

De $\kappa<\mathfrak{d}$ (e identificando naturalmente $\left\langle{ }^{H} D, \leqslant\right\rangle \operatorname{com}\langle\omega \omega, \leqslant\rangle$ a partir de nossas enumerações), $\left\{f_{\alpha}: \alpha<\kappa\right\}$ não é dominante em $\left\langle{ }^{H} D, \leqslant\right\rangle$, portanto

$$
(*) \quad\left(\exists g \in{ }^{H} D\right)(\forall \alpha<\kappa)\left(g \notin f_{\alpha}\right)
$$


e portanto a cobertura aberta

$$
\mathcal{U}=\left\{X \backslash H^{\prime}\right\} \cup\left\{U_{n} \backslash\left\{d_{i} \in D: i \leqslant j, \text { onde } d_{j}=g\left(x_{n}\right)\right\}: n<\omega\right\}
$$

testemunha (juntamente com $D$ ) que $X$ não possui a Propriedade $(a)$, já que se tivéssemos $F \subset D$ fechado e discreto tal que $S t(F, \mathcal{U})=X$ então, tomando-se $\alpha<\kappa$ tal que $F \subseteq C_{\alpha}$, teríamos (com argumentos análogos aos do teorema anterior) que $g \leqslant f_{\alpha}$, o que nos levaria. a. uma contradição com $(*)$.

É fácil verificar que se $H$ for um fechado e discreto infinito e sem pontos isolados em $X$, então $D \backslash H$ é denso em $X$ sempre que $D$ for denso em $X$; tal verificação não necessita de axiomas de separação, mas, se assumirmos o axioma $T_{1}, D \backslash H$ é necessariamente um denso infinito. Portanto, se $X$ é um espaço $T_{1}$ separável que contém um denso $D$ satisfazendo $|D|=d(X)=\omega$ e um fechado e discreto $H$ sem pontos isolados em $X$, então $D \backslash H$ é denso e $|D \backslash H|=\omega$; mais ainda, podemos afirmar que $c f\left(\mathcal{F}_{D \backslash H}\right) \leqslant c f\left(\mathcal{F}_{D}\right)$ (note que se $\mathcal{G}$ é uma família cofinal em $\mathcal{F}_{D}$ então $\{G \backslash H: G \in \mathcal{G}\}$ é cofinal em $\mathcal{F}_{D \backslash H}$; em particular, se $c f\left(\mathcal{F}_{D}\right)=d d c_{1}(X)$ então $\left.c f\left(\mathcal{F}_{D \backslash H}\right)=d d c_{1}(X)\right)$. Essas observações nos permitem enunciar o seguinte

Corolário 5.14 Seja X um espaço $T_{1}$ localmente compacto e separável que contenha um fechado e discreto infinito e sem pontos isolados em $X$. Suponha que, para algum $D$ denso enumerável em $X, c f\left(\mathcal{F}_{D}\right)<\mathfrak{d}$. Então, X não é um $(a)$-espaço. Em particular, se $X$ é um espaço nas condições dadas para o qual $d d c_{1}(X)<\mathfrak{o}$ então $X$ não possui a Propriedade (a).

Nosso próximo resultado tem duas partes: a primeira é essencialmente devida a Szeptycki e Vaughan (Teorema 8 de [SV98]: ali, a parte (1) do seguinte teorema é apresentada de um modo que não usa a hipótese "o denso e o fechado e discreto são disjuntos" mas a mesma é substituída por uma asserção que é consequiência dessa: "o fechado e discreto tem interior vazio"). É interessante, porém, apresentar essa primeira parte aqui para que possamos compará-la com a segunda, que trata do caso "separável e localmente compacto", verificando que, para (a)-espaços $T_{1}$ localmente compactos e separáveis vale que, dado um denso enumerável $D$, famílias cofinais "pequenas" em $\mathcal{F}_{D}$ 
não podem ser "muito pequenas" (elas devem garantir que uma certa família de funções é dominante) mas que, por outro lado, uma família cofinal "pequena" em $\mathcal{F}_{D}$ já é "grande o suficiente" para limitar superiormente, de modo estrito, a cardinalidade de qualquer subconjunto fechado e discreto disjunto de $D$.

Teorema 5.15 Seja $X$ um (a)-espaço que contenha subconjuntos disjuntos $D$ e H tais que $D$ é um subconjunto denso e $H$ é um fechado e discreto infinito. Então, valem as seguintes afirmações:

(1) $|H|<c f\left(\mathcal{F}_{D}\right)$ e, mais ainda, $|H|<\operatorname{ddc}(X)$.

(2) Suponha ainda que $X$ é $T_{1}$, localmente compacto e separável e que o denso $D$ satisfaz $|D|=d(X)=\omega$. Nessas condiçôes, $\mathfrak{d} \leqslant c f\left(\mathcal{F}_{D}\right)$ e, mais ainda, $\mathfrak{o} \leqslant d d c_{1}(X)$.

Demonstração : Para a primeira afirmação em $(1), \operatorname{sejam~} \kappa=c f\left(\mathcal{F}_{D}\right)$ e $\left\{C_{\alpha}: \alpha<\kappa\right\}$ uma enumeração de uma família cofinal em $\mathcal{F}_{D}$ de tamanho mínimo. Suponhamos por absurdo que $|H| \geqslant \kappa$; enumeramos então um subconjunto $H^{\prime} \subseteq H$ (de tamanho $\kappa$ ) por $H^{\prime}=\left\{x_{\alpha}: \alpha<\kappa\right\}$. Para cada $\alpha<\kappa$, tomamos uma vizinhança aberta $U_{\alpha}$ de $x_{\alpha}$ satisfazendo

(i) $U_{\alpha} \cap H^{\prime}=\left\{x_{\alpha}\right\}$

(ii) $U_{\alpha} \cap C_{\alpha}=\emptyset$

(Note que, nas condições do enunciado, basta tomar $U_{\alpha}=X \backslash\left(C_{\alpha} \cup\left(H^{\prime} \backslash\left\{x_{\alpha}\right\}\right)\right)$ ). Consideremos agora a cobertura aberta de $X$ dada por

$$
\mathcal{U}=\left\{X \backslash H^{\prime}\right\} \cup\left\{U_{\alpha}: \alpha<\kappa\right\}
$$

e consideremos $G \subseteq D$ fechado e discreto arbitrário: tomando-se $\alpha<\kappa$ tal que $G \subseteq C_{\alpha}$, segue de $(i)$ e (ii) que

$$
S t(G, \mathcal{U}) \subseteq S t\left(C_{\alpha}, \mathcal{U}\right) \subseteq X \backslash\left\{x_{\alpha}\right\}
$$

logo $\mathcal{U}$ e $D$ testemunhariam que $X$ não é um $(a)$-espaço, o que é uma contradição. Com relação a $|H|<d d c(X)$, como $H$ é disjunto de um subconjunto denso temos que $H$ não 
possui pontos isolados, donde, se $E$ é um subconjunto denso de $X$ satisfazendo $c f\left(\mathcal{F}_{E}\right)=$ $d d c(X)$ basta trabalhar com o denso $E \backslash H$ e teremos $d d c(X) \leqslant c f\left(\mathcal{F}_{E \backslash H}\right) \leqslant c f\left(\mathcal{F}_{E}\right)=$ $d d c(X)$ e basta aplicar a primeira parte de (1) para $E \backslash H$.

Para (2), $\mathfrak{d} \leqslant \kappa$ segue diretamente do Teorema 5.13, já que $\kappa<\mathfrak{d}$ implicaria que $X$ não possui a Propriedade $(a)$; com relação a $\mathfrak{d} \leqslant d d c_{1}(X)$, já observamos que nas condições do enunciado o fechado e discreto $H$ não possui pontos isolados e, portanto, o resultado segue do Corolário 5.14.

Note que, com este último teorema, podemos afirmar que, se existir um modelo de $Z F C$ que tenha um espaço $\Psi(\mathcal{A}) \operatorname{com}|\mathcal{A}|=\omega_{1}$ que responda afirmativamente a Questão 5.2 então nesse modelo, além das desigualdades $\omega_{1}<2^{\omega}<2^{\omega_{1}}$, deve valer também $\omega_{1}<c f\left(\mathcal{F}_{\omega}\right)$ e $\mathfrak{d} \leqslant c f\left(\mathcal{F}_{\omega}\right)$ (além disso, lembramos que deve valer $\mathfrak{t}=\omega_{1}$ nesse modelo, já que $\kappa<\mathfrak{t} \Rightarrow 2^{\kappa}=2^{w}$ (Teorema 1.1)).

Podemos agora apresentar uma caracterização topológica do cardinal $\mathfrak{d}$; na literatura, diz-se que o resultado a seguir mostra que um "cardinal conjuntístico" é também um "cardinal topológico".

Teorema $5.16 \quad \mathfrak{d}=\mathfrak{d}_{1}=\mathfrak{d}_{2}$, onde

$$
\begin{aligned}
\mathfrak{D}_{1}=\min \{|\mathcal{C}|: & \text { existe um }\left(\text { a)-espaço } T_{1}\right. \text { separável com subconjuntos disjuntos } \\
& D \text { e } H \text { tais que } D \text { é enumerável denso, } H \text { é fechado e discreto } \\
& \text { infinito, } \mathcal{C} \text { é cofinal em } \mathcal{F}_{D} \text { e cada ponto de } H \text { possui uma } \\
& \text { vizinhança compacta }\} \\
\mathfrak{d}_{2}=\min \{|\mathcal{C}|: & \text { existe um }(a) \text {-espaço } T_{1} \text { separável e localmente compacto com } \\
& \text { subconjuntos disjuntos } D \text { e } H \text { tais que } D \text { é enumerável denso, } H \\
& \text { é fechado e discreto infinito e } \left.\mathcal{C} \text { é cofinal em } \mathcal{F}_{D}\right\}
\end{aligned}
$$

Justificativa: As demonstrações dos Teoremas 5.13 e 5.15 nos garantem que $\mathfrak{d} \leqslant \mathfrak{d}_{1}$ (conforme observado no final da seção anterior (página 74)), e $\mathfrak{d}_{1} \leqslant \mathfrak{d}_{2}$ é imediato; para estabelecer a igualdade, basta verificar que $\mathfrak{d}_{2} \leqslant \mathfrak{d}$, o que faremos exibindo um exemplo de um espaço topológico que satisfaça as condições da definição de $\mathfrak{d}_{2}$ e que possua 
uma família cofinal de tamanho $\mathfrak{d}$ na família de fechados e discretos contidos no denso enumerável.

Pois bem: tomemos $\left\{X_{n}: n<\omega\right\}$ uma família disjunta de conjuntos infinitos, com $\left|X_{n}\right|=\omega$ para todo $n<\omega$. Cada um dos conjuntos $X_{n}$ recebe uma enumeração $X_{n}=\left\{x_{n, m}: m<\omega\right\} \cup\left\{x_{n, \omega}\right\}$, e consideramos $X=\bigcup_{n<\omega} X_{n}$. Damos a $X$ a seguinte topologia: os pontos da forma $x_{n, m}$ para $n, m<\omega$ são declarados isolados e cada um dos pontos da forma $x_{n, \omega}$ para $n<\omega$ têm como vizinhanças básicas os conjuntos da forma

$$
B_{n, i}=\left\{x_{n, \omega}\right\} \cup\left\{x_{n, m}: m>i\right\}
$$

Ou seja, $X$ é a soma topológica de $\omega$ espaços homeomorfos a $\omega+1 \mathrm{com}$ a topologia da ordem; também é fácil ver que $X$ é homemorfo a um espaço $\Psi(\mathcal{A})$ para o caso de $\mathcal{A}$ ser uma família efetivamente disjunta que particiona $\omega$ em $\omega$ conjuntos infinitos. Segue que $X$ possui a Propriedade $(a)$, e, mais ainda, note que $X$ é metrizável. $X$ é portanto um espaço normal que é claramente zero-dimensional e localmente compacto. Fazendo $H=\left\{x_{n, \omega}: n<\omega\right\}$ e $D=X \backslash H$ temos que $D$ e $H$ são disjuntos com $D$ enumerável e denso e $H$ fechado e discreto infinito. Vamos agora construir uma família dominante de cardinalidade $\mathfrak{d}$ em $\mathcal{F}_{D}$ : seja $\left\{f_{\alpha}: \alpha<\mathfrak{d}\right\}$ uma família dominante em $\left\langle{ }^{\omega} \omega, \leqslant\right\rangle$ e para cada $\alpha<\mathfrak{v}$ considere o fechado e discreto contido em $D$ dado por

$$
C_{\alpha}=\bigcup_{n<\omega}\left\{x_{n, m}: m \leqslant f_{\alpha}(n)\right\}
$$

e tome $\mathcal{C}=\left\{C_{\alpha}: \alpha<\mathfrak{d}\right\}$. $\mathcal{C}$ é cofinal em $\mathcal{F}_{D}$, pois, dado $G \subseteq D$ fechado e discreto devemos ter obrigatoriamente $G \cap\left(X_{n} \backslash\left\{x_{n, \omega}\right\}\right)$ finito para todo $n<\omega$, donde podemos definir uma função $f_{G}: \omega \mapsto \omega$ pondo

$$
f_{G}(n)= \begin{cases}j & \text { onde } j=\max \left\{m: x_{n, m} \in\left(X_{n} \backslash\left\{x_{n, \omega}\right\}\right) \cap G\right\}, \operatorname{se}\left(X_{n} \backslash\left\{x_{n, \omega}\right\}\right) \cap G \neq \emptyset \\ 0 & \text { caso contrário }\end{cases}
$$

e, tomando-se $\alpha<\mathfrak{d}$ tal que $f_{\alpha} \geqslant f_{G}$ temos claramente $G \subseteq C_{\alpha}$. O argumento de dominação de funções também pode ser usado para uma verificação alternativa de que $X$ possui a Propriedade $(a)$ : $\operatorname{consideremos} \mathcal{U}$ uma cobertura de $X$ formada por abertos básicos. Para cada $n<\omega$ podemos fixar $U_{n} \in \mathcal{U}$ tal que $U_{n}$ é vizinhança básica de $x_{n, w}$. 
Definimos então $f: \omega \mapsto \omega$ pondo $f(n)=i+1$ se $U_{n}=B_{n, i}$. Com isso, segue que se $\alpha<\mathfrak{o}$ é tal que $f_{\alpha}$ domina $f$ então $S t\left(C_{\alpha}, \mathcal{U}\right)=X$. Como $D$ é um conjunto denso de pontos isolados, $X$ é um (a)-espaço.

Nas demonstrações dos últimos resultados usamos essencialmente a finitude da intersecção de um fechado e discreto contido num denso enumerável com um subconjunto compacto de um espaço topológico; na verdade, seria suficiente para nós que a intersecção fosse feita com um subconjunto enumeravelmente compacto. Feita essa observação, segue que, com as mesmas demonstrações, ficam demonstrados resultados análogos aos anteriores para espaços localmente enumeravelmente compactos.

De certo modo, nossos resultados envolvendo o cardinal $\mathfrak{d}$ procuram estender para localmente enumeravelmente compactos, em condições mais gerais, resultados do tipo do Teorema 2.4 e do "Corolário do Lema" (Corolário 2.6): incluindo a hipótese de compacidade enumerável local para um espaço separável, então, mesmo com fechados e discretos infinitos contidos no denso enumerável (o que não seria permitido numa utilização direta do Corolário do Lema), basta ter algum controle sobre a cardinalidade de uma família cofinal "pequena" nos fechados e discretos contidos no denso: se esta família tiver tamanho menor que $\mathfrak{d}$, o espaço em questão não possui a Propriedade $(a)$. No espírito de explicitar esse desejo de ampliar o Teorema 2.4 e o Corolário 2.6 e de obtermos um enunciado o mais geral, vamos provar o seguinte

Teorema 5.17 Sejam $X$ um espaço topológico e $\theta, \lambda$ cardinais infinitos. Suponha que existam $D \subset X$ denso e $H \subset X$ fechado e discreto em $X$ que satisfaçam as seguintes propriedades:

(i) $|D|=\lambda$

(ii) $|H|=\theta$

(iii) Se $C \subset D$ é tal que $|C|<\lambda$, então $\bar{C} \cap H=\emptyset$

Suponha ainda que $X$ é localmente enumeravelmente compacto e que $\kappa<\mathfrak{d}(\theta, \lambda)$, onde $\kappa \in \mathfrak{D}(\theta, \lambda)$ são dados por:

(iv) $\kappa=c f\left(\mathcal{F}_{D}\right)$ 
(v) $\mathfrak{o}(\theta, \lambda)=\min \left\{\mathcal{F} \subseteq{ }^{\theta} \lambda: \mathcal{F}\right.$ é dominante em $\left.\left\langle{ }^{\theta} \lambda, \leqslant\right\rangle\right\}$

Então, $X$ não possui a Propriedade $(a)$.

Demonstração: Enumeramos $D=\left\{d_{\alpha}: \alpha<\lambda\right\}$ e $H=\left\{x_{\beta}: \beta<\theta\right\}$. Para cada $\beta<\theta$ tomamos $U_{\beta}$ vizinhança aberta de $x_{\beta}$ satisfazendo

(1) $U_{\beta} \cap H=\left\{x_{\beta}\right\}$

(2) $U_{\beta} \subseteq K_{\beta}$, onde $K_{\beta}$ é um subconjunto enumeravelmente compacto de $X$.

Seja $\mathcal{C}=\left\{C_{\xi}: \xi<\kappa\right\}$ uma família cofinal em $\mathcal{F}_{D}$ de cardinalidade mínima. Observamos que, para quaisquer $\beta<\theta$ e $\xi<\kappa, K_{\beta} \cap C_{\xi}$ é um fechado e discreto contido em $K_{\beta}$ que é um subconjunto enumeravelmente compacto de $X$; segue que $K_{\beta} \cap C_{\xi}$ é finito. Assim, podemos definir para cada $\xi<\kappa$ uma função $f_{\xi}: H \mapsto D$ pondo, para cada $x_{\beta} \in H$,

$$
f_{\xi}\left(x_{\beta}\right)= \begin{cases}d_{\zeta} & \text { onde } \zeta=\max \left\{\delta: d_{\delta} \in U_{\beta} \cap C_{\xi}\right\}, \text { se } U_{\beta} \cap C_{\xi} \neq \emptyset \\ d_{0} & \text { caso contrário }\end{cases}
$$

Por hipótese, temos $\kappa<\mathfrak{d}(\theta, \lambda)$, donde, identificando naturalmente $\left\langle{ }^{H} D, \leqslant\right\rangle$ com $\left\langle{ }^{\theta} \lambda, \leqslant\right\rangle$ a partir de nossas enumerações, $\left\{f_{\xi}: \xi<\kappa\right\}$ não é dominante $\mathrm{em}\left\langle{ }^{H} D, \leqslant\right\rangle$, portanto

$$
(*) \quad\left(\exists g \in{ }^{H} D\right)(\forall \xi<\kappa)\left(g \nless f_{\xi}\right)
$$

Com o auxílio da função $g$, que não é dominada por nenhuma das funções de $\left\{f_{\xi}: \xi<\kappa\right\}$, construiremos uma cobertura que testemunhará (juntamente com $D$ ) que $X$ não possui a Propriedade $(a)$. Observamos que, para cada $\beta<\theta$, o subconjunto de $D$ dado por $\left\{d_{\delta} \in D: \delta \leqslant \eta\right.$, onde $\left.d_{\eta}=g\left(x_{\beta}\right)\right\}$ tem cardinalidade menor que $\lambda$, logo, por (iii), tem seu fecho disjunto de $H$; portanto o aberto $V_{\beta}$ dado por

$$
V_{\beta}=U_{\beta} \backslash \overline{\left\{d_{\delta} \in D: \delta \leqslant \eta, d_{n}=g\left(x_{\beta}\right)\right\}}
$$

é uma vizinhança de $x_{\beta}$ que satisfaz $V_{\beta} \cap H=\left\{x_{\beta}\right\}$, e, definindo-se a cobertura 


$$
\mathcal{U}=\{X \backslash H\} \cup\left\{V_{\beta}: \beta<\theta\right\}
$$

temos que $V_{\beta}$ é o único aberto de $\mathcal{U}$ que contém $x_{\beta}$.

Seja agora $F \subset D$ um fechado e discreto arbitrário. Existe $\xi<\kappa$ tal que $F \subseteq C_{\xi}$. Por $(*), g \notin f_{\xi}, \log \mathrm{O}$

$$
(\exists \beta<\theta)\left[f_{\xi}\left(x_{\beta}\right) \in\left\{d_{\delta} \in D: \delta<\eta, d_{\eta}=g\left(x_{\beta}\right)\right\}\right]
$$

donde, pela definição de $f_{\xi}$ e de $V_{\beta}, C_{\xi} \cap V_{\beta}=\emptyset$ e portanto

$$
S t(F, \mathcal{U}) \subseteq S t\left(C_{\xi}, \mathcal{U}\right) \subseteq X \backslash\left\{x_{\beta}\right\}
$$

e assim, pela arbitrariedade na escolha de $F, X$ não é um (a)-espaço.

Com relação aos invariantes cardinais $\mathfrak{d}(\theta, \lambda)$ já existem vários resultados de consistência, em particular para o caso " $\theta=\lambda$ " para $\lambda$ regular; é interessante, pois, visualizar o Teorema 5.17 à luz desses resultados de consistência. Com esse intuito de contextualizar da melhor maneira possivel o Teorema 5.17, apresentamos agora uma série de observações a respeito de suas hipóteses, conclusões e possiveis aplicações:

Observação 5.18 Nâo é necessário incluir " $\theta \geqslant \lambda$ " ou " $\lambda$ é regular" entre as hipóteses do Teorema 5.17, mas estas condições estarão muito possivelmente presentes nos casos de maior interesse.

É interessante trabalhar com " $\lambda$ é regular" por, pelo menos, três motivos: primeiro, para explicitar que o Teorema 5.17 funciona como uma extensão do "Corolário do Lema" para os casos em que existe alguma compacidade local; em segundo lugar, porque é usual trabalhar primeiramente com hipóteses sobre cardinais sucessores como $\omega_{1}, \omega_{2}, \omega_{3}$, etc., em modelos obtidos por forcing que poderiam abrigar exemplos interessantes; e, em terceiro lugar, porque para o caso " $\theta=\lambda$ " e " $\lambda$ é regular" já existem vários resultados de consistência estabelecidos, como veremos a seguir (em nossa última observação).

E, se $\lambda$ é regular, os casos em que $\theta<\lambda$ resultam numa estrutura não muito "elástica" em termos da cardinalidade mínima de famílias dominantes, pois valem os seguintes resultados: 
Lema 5.19 Sejam $\theta, \lambda$ cardinais infinitos, $\operatorname{com} \theta<c f(\lambda)$. Então $\left\langle{ }^{\theta} \lambda, \leqslant\right\rangle$ tem uma familia dominante de cardinalidade $\lambda$.

Demonstração: Dados $\theta$ e $\lambda$ como no enunciado, definimos para cada $\alpha<\lambda$ uma função $f_{\alpha}: \theta \mapsto \lambda$ pondo $f_{\alpha}(\xi)=\alpha$ para todo $\xi<\theta$ (isto é, $f_{\alpha}$ é a função constante de valor $\alpha$ ). Temos que $\left\{f_{\alpha}: \alpha<\lambda\right\}$ é dominante, pois dada qualquer $g \in{ }^{\theta} \lambda$ segue de $\theta<c f(\lambda)$ que $\beta=\sup \{g(\xi): \xi<\theta\}<\lambda$; tomando-se $\alpha=\beta+1$ temos que $f_{\alpha}$ domina $g$.

Proposição 5.20 Sejam $\theta, \lambda$ cardinats infinitos, com $\lambda$ regular e $\theta<\lambda$. Então $\mathfrak{d}(\theta, \lambda)=$ $\lambda$.

Demonstração : O Lema anterior nos garante que $\mathfrak{d}(\theta, \lambda) \leqslant \lambda$; para estabelecer a igualdade, basta verificar que famílias de cardinalidade menor que $\lambda$ não podem ser dominantes. De fato: seja $\mathcal{F} \subseteq{ }^{\theta} \lambda \operatorname{com}|\mathcal{F}|<\lambda$. Para cada $\xi<\theta, \sup \{f(\xi): f \in \mathcal{F}\}<\lambda, \operatorname{logo}$ a função $g: \theta \mapsto \lambda$ dada por $g(\xi)=\sup \{f(\xi): f \in \mathcal{F}\}+1$ não é dominada por nenhuma das funções de $\mathcal{F}$. Portanto, $\mathfrak{o}(\theta, \lambda)=\lambda$.

Observação 5.21 O Teorema 5.17 não inclui entre suas hipóteses nenhum axioma de separação, mas, para os casos em que $\lambda=\omega$, podemos eliminar a hipótese (iii) se assumirmos que $X$ é $T_{1}$ e que $D$ e $H$ são disjuntos.

Isso é conseqüência imediata do fato de que os conjuntos finitos são fechados em espaços $T_{1}$.

Observação 5.22 Não é necessário supor que X seja localmente inicialmente $\lambda$-compacto.

Se $X$ é inicialmente $\lambda$-compacto e $|D|=\lambda$, todos os subconjuntos infinitos de $D$ possuem pontos de acumulação completos, sem dúvida, mas basta garantir que os subconjuntos infinitos enumeráveis de $D$ tenham pontos de acumulação completos, pois isso garante que os fechados e discretos contidos em $D$ sejam necessariamente finitos. 
Observação 5.23 Também para cardinais não-enumeráveis é verdade que os problemas de "cardinalidade minima de uma familia dominante" são equivalentes para estruturas do tipo $\leqslant$ ou $\leqslant *$.

Este é um resultado estabelecido por Comfort em [Com88]. Definindo, para $\theta$ e $\lambda$ cardinais infinitos quaisquer, as pré-ordens em ${ }^{\theta} \lambda$ dadas por $f<g \Longleftrightarrow[f(\xi)<$ $g(\xi)$ para todo $\xi<\theta]$ e $f<{ }^{*} g \Longleftrightarrow(\exists \zeta<\theta)[f(\xi)<g(\xi)$ para todo $\zeta \leqslant \xi<\theta]$, Comfort demonstrou que as cardinalidades minimas de famílias cofinais em ambas préordens coincidem (para o caso $\theta=\lambda=\omega$ esse já era um resultado bastante conhecido, mas, para o caso geral, Comfort muito bem-humoradamente comentou que "... Set theorists of our acquaintance have responded to this theorem with reactions ranging from 'that is probably well-known' to 'that is probably false'...").

Observação 5.24 Para os casos em que " $\theta=\lambda "$ ( $\lambda$ regular $)$, entâo, escrevendo-se $\mathfrak{o}(\lambda)=$ $\mathfrak{d}(\lambda, \lambda)$, é consistente que $\mathfrak{d}(\lambda)$ assuma qualquer valor "razoável" entre $\lambda^{+} e 2^{\lambda}$.

Esta observação baseia-se nos resultados de Cummings e Shelah apresentados em [CS95]. Definindo-se:

$$
\begin{aligned}
& \mathfrak{b}(\lambda)=\min \left\{B \subseteq{ }^{\lambda} \lambda: B \text { é ilimitada em }\left\langle{ }^{\lambda} \lambda, \leqslant^{*}\right\rangle\right\} \\
& \mathfrak{d}(\lambda)=\min \left\{D \subseteq{ }^{\lambda} \lambda: D \text { é dominante em }\left\langle{ }^{\lambda} \lambda, \leqslant^{*}\right\rangle\right\}
\end{aligned}
$$

demonstra-se em [CS95](adaptando-se certas noções de forcing devidas a Hechler e Easton) que dado um cardinal regular $\lambda$ e uma tripla "razoável" de cardinais, então é consistente que esta tripla assuma os valores $\mathfrak{b}(\lambda), \mathfrak{o}(\lambda)$ e $2^{\lambda}$. Resta uma explicação para o que significa razoável. O seguinte lema exibe as (essencialmente únicas) restrições que $\mathfrak{b}(\lambda), \mathfrak{o}(\lambda)$ e $2^{\lambda}$ devem obedecer em $Z F C$ :

Lema 5.25 ([CS95]) Se $\lambda$ é um cardinal regular, entâo valem as seguintes afirmaçôes:

(i) $\lambda^{+} \leqslant \mathfrak{b}(\lambda)$

(ii) $\mathfrak{b}(\lambda)$ é regular. 
(iii) $\mathfrak{b}(\lambda) \leqslant c f(\mathfrak{d}(\lambda))$

(iv) $\mathfrak{d}(\lambda) \leqslant 2^{\lambda}$

(v) $\operatorname{cf}\left(2^{\lambda}\right)>\lambda$.

Neste último lema, (v) é o célebre resultado de König, (iv) é óbvio, (ii) e (iii) são resultados gerais sobre famílias ilimitadas e dominantes em ordens parciais e $(i)$ segue de um argumento diagonal tradicional (se $\left\{f_{\alpha}: \alpha<\lambda\right\} \subset{ }^{\lambda} \lambda$, podemos definir uma $f: \lambda \mapsto \lambda$ pondo, para cada $\beta<\lambda, f(\beta)=\sup \left\{f_{\zeta}(\beta)+1: \zeta<\beta\right\}$ e é fácil verificar que $f$ é um limitante superior para $\left\{f_{\alpha}: \alpha<\lambda\right\}$ ).

Com essas restrições em mente, podemos explicar o que é a "consistência de qualquer tripla razoável": o principal resultado de Cummings e Shelah em [CS95] garante que, dado um modelo de GCH que possua uma associação ("função-classe") que a cada cardinal regular $\lambda$ associa uma tripla de cardinais $(\beta(\lambda), \delta(\lambda), \mu(\lambda))$ que satisfaçam as condiçöes $\lambda^{+} \leqslant \beta(\lambda)=c f(\beta(\lambda)) \leqslant c f(\delta(\lambda)) \leqslant \delta(\lambda) \leqslant \mu(\lambda)$ e $c f(\mu(\lambda))>\lambda$ para todo $\lambda$ regular, então existe um "forcing-classe". que preserva cardinais e cofinalidades e para o qual vale em uma extensão genérica que $\mathfrak{b}(\lambda)=\beta(\lambda), \mathfrak{o}(\lambda)=\delta(\lambda)$ e $\mu(\lambda)=2^{\lambda}$ para todo cardinal regular $\lambda$.

Finalizadas as nossas observações, apresentamos ainda o seguinte

Corolário 5.26 Sejam $\theta, \lambda$ cardinais infinitos, $\operatorname{com} \theta \geqslant \lambda$, e $X$ um espaço localmente enumeravelmente compacto que contenha subconjuntos $D$ denso e $H$ fechado e discreto que satisfaçam as condições (i), (ii) e (iii) do Teorema 5.17. Suponha ainda que $\kappa<\mathfrak{o}(\lambda)$, onde $\kappa=c f\left(\mathcal{F}_{D}\right)$. Então, $X$ não possui a Propriedade $(a)$.

De fato: nas condições do Corolário, basta repetir a demonstração do teorema para um subconjunto de $H$ de cardinalidade $\lambda$.

Antes de encerrarmos esta seção dedicada a invariantes cardinais do tipo do cardinal $\mathfrak{d}$, apresentamos um "metateorema" que descreve o "sabor" dos resultados de consistência que podem ser obtidos a partir do que apresentamos nesta subseção. 
Teorema 5.27 Seja $X$ um espaço $T_{1}$ localmente enumeravelmente compacto e separável que contenha um fechado e discreto infinito e sem pontos isolados em X. Suponha que, para algum $D$ denso enumerável em $X$,

$$
Z F C \vdash " c f\left(\mathcal{F}_{D}\right) \in\left\{\omega_{1}, \mathfrak{p}, \mathfrak{t}, \mathfrak{b}, \mathfrak{s}, \mathfrak{a}\right\} "
$$

Então, é consistente que $X$ não possua a Propriedade (a). Em particular, se $X$ é um espaço nas condiçôes do enunciado para o qual $Z F C \vdash$ "dd $d c_{1}(X) \in\left\{\omega_{1}, \mathfrak{p}, \mathfrak{t}, \mathfrak{b}, \mathfrak{s}, \mathfrak{a}\right\}$ " Então é consistente que $X$ não seja um (a)-espaço.

Demonstração : Seja $\kappa=c f\left(\mathcal{F}_{D}\right)$. Se $\kappa \in\left\{\omega_{1}, \mathfrak{p}, \mathfrak{t}, \mathfrak{b}, \mathfrak{s}, \mathfrak{a}\right\}$, então a desigualdade estrita " $<<\mathfrak{d} "$ é consistente (cf. [vD84]). Seja $M$ um modelo de ZFC para o qual

$$
M \vDash " \kappa<\mathfrak{d} "
$$

Pelo análogo para localmente enumeravelmente compactos do Corolário 5.14,

$$
M \models \text { "X não é um }(a) \text {-espaço" }
$$

e é portanto consistente que $X$ não possua a Propriedade (a).

Uma boa aplicação do teorema anterior seria: apresentar um espaço enumeravelmente paracompacto e de tightness enumerável que cumprisse as condições do enunciado e para o qual pudéssemos verificar que, para algum $D$ denso enumerável,

$$
Z F C \vdash " c f\left(\mathcal{F}_{D}\right) \in\left\{\omega_{1}, \mathfrak{p}, \mathfrak{t}, \mathfrak{b}, \mathfrak{s}, \mathfrak{a}\right\} "
$$

Então um modelo de " $c f\left(\mathcal{F}_{D}\right)<\mathfrak{d}$ " nos daria um contra-exemplo consistente para a questão de Matveev (Questão 4.2) apresentada na Seção 4.1 do Capítulo 4 deste trabalho.

Os resultados desta subseção também nos dão informações sobre espaços que satisfazem condições que sabemos implicarem a Propriedade $(a)$ : por exemplo, se $X$ é um espaço métrico separável, localmente compacto e que possua um fechado e discreto infinito e sem pontos isolados em $X$, então qualquer família cofinal por inclusão no conjunto dos fechados e discretos contidos num denso enumerável arbitrário deve ter cardinalidade maior ou igual a 0 . 


\subsection{Mais questões envolvendo hipóteses sobre grandes cardinais}

Questões que envolvam famílias dominantes de cardinalidade menor que $2^{\omega_{1}} \mathrm{em}$ $\left\langle\omega_{1} \omega, \leqslant\right\rangle$ envolvem grandes cardinais, conforme já destacamos; isso justifica o título desta seção. Uma primeira questão que apresentamos é se existe uma espécie de "recíproca" para o Teorema 5.3:

Questão $5.28 " 2^{\omega}<2^{\omega_{1}} "+$ "Existe família dominante de cardinalidade $\mathrm{c}$ em $\left\langle\omega_{1} \omega, \leqslant\right\rangle "$ implica a existência de uma família a.d. A que responda afirmativamente a Questão 5.2?

Para estabelecer que uma família dominante de cardinalidade $2^{\omega}$ em $\left\langle{ }^{\omega_{1}} \omega, \leqslant\right\rangle$ implica a existência de um espaço enumeravelmente paracompacto e separável com um fechado e discreto não-enumerável (Teorema 5.5, [Wat85]), Watson exibiu uma construção explícita: seria muito interessante estudar a presença da Propriedade (a) numa construção como a que ele apresentou.

Questão 5.29 Seja dado um modelo no qual exista uma familia dominante de cardinalidade $\mathfrak{c}$ em $\left\langle{ }^{\omega_{1}} \omega, \leqslant\right\rangle$. Nesse modelo existe um espaço enumeravelmente paracompacto nos moldes do construido por Watson para provar o "se" do Teorema 5.5. Esse espaço possui a Propriedade $(a)$ ? Se possuir, obtemos um exemplo consistente (módulo famílias dominantes pequenas) de um (a)-espaço separável com um fechado e discreto não-enumerável num modelo $\operatorname{com} 2^{\omega}<2^{\omega_{1}}$. Se não possuir, obtemos um exemplo consistente (sob mesmas condições) de um espaço enumeravelmente paracompacto de tightness enumerável e sem a Propriedade (a).

Com relação à questão anterior, nảo podemos provar em $Z F C$ que um espaço como o do exemplo de Watson não possui a Propriedade (a); por um resultado de Just, Matveev e Szeptycki em [JMS00], espaços zero-dimensionais de cardinalidade estritamente menor que $\mathfrak{p}$ que possuam um denso enumerável de pontos isolados possuem a Propriedade $(a)$. 
Num modelo com " $\omega_{1}<\mathfrak{p}$ ", tem-se $2^{\omega}=2^{\omega_{1}}$ e nessas condições evidentemente existem famílias dominantes de cardinalidade $2^{\omega}$ em $\left\langle{ }^{\omega}{ }^{1} \omega, \leqslant\right\rangle$; o exemplo de Watson (que é o refinamento de um subespaço do espaço-produto $\left.{ }^{\left(2^{\omega}\right)} \omega\right)$ é um espaço zero-dimensional, tem cardinalidade $\omega_{1}$ e possui um denso enumerável de pontos isolados, portanto nesse modelo ele possui a Propriedade $(a)$, mas exatamente por valer $2^{\omega}=2^{\omega_{1}}$ nesse modelo ele não fornece uma resposta positiva para a Questão 5.2. 


\section{Apêndice A}

\section{Sobre o Lema de Jones}

\section{e seu análogo para $(a)$-espaços}

O objetivo deste apêndice é dar o contexto no qual apareceram as Questões 5.1 e 5.2 que motivaram os resultados do Capítulo 5. Também destacamos alguns dos principais resultados de consistência envolvendo cardinais relacionados à Propriedade $(a)$ no contexto de espaços $\Psi(\mathcal{A})$.

\section{A.1 Comparando o Lema de Jones com o Teorema de Matveev}

O Lema de Jones é um resultado clássico (de 1937) sobre espaços normais e atualmente consta nas referências básicas de topologia geral (ver, por exemplo, [Eng89] exercício $1.7 .12(\mathrm{c}))$

Lema A.1 (Lema de Jones) Se $X$ é um espaço normal, $D$ é um subconjunto denso de $X$ e Fé um subconjunto fechado e discreto de $X$, então $2^{|F|} \leqslant 2^{|D|}$.

Inclúmos aqui uma rápida demonstração desse resultado para servir como ilus- 
tração para várias comparações que serão feitas em breve.

Demonstração : Se $F \subseteq X$ é fechado e discreto, a cada $S \subseteq F$ temos que $S$ e $F \backslash S$ são fechados (discretos) disjuntos em $X$ : segue da normalidade de $X$ que a cada $S \subseteq F$ existe um aberto $U_{S}$ tal que $S \subseteq U_{S}$ e $F \backslash S \subseteq X \backslash \overline{U_{S}}$. É fácil verificar que a aplicação $\varphi: \mathcal{P}(F) \mapsto \mathcal{P}(D)$ dada por $\varphi(S)=D \cap U_{S}$ é uma injeção de $\mathcal{P}(F)$ em $\mathcal{P}(D)$, donde segue o desejado.

Vários "corolários" do Lema de Jones (considerando-se como "Lema de Jones" exatamente o enunciado acima, conforme apresentado em nossa referência. [Eng89]) são freqüentemente referidos também como sendo "o" Lema de Jones, o que pode causar alguma confusão. Preferimos utilizar o enunciado apresentado porque o mesmo "enuncia a demonstração", no sentido de que a desigualdade $2^{|F|} \leqslant 2^{|D|}$ refere-se exatamente a uma aplicação injetora de $\mathcal{P}(F) \operatorname{em} \mathcal{P}(D)$. Vejamos agora três asserções que são conseqüuencia imediata do Lema de Jones e que constituem três "enunciados alternativos" referidos também como "Lema de Jones" em inúmeros textos e artigos:

Como $|F|<2^{|F|} \leqslant 2^{|D|}$ nas condiçôes do enunciado, se tomarmos $D$ com cardinalidade mínima $d(X)$, então podemos afirmar também que

(1) Se $X$ é um espaço normal, então $X$ não pode conter um fechado e discreto de cardinalidade maior ou igual a $2^{d(X)}$.

Se $d(X)=\omega$ (isto é, se o espaço normal $X$ é separável), a existência de um fechado e discreto não-enumerável em $X$ implica claramente a igualdade $2^{\omega}=2^{\omega_{1}}$ ! Com isso, temos

(2) Se $X$ é normal e separável e $2^{\omega}<2^{\omega_{1}}$, então $X$ não pode conter um fechado e discreto não-enumerável.

e, generalizando,

(3) Se $X$ é normal, $d(X)=\kappa$ e $2^{\kappa}<2^{\kappa^{+}}$, então $X$ não pode conter um fechado $\epsilon$ discreto de cardinalidade $\kappa^{+}$.

É interessante notarmos que as asserções (1), (2) e (3) são corolários do Lema 
de Jones, mas não são equivalentes a ele: note, por exemplo, que um enunciado do tipo de (1) ("Se um espaço possui uma determinada propriedade $\varphi$, então ele não pode ter um fechado e discreto de cardinalidade maior ou igual a $2^{d(X)}$ ") pode ser, a princípio, consistente com um contra-exemplo para um enunciado análogo do tipo de (3), num modelo em que $d(X)^{+}<2^{d(X)}<2^{d(X)^{+}}$.

Conforme comentamos no Capítulo 2, existem muitas discussões na literatura a respeito das relações e similaridades existentes entre a normalidade e a Propriedade $(a)$. Um resultado muito importante neste sentido foi obtido por Matveev em 97 ([Mat97]), que é um resultado (análogo ao Lema de Jones) para a Propriedade $(a)$ :

Teorema 2.7 (Matveev, [Mat97], pág.24) Se um (a)-espaço separável X possui um. fechado e discreto de cardinalidade $\kappa$, então $\kappa<2^{\omega}$.

Apresentamos também uma demonstração da seguinte generalização, como contribuição do nosso trabalho:

Teorema 2.8 (pág.24) Seja X um espaço topológico que possui um fechado e discreto de cardinalidade maior ou igual a $2^{d(X)}$. Então $X$ não possui a Propriedade $(a)$.

Szeptycki e Vaughan ([SV98]) já tinham observado (porém, sem exibir uma demonstraçào) que a generalização do resultado de Matveev para $d(X)=\kappa$ era verdadeira. Ressaltamos, porém, que o resultado original de Matveev é análogo a um "enunciado do Lema de Jones" do tipo de nossa asserção (1), mas não ao enunciado que consta em [Eng89], ou seja, não se garante uma desigualdade do tipo $2^{|F|} \leqslant 2^{|D|}$ durante a demonstração do Teorema 2.7 .

Em comunicação particular logo após meu exame de qualificação, a Profa. Ofélia Teresa Alas me apresentou resultados análogos ao Lema de Jones para espaços normais e questionou-me sobre uma possível extensão desses resultados para a Propriedade $(a)$. Nesses resultados, a função cardinal densidade é substituída pelas funções cardinais celularidade e caráter (a celularidade $c(X)$ de um espaço é definida como $c(X)=\sup \{|\mathcal{V}|: \mathcal{V}$ é família celular em $X\}+\omega$, onde uma família celular é uma família de abertos dois-a-dois disjuntos, e o caráter $\chi(X)$ de um espaço é definido como $\chi(X)=\sup \{\chi(p, X): p \in$ $X\}+\omega$, onde, para cada $p \in X, \chi(p, X)=\min \{|\mathcal{B}|: \mathcal{B}$ é base local de abertos em $p\}$. 
Assim, $\chi(X)=\omega$ significa que " $X$ satisfaz o primeiro axiona da enumerabilidade" ou ainda " $X$ é primeiro-enumerável".).

O principal resultado nesse sentido (envolvendo celularidade e caráter) a mim apresentado nessa ocasião foi o seguinte

Teorema A.2 ("folklore"; mencionado por Frank Tall) Se X é um espaço normal, primeiro enumerável e de celularidade enumerável, e $2^{\omega}<2^{\omega_{1}}$, então $X$ não pode conter um fechado e discreto não-enumerável.

A generalização desse teorema para $\kappa=c(X) \cdot \chi(X)$ é simples, como podemos ver a seguir:

Teorema A.3 Se X é um espaço normal, $\kappa=c(X) \cdot \chi(X)$ e. $2^{\kappa}<2^{\kappa^{+}}$, então $X$ não pode conter um fechado e discreto de cardinalidade $\kappa^{+}$.

Demonstração: Suponhamos por absurdo que exista um subconjunto fechado e discreto $F \subseteq X \operatorname{com}|F|=\kappa^{+}$. A cada $x \in F$ tomamos $\mathcal{V}_{x}$ uma base local para $x$ satisfazendo $V \cap F=\{x\}$ para todo $V \in \mathcal{V}_{x}$ e $\left|\mathcal{V}_{x}\right| \leqslant \chi(X) \leqslant \kappa$. Definindo-se $\mathcal{V}=\bigcup_{x \in F} \mathcal{V}_{x}$, temos que $|\mathcal{V}|=\kappa^{+}$pois $\kappa^{+} \leqslant|\mathcal{V}|=|F| \cdot \sup _{x \in F}\left|\mathcal{V}_{x}\right| \leqslant \kappa^{+} . \kappa=\kappa^{+}$.

Da normalidade de $X$, a cada $A \subseteq F$ existe um aberto $U_{A}$ tal que $A \subseteq U_{A} \mathrm{e}$ $F \backslash A \subseteq X \backslash \overline{U_{A}}$.

Para cada $A \subseteq F$ fixamos (com o auxílio do Lema de Zorn) uma família $\mathcal{B}_{A} \subseteq \mathcal{V}$ satisfazendo

(1) $\mathcal{B}_{A}$ é celular e $\bigcup \mathcal{B}_{A} \subseteq U_{A}$

(2) $\mathcal{B}_{A}$ é maximal para (1).

De (1) segue que

(3) $\left|\mathcal{B}_{A}\right| \leqslant c(X) \leqslant \kappa$

e de (2) (maximalidade de $\mathcal{B}_{A}$ ) segue que 
(4) $A \subseteq \longdiv { \cup _ { B } }$

Afirmamos agora que a aplicação $\varphi: \mathcal{P}(F) \mapsto[\mathcal{V}]^{\leqslant \kappa}$ dada por $\varphi(A)=\mathcal{B}_{A}$ é uma aplicação injetora. De fato: sejam $A, A^{\prime} \subseteq F \operatorname{com} A \neq A^{\prime}$. Podemos supor s.p.g. que $A^{\prime} \backslash A \neq \emptyset$; seja então $y \in A^{\prime} \backslash A$ e suponhamos por absurdo que $\mathcal{B}_{A}=\mathcal{B}_{A^{\prime}}$. Então $\overline{\mathrm{UB}_{A}}=\overline{\mathrm{UB}_{A^{\prime}}}$ donde, por (4), $y \in \overline{\cup \mathcal{B}_{A}}$. Mas, por outro lado, $y \in F \backslash A \subseteq X \backslash \overline{U_{A}}$, o que é uma contradição com $y \in \overline{\cup \mathcal{B}_{A}}$ já que $X \backslash \overline{U_{A}}$ é uma vizinhança aberta de $y$ que não intersecta nenhum aberto de $\mathcal{B}_{A}$, já que estes estão contidos em $U_{A}$.

Segue que $2^{|F|} \leqslant\left|[\mathcal{V}]^{\leqslant \kappa}\right|$, donde $2^{\kappa^{+}} \leqslant\left(\kappa^{+}\right)^{\kappa}=\kappa^{+} \cdot \kappa^{\kappa}=2^{\kappa}$, o que contradiz $2^{\kappa}<2^{\kappa^{+}}$.

Diante das relações e similaridades existentes entre a Propriedade ( $a$ ) e a normalidade, foi natural que surgisse a seguinte questão:

Questão 5.1 (pág. 66) Vale o resultado análogo para a Propriedade (a), isto é, se $X$ é um (a)-espaço, $\kappa=c(X) \cdot \chi(X)$ e $2^{\kappa}<2^{\kappa^{+}}$então $X$ não pode conter um fechado e discreto de cardinalidade $\kappa^{+}$?

Uma tentativa de utilizar as mesmas técnicas usadas em espaços normais para mostrar que a questão tem resposta afirmativa tende a ser infrútifera. O principal problema é a diferença existente entre as técnicas de demonstração de resultados para espaços normais e para (a)-espaços. Para espaços normais, sempre se obtém uma injeção do conjunto das partes de um fechado e discreto $F$ em uma outra família: no caso do Lema de Jones, injeta-se $\mathcal{P}(F)$ numa família de subconjuntos do denso, e no caso do análogo para celularidade e caráter, injeta-se $\mathcal{P}(F)$ numa família de famílias celulares maximais. Ora, para a Propriedade $(a)$ a técnica é diferente: num resultado do tipo do de Matveev, supondo-se por absurdo que no (a)-espaço exista um fechado e discreto $H$ tal que $|H| \geqslant 2^{d(X)}$, injeta-se uma família de subconjuntos de um denso $D$ de cardinalidade mínima no próprio fechado e discreto $H$ para daí chegar a uma contradição, que é a construçăo de uma cobertura que testemunhe que $X$ não pode ser um $(a)$-espaço.

Essa diferença entre as técnicas de demonstração (que também reflete um pouco as sutilezas que envolvem os "enunciados possíveis" para o Lema de Jones) sugere que pode existir um contra-exemplo que responda negativamente à questão. Um fato interessante 
que podemos vislumbrar com relação a um possivel contra-exemplo é o seguinte: se existir um contra-exemplo para a Questão 5.1 na familia dos espaços $\Psi(\mathcal{A})$, então esse contraexemplo não está em nenhum dos modelos citados até o momento dentro da literatura sobre (a)-espaços.

Justifiquemos esta nossa última afirmação: ela segue de resultados de Szeptycki e Vaughan apresentados em [SV98]. Esse é o mesmo artigo no qual os autores apresentaram sua caracterização combinatória para os espaços $\Psi(\mathcal{A})$ que possuem a Propriedade $(a)$ (Fato 3.12, pág. 38). Usando essa caracterização combinatória, eles obtiveram muitos resultados de consistência, como por exemplo:

Teorema A.4 (Szeptycki, Vaughan([SV98])) Valem as afirmações:

(i) $[\mathfrak{p}=\mathfrak{c}] \Rightarrow \Psi(\mathcal{A})$ é um $(a)$-espaço se e somente se $|\mathcal{A}|<\mathfrak{c}$.

(ii) Adicionando qualquer quantidade de reais de Cohen a um modelo de $\mathrm{CH}$ obtemos um modelo no qual $\Psi(\mathcal{A})$ satisfaz $(a)$ se e somente se $\mathcal{A}$ é enumerável.

(iii) Existe um modelo que possui uma família a.d. $\mathcal{A}$ com $|\mathcal{A}|=\mathfrak{p}$ e tal que $\Psi(\mathcal{A})$ é um (a)-espaço.

A afirmação que fiz - de que ainda não surgiu na literatura sobre (a)-espaços um modelo no qual possa existir um contra-exemplo para a Questão 5.1 na família dos espaços $\Psi(\mathcal{A})$, o que pode ser reescrito na forma: ainda não surgiu na literatura sobre (a)-espaços um modelo no qual existe uma família a.d. $\mathcal{A} \operatorname{com}|\mathcal{A}|=\omega_{1}, 2^{\omega}<2^{\omega_{1}}$ e $\Psi(\mathcal{A})$ um (a)-espaço - é corolário da demonstração dos itens (i) e (iii) do teorema anterior. O item $(i)$ é consequência imediata de um resultado apresentado pelos mesmos autores em [SV98]: se $|\mathcal{A}|<\mathfrak{p}$, então $\Psi(\mathcal{A})$ é um $(a)$-espaço (note que, se $|\mathcal{A}|=\mathfrak{c}$ então um $\Psi(\mathcal{A})$ não é um (a)-espaço pois é separável e $\mathcal{A}$ é fechado e discreto; segue do resultado de Matveev). Mas, se $|\mathcal{A}|<\mathfrak{p}$, de $\mathfrak{p} \leqslant \mathfrak{t}$ vem $|\mathcal{A}|<\mathfrak{t}$ e conseqüentemente $2^{|\mathcal{A}|}=\mathfrak{c}$ (pois vale que se $\omega \leqslant \kappa<t$ então $2^{\kappa}=\mathfrak{c}$ : veja o Teorema 1.1 na pág. 7 ou em [vD84]), logo não existe um contra-exemplo para a Questão 5.1 na família dos espaços $\Psi(\mathcal{A}) \operatorname{com}|\mathcal{A}|<\mathfrak{p}$. Observamos ainda que um espaço $\Psi(\mathcal{A}) \operatorname{com}$ a Propriedade $(a) \operatorname{com} 2^{\omega}<2^{|\mathcal{A}|}$ nào pode ser normal, pelo Lema de Jones.

Como não podem existir exemplos abaixo de $\mathfrak{p}$, restaria a possibilidade de encontrar um contra-exemplo para $|\mathcal{A}| \geqslant \mathfrak{p}$, mas o único exemplo consistente (até o momento) 
de uma família a.d. $\mathcal{A} \operatorname{com}|\mathcal{A}| \geqslant \mathfrak{p} \operatorname{com} \Psi(\mathcal{A})$ um $(a)$-espaço é exatamente o modelo apresentado para a demonstração do item (iii) do Teorema A.4 (nesse modelo, $|\mathcal{A}|=\mathfrak{p}=\omega_{1}$ ): porém, em tal modelo (devido a Fleissner e Miller) existe um $Q$-conjunto não-enumerável, e portanto nesse modelo existe um espaço normal (separável, não-metrizável) que é exatamente o espaço de Moore derivado desse Q-conjunto, um subespaço do Plano de Niemitzky; nesse espaço normal, o $Q$-conjunto de cardinalidade $\omega_{1}$ é um fechado e discreto, conseqüentemente $2^{\omega}=2^{\omega_{1}}$ nesse modelo - exatamente o que não queríamos.

Portanto, um problema que surge naturalmente desta discussão é: será possivel construir um modelo sem $Q$-conjuntos no qual exista uma família $\mathcal{A} \operatorname{com}|\mathcal{A}|=\omega_{1}$, $\Psi(\mathcal{A})$ um $(a)$-espaço não-normal e $\mathfrak{c}=2^{\omega}<2^{\omega_{1}}$ ? Como para um espaço $X$ da família $\Psi(\mathcal{A})$ vale $\omega \leqslant c(X) \leqslant d(X)=\omega=\chi(X)$, um contra-exemplo nessa família de espaços também forneceria um contra-exemplo para a questão que apresentamos a seguir - o que evidenciaria que "nem todas as versões do Lema de Jones" podem possuir análogos para. a Propriedade $(a)$.

Questão 5.2 (pág. 67) É possível construir um modelo de ZFC no qual exista um espaço $X$ com a Propriedade $(a)$ que possua um fechado e discreto de cardinalidade $d(X)^{+}$com $2^{d(X)}<2^{d(X)^{+}}$? (Obviamente, em tal modelo devem valer as desigualdades $d(X)^{+}<$ $\left.2^{d(X)}<2^{d(X)^{+}}\right)$.

Conforme visto no Capítulo 5, o estudo das Questões 5.1 e 5.2 no contexto de espaços $\Psi(\mathcal{A})$ (ou, mais geralmente, de espaços $T_{1}$ localmente compactos e separáveis) nos levam a tratar de grandes cardinais.

Observamos também que um (a)-espaço que seja um exemplo que responda afirmativamente à Questão 5.2 näo pode ser paracompacto; como sabe-se que espaços paracompactos $T_{1}$ satisfazem a Propriedade $(a)$, uma tentativa natural de responder afirmativamente a essa questão seria procurar um exemplo (consistente com " $2^{\omega}<2^{\omega_{1}}$ ") de um espaço paracompacto $T_{1}$, não Hausdorff, separável, que possuísse um fechado e discreto não-enumerável (tal exemplo não poderia ser Hausdorff porque espaços paracompactos Hausdorff são normais e aí vale o Lema de Jones). No entanto, um tal exemplo não pode existir nem mesmo entre os metacompactos, devido ao Teorema 4.1. 


\section{Apêndice B}

\section{Caracterização combinatória dos espaços $\Psi(\mathcal{A})$}

\section{enumeravelmente paracompactos}

Neste Apêndice apresentamos, como uma contribuição do nosso trabalho, uma caracterização combinatória das famílias a.d. $\mathcal{A} \subseteq[\omega]^{\omega}$ para as quais o respectivo espaço $\Psi(\mathcal{A})$ é enumeravelmente paracompacto. Nosso objetivo ao apresentar essa caracterização é fornecer mais elementos para a discussão das questões que formulamos com respeito à presença da paracompacidade enumerável e da Propriedade (a) nesses espaços (ver Questões 3.15 e 4.17).

Existe uma caracterização topológica bastante conhecida para a classe dos espaços enumeravelmente paracompactos em geral:

Fato B.1 ([Eng89], 5.2.1) Um espaço topológico $X$ é enumeravelmente paracompacto se e somente se para toda seqüencia decrescente $\left\langle F_{n}: n<\omega\right\rangle$ de subconjuntos fechados de $X$ satisfazendo $\bigcap_{n<\omega} F_{n}=\emptyset$ existe uma seqüencia $\left\langle W_{n}: n<\omega\right\rangle$ de abertos de $X$ satisfazendo $F_{n} \subseteq W_{n}$ para todo $n<\omega$ e $\bigcap_{n<\omega} \overline{W_{n}}=\emptyset$.

Nossa caracterização para a classe dos espaços $\Psi(\mathcal{A})$ enumeravelmente paracompactos mostra que, para tais espaços, as únicas seqüencias decrescentes de fechados "que 
importam" são as de subconjuntos da família a.d. $\mathcal{A}$; com isso, pode-se caracterizar a presença da paracompacidade enumerável em espaços $\Psi(\mathcal{A})$ a partir de informações combinatórias a respeito da respectiva família a.d. $\mathcal{A}$ (o que parece ser bastante razoável, já que as presenças tanto da normalidade quanto da Propriedade (a) nesses espaços podem ser caracterizadas combinatoriamente a partir da família a.d.; ver Fatos 3.5 e 3.12).

Além de seqüências decrescentes (no sentido da inclusão) e enumeráveis de subconjuntos de $\mathcal{A}$, também podemos trabalhar com partições enumeráveis de $\mathcal{A}$, conforme veremos a seguir:

Teorema B.2 Seja $\mathcal{A} \subseteq[\omega]^{\omega}$ uma familia a.d. e considere o espaço $\Psi(\mathcal{A})$ associado. São equivalentes as seguintes asserçôes:

(i) $\Psi(\mathcal{A})$ é enumeravelmente paracompacto.

(ii) Para toda seqüência decrescente $\left\langle\mathcal{F}_{n}: n<\omega\right\rangle$ de subconjuntos de $\mathcal{A}$ satisfazendo $\bigcap_{n<\omega} \mathcal{F}_{n}=\emptyset$ existe uma seqüencia $\left\langle E_{n}: n<\omega\right\rangle$ de subconjuntos de $\omega$ que satisfazem as condições:

$$
\begin{aligned}
& \text { (ii).1 }(\forall n<\omega)\left(\forall A \in \mathcal{F}_{n}\right)\left[A \subseteq^{*} E_{n}\right] \\
& \left(\text { ii). } 2(\forall A \in \mathcal{A})(\exists n<\omega)\left[\left|A \cap E_{n}\right|<\omega\right]\right.
\end{aligned}
$$

(iii) Para toda partição $\left\{\mathcal{A}_{n}: n<\omega\right\}$ de $\mathcal{A}$ existe uma seqüência $\left\langle E_{n}: n<\omega\right\rangle$ de subconjuntos de $\omega$ que satisfazem as condições:

$$
\begin{aligned}
& \text { (iii).1 }(\forall n<\omega)(\forall m \geqslant n)\left(\forall A \in \mathcal{A}_{m}\right)\left[A \subseteq^{*} E_{n}\right] \\
& \text { (iii).2( } \forall A \in \mathcal{A})(\exists n<\omega)\left[\left|A \cap E_{n}\right|<\omega\right]
\end{aligned}
$$

Demonstração : Mostraremos que $(i) \Rightarrow(i i),(i i) \Leftrightarrow(i i i)$ e (ii) $\Rightarrow(i)$.

Prova de $(i) \Rightarrow($ ii $)$ : Assuma que $\Psi(\mathcal{A})$ é enumeravelmente paracompacto e considere $\left\langle\mathcal{F}_{n}: n\langle\omega\rangle\right.$ como em $(i i)$. Como $\mathcal{A}$ é fechado e discreto em $\Psi(\mathcal{A})$, a seqüência considerada é uma seqüência decrescente de fechados com intersecção vazia num espaço enumeravelmente paracompacto; segue do Fato B.1 que existe uma seqüência $\left\langle W_{n}: n\langle\omega\rangle\right.$ de abertos de $\Psi(\mathcal{A})$ que satisfazem $\mathcal{F}_{n} \subset W_{n}$ para todo $n<\omega$ e $\bigcap_{n<\omega} \overline{W_{n}}=\emptyset$.

Definimos agora uma seqüência $\left\langle E_{n}: n<\omega\right\rangle$ de subconjuntos de $\omega$ pondo, para. cada $n<\omega$, 


$$
E_{n}=W_{n} \backslash \mathcal{A}
$$

Afirmamos que essa seqüência cumpre as condições desejadas. De fato: como para cada $n<\omega W_{n}$ é uma vizinhança de $\mathcal{F}_{n}$ então para cada $A \in \mathcal{F}_{n}$ existe $F_{A} \in[\omega]^{<\omega}$ tal que

$$
\{A\} \cup\left(A \backslash F_{A}\right) \subseteq W_{n}
$$

e portanto $A \backslash F_{A} \subseteq E_{n}$, donde segue (ii).1. Já o fato de termos $\bigcap_{n<\omega} \overline{W_{n}}=\emptyset$ garante que dado $A \in \mathcal{A}$ arbitrário existe $n<\omega$ para o qual $A \notin \overline{W_{n}}$, e conseqüentemente existe $G_{A} \in[\omega]^{<\omega}$ para o qual

$$
\{A\} \cup\left(A \backslash G_{A}\right) \subseteq \Psi(\mathcal{A}) \backslash W_{n}
$$

e portanto $A \backslash G_{A} \subseteq \omega \backslash E_{n}$ e $A \cap E_{n} \subseteq G_{A}$, donde segue (ii).2.

Prova de (ii) $\Leftrightarrow$ (iii): É fácil ver que (ii) e (iii) são equivalentes, pois dada uma partição de $\mathcal{A}$ da forma $\left\{\mathcal{A}_{n}: n<\omega\right\}$ pode-se definir uma seqüência decrescente $\left\langle\mathcal{F}_{n}: n<\omega\right\rangle$ de subconjuntos de $\mathcal{A}$ com intersecção vazia pondo-se, para cada $n<\omega$,

$$
\mathcal{F}_{n}=\mathcal{A} \backslash\left(\bigcup_{i<n} \mathcal{A}_{i}\right)=\bigcup_{m \geqslant n} \mathcal{A}_{m}
$$

e dada uma seqüência decrescente $\left\langle\mathcal{F}_{n}: n<\omega\right\rangle$ de subconjuntos de $\mathcal{A}$ com intersecção vazia podemos assumir s.p.g. que $\mathcal{F}_{0}=\mathcal{A}$ e segue que a família de conjuntos dada por

$$
\mathcal{A}_{n}=\mathcal{F}_{n} \backslash \mathcal{F}_{n+1}
$$

para cada $n<\omega$ é claramente uma partição de $\mathcal{A}$. As condições relativas à seqüência $\left\langle E_{n}: n<\omega\right\rangle$ de subconjuntos de $\omega$ traduzem-se imediatamente da seqüência decrescente para a partição e vice-versa.

Prova de $(i i) \Rightarrow(i)$ : Seja $\mathcal{U}$ uma cobertura aberta enumerável e arbitrária de $\Psi(\mathcal{A})$ e seja

$$
\mathcal{U}_{\mathcal{A}}=\{U \in \mathcal{U}: U \cap \mathcal{A} \neq \emptyset\}
$$

É óbvio que $\mathcal{U}_{\mathcal{A}}$ cobre $\mathcal{A}$. Se $\mathcal{U}_{\mathcal{A}}$ for um conjunto finito, $\mathcal{U}_{\mathcal{A}} \cup\{\{n\}: n \in \Psi(\mathcal{A}) \backslash$ $\left.\left(\bigcup \mathcal{U}_{\mathcal{A}}\right)\right\}$ é um refinamento aberto localmente finito de $\mathcal{U}$ e estamos feitos. Se $\mathcal{U}_{\mathcal{A}}$ for infinito, enumeramos $\mathcal{U}_{\mathcal{A}}=\left\{U_{n}: n<\omega\right\}$ e definimos uma seqüencia $\left\langle\mathcal{F}_{n}: n<\omega\right\rangle$ de subconjuntos de $\mathcal{A}$ pondo, para cada $n<\omega$, 


$$
\mathcal{F}_{n}=\mathcal{A} \backslash \bigcup_{i<n} U_{i}
$$

Temos que essa seqüência é descrescente e como $\mathcal{U}_{\mathcal{A}}$ cobre $\mathcal{A}$ vale que $\bigcap_{n<\omega} \mathcal{F}_{n}=\emptyset$. A asserção (ii) nos garante então que existe uma seqüencia $\left\langle E_{n}: n<\omega\right\rangle$ de subconjuntos de $\omega$ satisfazendo as condições (ii).1 e (ii).2.

Definimos agora, para cada $n<\omega$, um conjunto

$$
W_{n}=\mathcal{F}_{n} \cup\left(E_{n} \backslash n\right)
$$

e temos que $W_{n}$ é uma vizinhança aberta de $\mathcal{F}_{n}$ para cada $n<\omega$, pois (ii). 1 garante que $A \backslash E_{n}$ é finito se $A \in \mathcal{F}_{n}$ donde $A \backslash\left(E_{n} \backslash n\right)=\left(A \backslash E_{n}\right) \cup(A \cap n)$ também é finito e conseqüentemente vale para todo $A \in \mathcal{F}_{n}$ que

$$
\{A\} \cup\left(A \backslash\left(A \backslash\left(E_{n} \backslash n\right)\right)\right) \subseteq W_{n}
$$

e portanto $W_{n}$ é um aberto de $\Psi(\mathcal{A})$. Definimos agora uma seqüência $\left\langle H_{n}: n<\omega\right\rangle$ de fechados de $\Psi(\mathcal{A})$ pondo, para cada $n<\omega$,

$$
H_{n}=\Psi(\mathcal{A}) \backslash W_{n}
$$

Observamos que, para cada $n<\omega$,

$$
H_{n} \subseteq\left(\Psi(\mathcal{A}) \backslash \mathcal{F}_{n}\right) \subseteq\left(\left(\bigcup_{j<n} U_{j}\right) \cup \omega\right)
$$

e que, por (ii).2, dado $A \in \mathcal{A}$ arbitrário existe $m<\omega$ para o qual $A \cap E_{m}$ é finito; conseqüentemente, $A \cap\left(E_{m} \backslash m\right)$ é finito e $A \notin \mathcal{F}_{m}$, por (ii).1. Segue que

$$
\{A\} \cup\left(A \backslash\left(A \cap\left(E_{m} \backslash m\right)\right)\right) \subseteq \Psi(\mathcal{A}) \backslash W_{m}=H_{m}
$$

donde $A \notin \overline{W_{m}}$ ou, equivalentemente, $A \in \operatorname{int}\left(H_{m}\right)$. Assim, vale que

$$
\text { (*) } \mathcal{A} \subset \bigcup_{n<\omega} \operatorname{int}\left(H_{n}\right)
$$

Já podemos construir nosso refinamento localmente finito. Para cada $n<\omega$ definimos um aberto

$$
V_{n}=U_{n} \backslash \bigcup_{j<n} H_{j}
$$


Seja $\mathcal{V}_{\mathcal{A}}=\left\{V_{n}: n<\omega\right\}$. Como para cada $j<\omega$ fixado temos $H_{j} \subseteq\left(\left(\bigcup_{k<j} U_{k}\right) \cup \omega\right)$ segue que $\bigcup_{j<n} H_{j} \subseteq\left(\left(\bigcup_{j<n} U_{j}\right) \cup \omega\right)$ e portanto vale para todo $n<\omega$ que

$$
U_{n} \backslash\left(\left(\bigcup_{j<n} U_{j}\right) \cup \omega\right) \subseteq V_{n}
$$

o que garante que $\mathcal{V}_{\mathcal{A}}$ cobre $\mathcal{A}$ (note que, se $A \in \mathcal{A}$, então $A \in V_{k}$ para $k=\min \{i<\omega$ : $\left.\left.A \in U_{i}\right\}\right)$ e $\operatorname{assim} \mathcal{V}_{\mathcal{A}}$ refina $\mathcal{U}_{\mathcal{A}}$. Afirmamos que

$$
\mathcal{V}=\mathcal{V}_{\mathcal{A}} \cup\left\{\{n\}: n \in \Psi(\mathcal{A}) \backslash\left(\bigcup \mathcal{V}_{\mathcal{A}}\right)\right\}
$$

é um refinamento aberto localmente finito de $\mathcal{U}$. Note que se $m<\omega$ então $m \in H_{n}$ para todo $n>m$ e conseqüentemente $\{m\} \cap V_{n}=\emptyset$ para todo $n>m$. Com relação aos pontos em $\mathcal{A}$, tome $A \in \mathcal{A}$ arbitrário; segue de $(*)$ que existe $m<\omega$ para o qual $A \in \operatorname{int}\left(H_{m}\right)$ donde $A$ possui uma vizinhança que é disjunta de $V_{n}$ para todo $n>m$. Portanto, $\mathcal{V}$ faz o trabalho desejado. 


\section{Referências Bibliográficas}

[Bel81] Murray G. Bell. On the combinatorial principle $P(c)$. Fund. Math., 114(2);149$157,1981$.

[Com88] W. W. Comfort. Cofinal families in certain function spaces. Comment. Math. Univ. Carolin., 29(4):665-675, 1988.

[CS95] James Cummings and Saharon Shelah. Cardinal invariants above the continuum. Ann. Pure Appl. Logic, 75(3):251-268, 1995.

[DJ82a] A. J. Dodd and R. B. Jensen. The covering lemma for K. Ann. Math. Logic, $22(1): 1-30,1982$.

[DJ82b] A. J. Dodd and R. B. Jensen. The covering lemma for $L[U]$. Ann. Math. Logic, $22(2): 127-135,1982$.

[Eng89] Ryszard Engelking. General Topology, volume 6 of Sigma Series in Pure Mathematics. Heldermann Verlag, Berlin, 1989.

[Fle78] William G. Fleissner. Separation properties in Moore spaces. Fund. Math., $98(3): 279-286,1978$.

[Fle82] William G. Fleissner. If all normal Moore spaces are metrizable, then there is an inner model with a measurable cardinal. Trans. Amer. Math. Soc., 273(1):365$373,1982$.

[Hod84] R. Hodel. Cardinal functions. I. In Handbook of set-theoretic topology, pages 1-61. North-Holland, Amsterdam, 1984.

[Jec78] Thomas Jech. Set theory. Academic Press, New York, 1978. 
[JMS00] Winfried Just, Mikhai] V. Matveev, and Paul J. Szeptycki. Some results on property (a). Topology Appl., 100(1):103-111, 2000. Special issue in honor of Howard H. Wicke.

[Jon37] F. Burton Jones. Concerning normal and completely normal spaces. Bull. Amer. Math. Soc., 43:671-677, 1937.

[JP84] Thomas Jech and Karel Prikry. Cofinality of the partial ordering of functions from $\omega_{1}$ into $\omega$ under eventual domination. Math. Proc. Cambridge Philos. Soc., $95(1): 25-32,1984$.

[JS91] Haim Judah and Saharon Shelah. Q-sets, Sierpinski sets, and rapid filters. Proc. Amer. Math. Soc, 111(3):821-832, 1991.

[Kan94] Akihiro Kanamori. The higher infinite - Large cardinals in set theory from their beginnings. Springer-Verlag, Berlin, 1994.

[Kni93] R. W. Knight. $\Delta$-sets. Trans. Amer. Math. Soc., 339(1):45-60, 1993.

[Kun80] Kenneth Kunen. Set Theory-an introduction to the independence proofs, volume 102 of Studies in Logic and the Foundations of Mathematics. North Holland Publishing Company, Amsterdam, 1980.

[KV84] Kenneth Kunen and Jerry E. Vaughan, editors. Handbook of set-theoretic topology. North-Holland Publishing Co., Amsterdam, 1984.

[Mat94] Michael V. Matveev. Absolutely countably compact spaces. Topology Appl, $58(1): 81-92,1994$

[Mat97] M. V. Matveev. Some questions on property (a). Questions Answers Gen. Topology, 15(2):103-111, 1997.

[Mat98] M. V. Matveev. A survey on star covering properties. Topology Atlas, Preprint $330,1998$.

[NV87] P. J. Nyikos and J. E. Vaughan. Sequentially compact, Franklin-Rajagopalan spaces. Proc. Amer. Math. Soc., 101(1):149-155, 1987. 
[Nyi90] Peter Nyikos. On first countable, countably compact spaces. III. The problem of obtaining separable noncompact examples. In Open problems in topology, pages 127-161. North-Holland, Amsterdam, 1990.

[Pav01] Oleg Pavlov. A normal countably compact not absolutely countably compact space. Proc. Amer. Math. Soc., 129(9):2771-2775, 2001.

[Ree80] G. M. Reed. On normality and countable paracompactness. Fund. Math., 110(2):145-152, 1980 .

[RSV97] Mary Ellen Rudin, Ian S. Stares, and Jerry E. Vaughan. From countable compactness to absolute countable compactness. Proc. Amer. Math. Soc., 125(3):927-934, 1997.

[Rud77] Mary Ellen Rudin. Martin's axiom. In Handbook of Mathematical Logic, Part B.6, pages 491-501. North-Holland, Amsterdam, 1977.

[Rud84] Mary Ellen Rudin. Dowker spaces. In Handbook of set-theoretic topology, pages 761-780. North-Holland, Amsterdam, 1984.

[Si198] Samuel G. Silva. Uma introdução aos pequenos cardinais e às suas aplicações em topologia. Dissertação de Mestrado, IME/USP, 1998.

[SS95] Lynn Arthur Steen and J. Arthur Seebach, Jr. Counterexamples in topology. Dover Publications Inc., Mineola, NY, 1995. Reprint of the second (1978) edition.

[SV98] Paul J. Szeptycki and Jerry E. Vaughan. Almost disjoint families and property (a). Fund. Math., 158(3):229-240, 1998.

[SW93] Paul J. Szeptycki and William A. R. Weiss. Dowker spaces. In The work of Mary Ellen Rudin (Madison, WI, 1991), volume 705 of Ann. New York Acad. Sci., pages 119-129. New York Acad. Sci., New York, 1993.

[Sze02] Paul J. Szeptycki. Soft almost disjoint families. Proc. Amer. Math. Soc., $130(12): 3713-3717,2002$. 
[Tal77] F. D. Tall. Set-theoretic consistency results and topological theorems concerning the normal Moore space conjecture and related problems. Dissertationes Math. (Rozprawy Mat.), 148:1-53, 1977.

[TJ97] Artur Tomita and Lúcia Junqueira. Topologia geral - 1o.semestre de 1997. Notas de aula do IME/USP, 1997.

[Vau90] Jerry E. Vaughan. Small uncountable cardinals and topology. In Open problems in topology, pages 195-218. North-Holland, Amsterdam, 1990.

[Vau95] Jerry E. Vaughan. A countably compact, separable space which is not absolutely countably compact. Comment. Math. Univ. Carolin., 36(1):197-201, 1995.

[vD84] Eric K. van Douwen. The integers and topology. In Handbook of set-theoretic topology, pages 111-167. North-Holland, Amsterdam, 1984.

[vMR90] Jan van Mill and George M. Reed, editors. Open problems in topology. NorthHolland Publishing Co., Amsterdam, 1990.

[Wat85] W. Stephen Watson. Separation in countably paracompact spaces. Trans. Amer. Math. Soc., 290(2):831-842, 1985. 


\section{Índice Remissivo}

(a)-espaços, 19

c, 3

$={ }^{*}, 6$

$\mathfrak{d}, 7$

$A \subseteq^{*} B, 6$

$\mathfrak{p}, 7$

$A \backslash B, 1$

$\mathfrak{s}, 7$

$A^{\prime}, 11$

t, 7

$L, 5$

$\kappa^{+}, 3$

$M(B), 35$

$\neq, 5$

Q-conjunto, 34

$\omega^{\omega}, 15$

$S t(F, \mathcal{U}), 14$

$\omega, 2$

$T_{i}, 12$

$\omega_{0}, 3$

$V=L, 5$

$\omega_{\alpha}, 3$

$X^{\prime}, 11$

$\left\langle X, \leqslant^{*}\right\rangle, 5$

$X^{A}, 15$

$[X]^{\lambda}, 3$

$[X]^{<\lambda}, 3$

$[\omega] \omega, 3$

$[\omega]^{<\omega}, 3$

$\left\langle\alpha, \beta^{*}\right\rangle$-gap, 10

$\left\langle\mathcal{P}(\omega), \subseteq^{*}\right\rangle, 6$

$\left\langle\omega \omega, \leqslant^{*}\right\rangle, 6$

Q, 15

IR, 15

IP, 15

$\subset, 6$

$\Psi$-espaço, 27

$\tau, 11$

$\aleph_{0}, 3$

$\vdash, 5$

$\aleph_{\alpha}, 3$

${ }^{A} B, 2$

$\mathcal{P}(A), 1$

$\omega_{\omega, 2}$

$\chi(X), 15$

$c(X), 16$

$\chi(p, X), 15$

c $f(X), 6$

$\mathfrak{a}, 7$

c $f(\beta), 4$

$\mathfrak{b}, 7$

$c f\left(\mathcal{F}_{D}\right), 72$ 


$$
\begin{aligned}
& d(X), 16 \\
& d d c(X), 73 \\
& d d c_{1}(X), 73 \\
& e(X), 16 \\
& f \leqslant g, 67 \\
& f \leqslant^{*} g, 6 \\
& f[A], 2 \\
& f^{-1}[B], 2 \\
& \min (A), 2 \\
& \sup (A), 2 \\
& w(X), 15 \\
& x<* y, 6
\end{aligned}
$$

aberto-fechado, 12

$\mathrm{AC}, 2$

Axioma de Martin, 8

axiomas

de enumerabilidade, 11

de separação, 11

caráter, 15

cardinal, 2

(fortemente)inacessivel, 10

inacessível, 10

limite, 3

mensurável, 11

regular, 4

singular, 4

sucessor, 3

cardinalidade, 2

celularidade, 16

$\mathrm{CH}, 4$

clopen, 12 cofinal, 4

em um ordinal, 4

em uma pré-ordem, 6

cofinalidade

de um ordinal, 4

de uma pré-ordem, 6

consistência, 5

convergência

de seqüência, 13

de um conjunto, 13

densidade, 16

derivado, 11

enumerável, 4

enumeração, 3

espaço

$\Psi$-like, 27

$\Psi(\mathcal{A}), 27$

a.e.c., 19

anti-Dowker, 59

coletivamente normal, 35

compacto, 12

completamente regular, 12

de Dowker, 59

de Hausdorff, 12

de Lindelöf, 12

de Moore, 34

derivado de $B, 35$

discreto, 11

enumeravelmente

compacto, 12

metacompacto, 14 


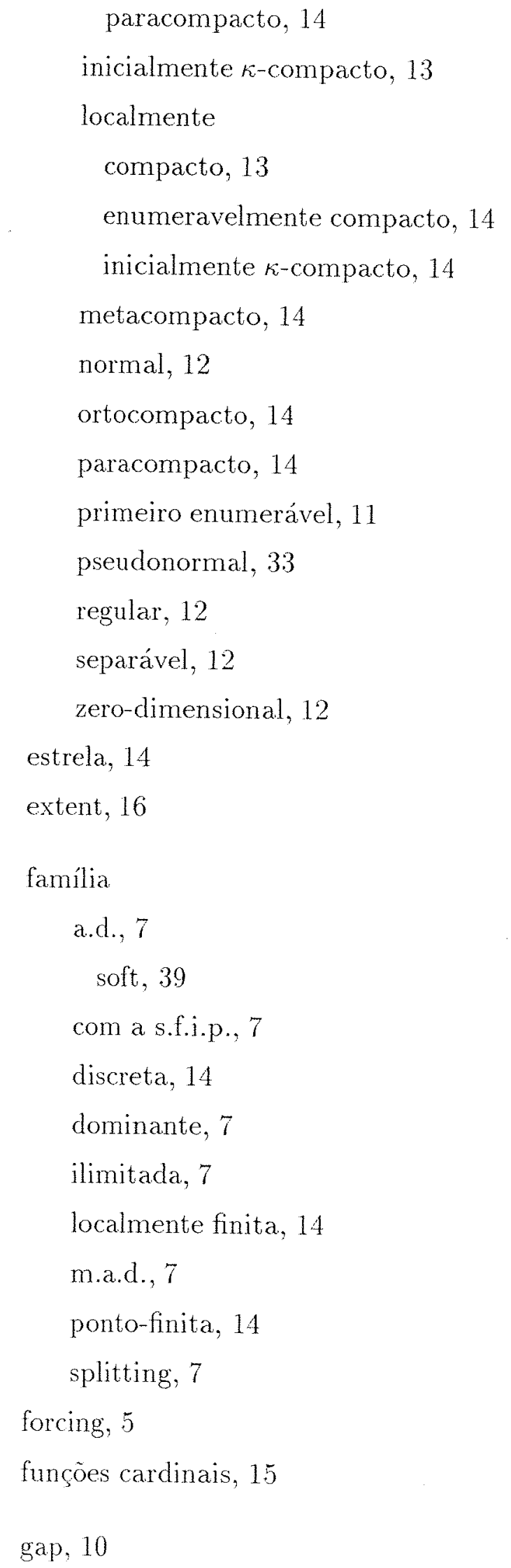

de Hausdorff, 10

de Luzin, 34

GCH, 4

grandes cardinais, 10

Handbook, 17

Hipótese

do Contínuo, 4

Generalizada do Contínuo, 4

ilimitado

em uma pré-ordem, 6

independência, 5

Lema de Jones, 24

demonstração, 90

MA, 8

$\mathrm{MA}(\kappa), 9$

MA $A_{\sigma-c e n t r a d a s}, 9$

$\mathrm{MA}_{\sigma-\text { centradas }}(\kappa), 9$

modelo, 5 interno, 65

números naturais, 2

Open Problems, 17

ordinal, 2

limite, 2

regular, 4

singular, 4

sucessor, 2

pequenos cardinais, 6

peso, 15

Plano de Niemytzki, 16 
ponto

de acumulação completo, 12

de acumulação de seqüência, 13

pré-ordem, 5

Propriedade $(a), 19$

propriedade topológica, 12

propriedade topológica

hereditária, 12

pseudo-intersecção, 7

refinamento, 14

Reta de Sorgenfrey, 16

s.p.g., 10

seqüência, 2

de comprimento $\alpha, 2$

star covering properties, 15

Teorema, 5

da Completude, 5

da Incompletude, Segundo, 10

de Cantor, 3

tightness, 16

enumerável, 16

topologia

de subespaço, 12

da ordem, 12

produto, 12

torre, 7

ZFC, 1 